\title{
Anisotropic gold nanoparticles: Preparation and applications in catalysis
}

\author{
Peter Priecel a, Hammed Adekunle Salami a, Romen Herrera Padilla a,b, Ziyi Zhong b,\#, Jose Antonio \\ Lopez-Sanchez ${ }^{\text {a,* }}$ \\ a Stephenson Institute for Renewable Energy, Department of Chemistry, University of Liverpool, Crown Street, L69 7ZD, Liverpool, United Kingdom \\ b Institute of Chemical and Engineering Sciences (ICES), Agency for Science, Technology and Research (A*STAR), 1 Pesek Road, Jurong Island, 627833, \\ Singapore
}

\section{A R T I C L E I N F O}

\section{Article history:}

Received 30 April 2016

Accepted 30 May 2016

Published 5 October 2016

\section{Keywords:}

Anisotropic metal nanoparticles

Gold nanoparticles

Gold catalysis

Photocatalysis

Electrocatalysis

Catalytic oxidation

Colloidal gold nanoparticles

Gold nanorods

Gold nanostars

Sol immobilisation

\begin{abstract}
A B S T R A C T
Despite the high amount of scientific work dedicated to the gold nanoparticles in catalysis, most of the research has been performed utilising supported nanoparticles obtained by traditional impregnation of gold salts onto a support, co-precipitation or deposition-precipitation methods which do not benefit from the recent advances in nanotechnologies. Only more recently, gold catalyst scientists have been exploiting the potential of preforming the metal nanoparticles in a colloidal suspension before immobilisation with great results in terms of catalytic activity and the morphology control of mono- and bimetallic catalysts. On the other hand, the last decade has seen the emergence of more advanced control in gold metal nanoparticle synthesis, resulting in a variety of anisotropic gold nanoparticles with easily accessible new morphologies that offer control over the coordination of surface atoms and the optical properties of the nanoparticles (tunable plasmon band) with immense relevance for catalysis. Such morphologies include nanorods, nanostars, nanoflowers, dendritic nanostructures or polyhedral nanoparticles to mention a few. In addition to highlighting newly developed methods and properties of anisotropic gold nanoparticles, in this review we examine the emerging literature that clearly indicates the often superior catalytic performance and amazing potential of these nanoparticles to transform the field of heterogeneous catalysis by gold by offering potentially higher catalytic performance, control over exposed active sites, robustness and tunability for thermal-, electro- and photocatalysis.
\end{abstract}

(C) 2016, Dalian Institute of Chemical Physics, Chinese Academy of Sciences. Published by Elsevier B.V. All rights reserved.

\section{Introduction}

Gold has always fascinated humankind for its many properties and, particularly its beauty, which makes it an extremely valuable and desirable metal used in the past and present often as a currency and measure of wealth and status. Even more interesting to chemists and physicists are some of the remark- able properties of this noble metal when in its colloidal form as nanoparticles. Its optical properties were already appreciated in the $4^{\text {th }}$ century AD in the form of the Lycurgus Cup, which is of a Roman origin. The interesting feature of this partly glass cup is that when it's backlit with visible light, the glass appears ruby red to violet in colour whereas no backlight shows it as green [1-3]. This is due to the colloidal gold and silver nano-

\footnotetext{
* Corresponding author. Tel: +44 (0)151 794 3535; E-mail: jals@liv.ac.uk

\# Corresponding author. Tel: 65-67963809; Fax: 65-63166182 ; E-mail: zhong_ziyi@ices.a-star.edu.sg

This work was supported by the Project from Institute of Chemical and Engineering Sciences (ICES), Singapore (ICES/15-1G4B01).

DOI: 10.1016/S1872-2067(16)62475-0 | http://www.sciencedirect.com/science/journal/18722067 | Chin. J. Catal., Vol. 37 , No. 10, October 2016
} 
particles dispersed in the glass [2]. In 1857, one of the most influential scientist in history was also fascinated by the properties of gold nanoparticles; Michael Faraday [4] was indeed the first to experimentally visually observe and document the plasmon resonance of small gold nanoparticles. When he reduced gold chloride with phosphorus in water he also produced stable colloidal gold nanoparticles (NP); whereas several decades later, Gustav Mie laid down the theoretical basis for the plasmon resonance phenomenon in his work on optical properties of colloidal metallic solutions [5]. On the other hand, it took almost a century for the realisation that finely divided gold could offer excellent properties as a catalyst. Despite the fact that Bond et al. [6] were first to apply heterogeneous gold catalysts in the hydrogenation of mono-olefins, it was the ground-breaking observations by Haruta [7] on low temperature oxidation of carbon monoxide and Hutchings [8] on the hydrochlorination of acetylene that led to the realisation of the fascinating properties of gold as a catalyst. Recently, a number of excellent reviews have been dedicated to gold catalysis in general [9-28], but also their application to total synthesis and homogeneous catalysis [15,29], photocatalysis [30], oxidation reactions [31-33] and anaerobic reactions in particular [16,20].

The majority of the catalytic work mentioned previously covered gold nanoparticles prepared by conventional heterogeneous catalysis methods, such as impregnation or deposition-precipitation in its different forms that lead to semi-spherical nanoparticles on a solid support. More recently, we have observed the success of colloidal preparation methods for gold nanoparticles and its alloys as a way of preforming spherical nanoparticles prior to their immobilisation on a solid support. This approach offers many advantages and higher control of the particle morphology and composition in the case of bimetallic nanoparticles, and can result in exceptional activity for a range of reactions [31,34-37]. However, despite the large amount of literature available on gold and methods of preparing gold nanoparticles for catalysis, little advance in the application of anisotropic gold nanoparticles for catalysis has been made so far. This is surprising, considering that already in 1909 Zsigmondy et al. [38] had shown that gold nanoparticles can be prepared in non-spherical shapes and Gans [39] extended Mie's theory [5] to account for optical properties of these anisotropic nanoparticles. In 1951 Turkevich et al. [40] documented plate-like and rod-shaped Au NP in a single solution method. However, it was not until 1989 when Wiesner et al. [41] first reported gold nanorods along with triangular and hexagonal platelets prepared by method utilising Faraday's synthesis [4] to prepare gold seeds and $\mathrm{HAuCl}_{4}$ growth solution with hydrogen peroxide [41]. Broader impact of anisotropic gold nanoparticles, especially rods, followed not long after this and was sprung by the photochemical method by Esumi et al. [42], electrochemical method by the group of Wang [43] and seed-mediated method developed by the groups of Murphy [44] and El-Sayed [45]. However, only at this later stage has become Wiesner's and Wokaun's method [41] using seeds and growth solution known as a seed-mediated method.

We have witnessed a tremendous success in the nanotechnology field of the preparation of anisotropic gold nanoparti- cles, now being able to produce different shapes of gold nanoparticles for a range of applications; especially due to the ability to tune and enhance optical properties by controlling the particle morphology and surface plasmon resonance (SPR) in particular $[3,46,47]$. Morphology control can also offer selectivity by exposing different crystallographic planes. Notably, both of these tunable properties found applications in sensing [3,46-50] and medicine [51-53] and this review aims to examine what new advances in the understanding and preparation of anisotropic nanoparticles have been utilised for catalysis and what is their outlook. Firstly, we will provide the reader with an overview of the established syntheses of various shapes of gold nanoparticles, highlighting new developments for their preparations and briefly discussing their main properties. In the second part of this review, we will review the application of anisotropic gold nanoparticles in catalysis and how this is determined by the preparation of the nanoparticles and their immobilisation on a suitable support. In addition to examine applications in thermal catalysis and electrocatalysis, we have paid particular attention to photocatalytic applications, where the anisotropic nanocrystals offer unique opportunities due to the potential of controlling the photocatalytic activity by modifying the nanoparticle morphology, which in turn tunes the surface plasmon.

\section{Synthesis of anisotropic nanoparticles and catalysts}

Several excellent reviews on the synthetic approaches to anisotropic gold nanoparticles [47,54-71] and their properties $[3,14,46,49,55,59,64,71-78]$ and various applications $[48,49,51,55,59,61,62,64-66,73,79-82]$ have been published. Nevertheless, we will examine the most successful approaches, paying special consideration to their potential applicability and impact in the preparation of catalysts.

\subsection{Preparation of anisotropic gold nanoparticles}

Fig. 1 shows an overview of the different nanoparticle shapes [47], most of which were synthesized also from gold, $[63,70,83-86]$ also highlighting the different crystallographic planes on the selected morphologies with different colours (e.g. the most abundant exposed planes are (111) in nanospheres [47], (100) in nanocubes [47] and (100) and (110) in nanorods [55,75,87-89]) (Fig. 1), which are particularly important for catalysis and therefore also for the nanoparticle synthesis. Variations on the techniques for the synthesis of anisotropic gold nanoparticles demonstrate that surfactants can direct crystal growth [90] but also how important the shape of the seed in seeded growth is (Fig. 1) [91]. Within this background, it is important to note that the interest in shape control of anisotropic gold nanoparticles was stirred by excellent studies in the groups of El-Sayed [92,93] and Murphy [44,94] to which we will pay particular attention in this review.

\subsubsection{Synthesis of gold nanorods}

One of the most studied shapes of anisotropic gold particles is the nanorods $[55,60,67,72,73,75,76,79,80,96]$. The history of 


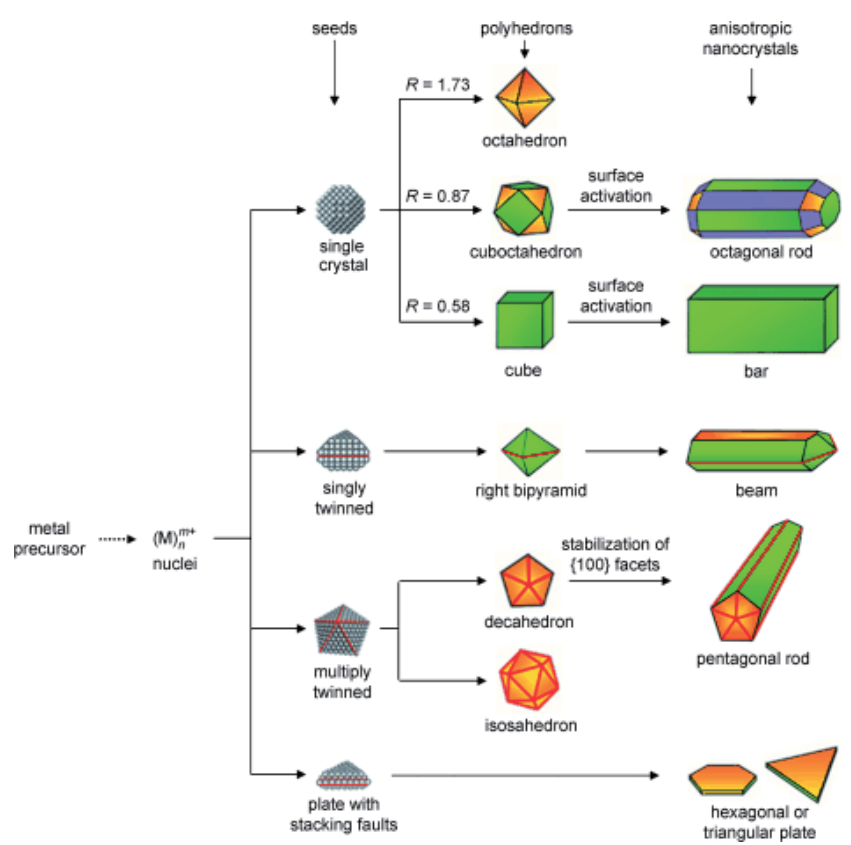

Fig. 1. Schematic illustration of the progression from the metal precursor to seeds and anisotropic fcc nanoparticles. Plate-like seeds are formed when stacking faults are introduced. $\{100\},\{111\}$, and $\{110\}$ facets are represented by green, orange, and purple colours and red lines outline the twin planes. $\mathrm{R}$ is the ratio between the growth rates along the $<100>$ and $<111>$ directions $[95,91]$. Reproduced with permission from Wiley-VCH Verlag GmbH \& Co. KGaA, Weinheim, Copyright 2007, 2009.

the development of the gold nanorods synthesis has been summarised by Lohse et al. [60] or Sharma et al. [97]. Also, the group of Murphy is one of the leaders in the synthesis of the anisotropic nanoparticles and regularly reports new developments in the synthesis of the gold nanorods and mechanistic

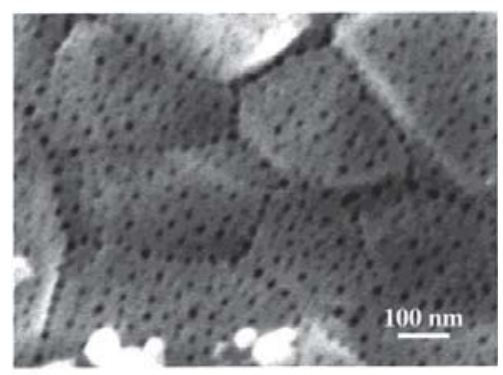

a)
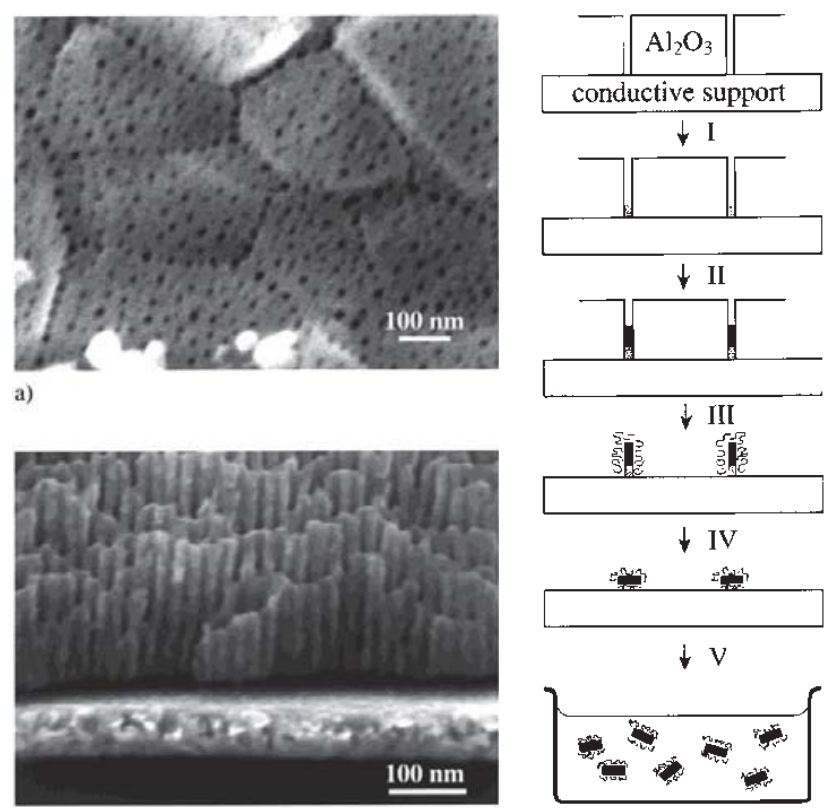

understanding of the involved processes [55,63,67,75,98]. Other excellent reviews on gold nanorods are available from El-Sayed [46,52,72] or Liz-Marzán [63,79]. Other reviews have been focused on the discussion of the synthetic approaches and parameters[76,96,97], functionalisation [96], self-assembly of nanorods into bigger aggregates [80, 96, 97] and optical properties and their use in sensing $[48,55,73,76,97]$.

Wet chemistry methods are generally preferred for the synthesis of gold nanorods due to their relative simplicity, the use of inexpensive materials and their good reproducibility. The three main wet chemistry methods are the template method $[99,100]$, the electrochemical method $[43,101]$ and the seed-mediated method [41,44,45]. Additionally, photochemical synthesis can also be used for the synthesis of $\mathrm{Au}$ nanorods [42]. Each succeeding method offers an improvement in quality and ease of preparation [79]. However, more emphasis has been given to the seed-mediated method because it has proven to be the most versatile and popular.

\subsubsection{Template method}

In 1992, the group of Martin [102] demonstrated the use of the template method [99] in the preparation of $<100 \mathrm{~nm}$ diameter gold nanorods among other similar shapes such as wires and tubules [99] which will be described Section 2.1.5. It should be noted that in this case even the rods were termed cylinders or fibrils and were not the same single crystalline rods as prepared by the electrochemical (Section 2.1.1.2) or seed-mediated method (Section 2.1.1.3). The method is hinged on the electrochemical deposition of Au within the pores of an alumina template or nanoporous polycarbonate membrane (Fig. 2 (left)). The surface of the template membrane is initially covered by $\mathrm{Cu}$ or Ag via sputtering and provides a conductive film for the electrodeposition. It also serves as a foundation for

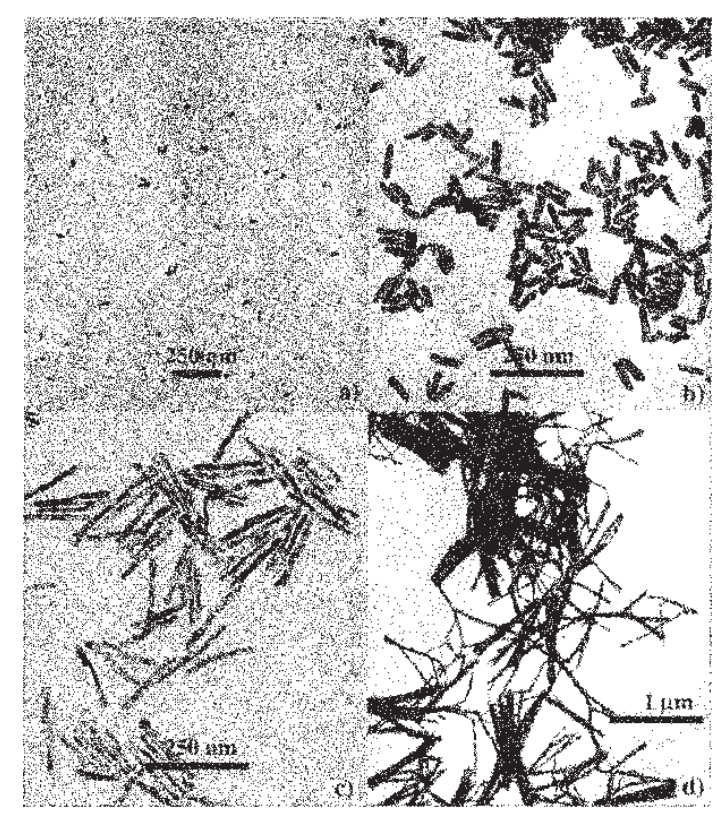

Fig. 2. Field emission gun-scanning electron microscope micrographs of an alumina membrane (left), schematic illustration of the successive stages during the formation of $\mathrm{Au}$ nanostructures via the template method (middle), TEM images of different Au rod-shaped nanoparticles synthesized by the template method. Scale bars of the TEM images (right) are all $250 \mathrm{~nm}$, but the bottom right one which is $1 \mu \mathrm{m}$ [104]. Reproduced with permission from the American Chemical Society, Copyright 2000. 
electrochemical growth of the Au nanoparticles. The gold can be then electrodeposited within the nanopores prior to the selective dissolution of both the alumina and the metal film in the presence of a suitable stabilizer such as poly(vinylpyridine) or poly(vinylpyrrolidone) (PVP) [103]. The schematic illustration of the successive stages during the formation of $\mathrm{Au}$ nanostructures via this method is shown in Fig. 2 (middle). Elongated gold nanoparticles (Fig. 2 (right)) are then finally dispersed in water or any suitable organic solvent for example by sonication.

This method offers control of the length of the nanostructures by adjusting the amount of gold deposited within the pores of the membrane [104] but also control of the diameter. The pore diameter of the alumina membrane determines the diameter of the nanoparticles, which overall makes it possible to synthesize $\mathrm{Au}$ nanostructures with different diameters and length $[105,106]$. However, there is a practical limit to the yield of rods using this template method as only monolayers of rods are synthesized. Nonetheless, the method serves as a pioneering confirmation of the basic optical effects of the nanorods such as the change of the position of plasmon band with the change in the aspect ratio of the nanoparticles and offers very homogeneous nanoparticles [99].

\subsubsection{Electrochemical method}

Unlike the template method, synthesising gold nanorods using an electrochemical route produced Au nanorods in high yield and controllable aspect ratios (Fig. 3), as was first demonstrated by the group of Wang in 1997 [43]. A simple two-electrode type electrochemical cell is used as shown in Fig. 3 (left). A gold metal plate is used as an anode while the cathode is made up of a platinum plate. The electrolytic solution is made up of a suitable cationic surfactant, e.g. cetyltrimethylammonium bromide (CTAB), which acts as a support for the electrolyte and stabilizes the nanoparticles to prevent aggregation. More hydrophobic cationic co-surfactant (e.g. tetraoctylammonium bromide) is added to help to induce the
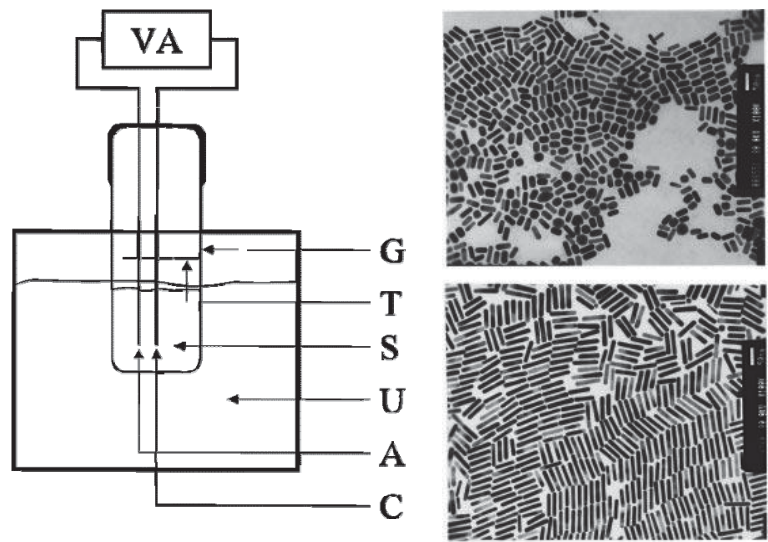

Fig. 3. General diagram of the electrochemical method set-up for preparation of gold nanorods (left). Capital letters correspond to: VA, power supply; G, glassware electrochemical cell; T, teflon spacer; S, electrode holder; U, ultrasonic cleaner; A, anode; C, cathode. TEM images of Au nanorods with different aspect ratios of 2.7 (top right) and 6.1 (bottom right). Scale bars correspond to $50 \mathrm{~nm}$ [101]. Reproduced with permission from the American Chemical Society, Copyright 1999. rod growth and acetone to facilitate the incorporation of this co-surfactant. The gold metal anode serves as a source of $\mathrm{Au}$ ions forming $\mathrm{AuBr}_{4}^{-}$anions during the synthesis. These anions form a complex with the cationic surfactant and co-surfactant and migrate to the cathode where the reduction takes place. To control the aspect ratio of the Au nanorods, a silver plate is gradually immersed close to the Pt electrode. It was found that the release rate and concentration of the silver ions determines the length of the rods (Fig. 3 (right)).

However, a complete mechanism of the process and especially the role of the silver ions was not explained at the time [43]. It was suggested later that silver ions underwent an under-potential deposition on the side $\{110\}$ facets which slows down the growth in that direction and promotes the elongation of the rods on their tips [107]. This effect is applied to both electrochemical and seeded-growth methods (Section 2.1.1.3) due to analogies in the synthesis, such as the use of CTAB. More insights into role of silver are presented in Section 2.1.1.4.

\subsubsection{Seed-mediated method}

Synthesis of rod-shaped colloidal gold nanoparticles using gold seeds dates back to 1989 when Wiesner et al. [41] added $\mathrm{HAuCl}_{4}$ to the preformed gold seeds produced by $\mathrm{HAuCl}_{4}$ reduction with phosphorus, similarly to Faraday's original colloidal synthesis [4]. The gold nanorods were grown by reducing the $\mathrm{Au}^{3+}$ salt with $\mathrm{H}_{2} \mathrm{O}_{2}$. One great advantage of this method is the ability to produce the step by step enlargement of nanoparticles thereby making it easier to control the shapes $[94,108,109]$ and sizes of the AuNRs [93,94,110]. As a consequence, this procedure has been widely adopted in recent shape- and size-controlled AuNRs synthesis [111]. Fig. 4 shows a general scheme for the initial multi-step silver-free procedure for nanorods synthesis (aspect ratios up to 25) although phosphorus as a reducing agent was substituted for sodium borohydride $[44,94]$.

However, it is also possible to synthesise the nanoparticles in just two steps as follows (usually with $\mathrm{AgNO}_{3}$ for higher yield

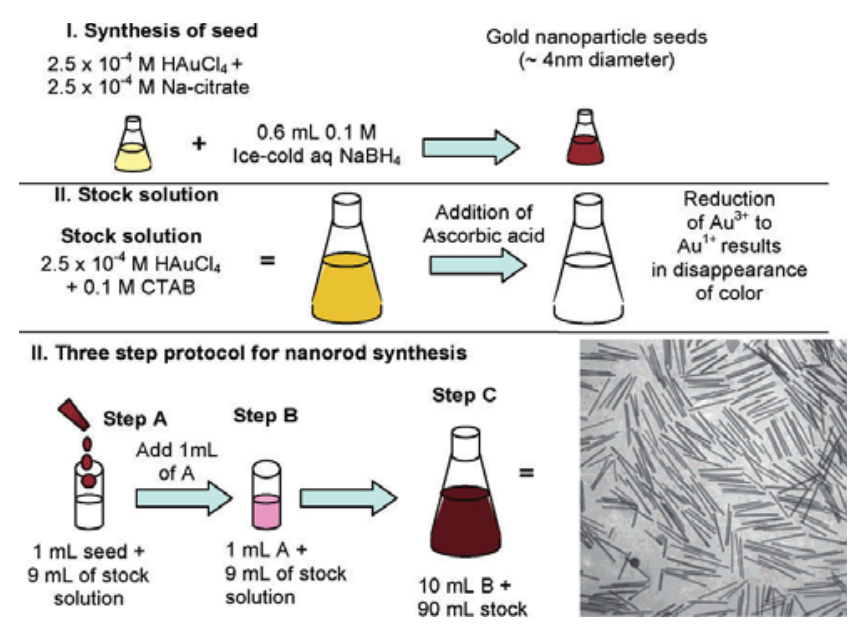

Fig. 4. Three-step seed-mediated growth approach for making gold nanorods with a controlled aspect ratio [55]. The TEM image represents $\mathrm{Au}$ nanorods after separation from the other by-products (e.g. spheres) by centrifugation. Reproduced with permission from the American Chemical Society, Copyright 2005. 
of the rods (aspect ratios up to 10) [93]. The first step involves the preparation of AuNP seeds in the 1.5-4 nm range employing a strong reducing agent such as sodium borohydride, which quickly reduces $\mathrm{Au}^{\mathrm{III}}$ to $\mathrm{Au}^{0}$. The second step involves the addition of the $\mathrm{Au}^{0}$ seeds to a "growth solution" containing $\mathrm{Au}^{\mathrm{I}}$ and made by reducing $\mathrm{HAuCl}_{4}$ with a mild reducing agent such as ascorbic acid in the presence of stabilizing or capping agents, such as CTAB [44]. Since the reducing agents used in the second step are mild, the Au seeds are needed to act both as a crystallisation centres and to reduce $\mathrm{Au}^{\mathrm{I}}$ in the growth solution to metallic $\mathrm{Au}^{0}$ as they grow on the Au seeds (Fig. 5).

In the next section, we review how the seed-mediated synthesis allows for the control of shape, size and surface properties of AuNRs by a careful manipulation of parameters such as the amount and nature of the reducing and capping agents, timing of the preparation steps or temperature of the solutions, as well as relative concentrations of all chemicals used [108].

\subsubsection{Parameters influencing the seeded growth of Au nano-} rods

Many studies have been devoted to address and explain the effects of parameters influencing the synthesis of gold nanorods, such as the nature of the surfactant $[44,45,75,90,93,108,112-117]$, the effect of silver ions $[75,107,108,115,117]$, the choice of reducing agent $[44,111,118-121]$, the use of halides $[63,113,117,122-124]$, the precise role of the initial seeds in the growth of the nanorod $[125,126]$ and the effect of $\mathrm{pH}$ in the synthesis $[75,111,127,128]$. Due to their importance in the final nanoparticle morphology, composition and catalytic activity, we will summarise the main findings for these parameters in the text below.

Surfactant. CTAB has been identified as the most widely

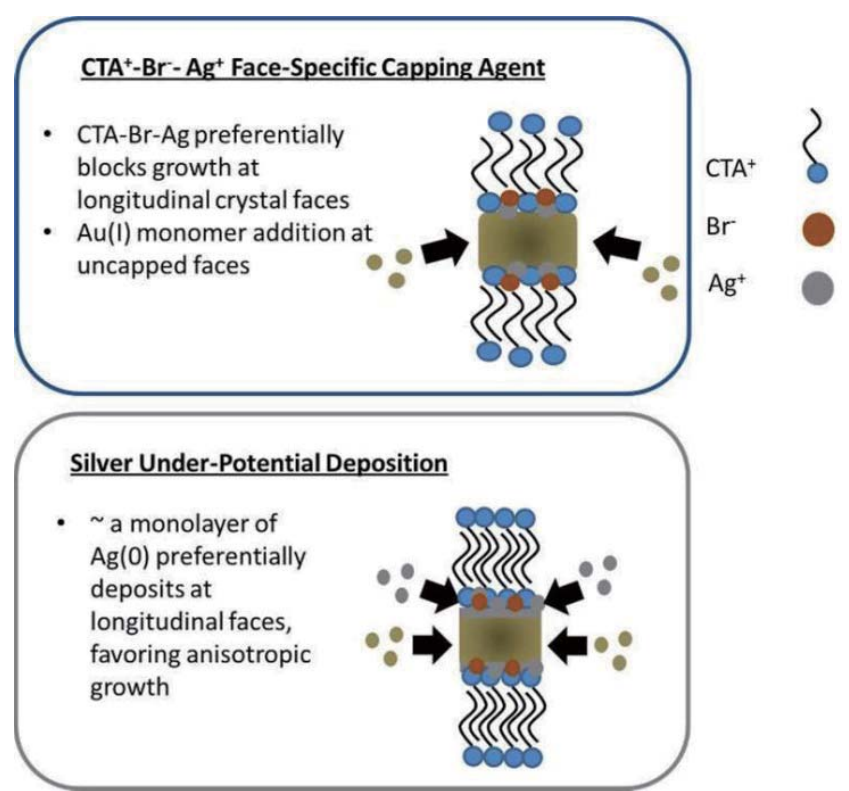

Fig. 5. Cartoon illustration of currently proposed AuNR growth mechanisms [60]. These are CTAB-silver face-specific capping agent (top) and silver under-potential deposition (bottom). CTAB is cetyltrimethylammonium bromide. Reproduced with permission from the American Chemical Society, Copyright 2013. used surfactant for the seed-mediated synthesis of Au nanorods [44] but also efficient in electrochemical [43] or photochemical methods [129]. There is a substantial amount of experimental evidence that supports that symmetry breaking is induced by the preferential adsorption of $\mathrm{CTA}^{+}-[\mathrm{Br}-\mathrm{Ag}-\mathrm{Br}]^{-}$ ionic complex on the $\{100\}$ facet of the Au crystal (Fig. 5), while alkyl chains are held together by van der Waals interactions. This allows for the AgBr crystal growth on the $\{100\}$ facet while still permitting electrostatic CTAB-AgBr interactions and directing the $\mathrm{Au}$ crystal growth in the $<100>$ direction [75,117]. This growth can compete with $\{110\}$ facet and depends on the $\mathrm{Ag}^{+}$concentration although it was suggested that the $\{100\}$ facet is still preferred [107]. Gao et al. [112] studied the influence of the CTAB analogues by varying the length of the hydrocarbon tail while keeping the counter ion and the head group constant. Their results highlighted the critical role played by the length of the surfactant tail in controlling the yield and length of the nanorods. It was found that longer chain lengths produced longer nanorods in high yields while a shorter chain length yielded shorter nanorods. However, it was demonstrated that other CTAB-related surfactants such as cetyltrimethylammonium chloride (CTAC) [113] or benzyldimethylcetylammonium chloride (BDAC) [93] are suitable for rods formation, although this required other parameters in the synthesis to be carefully tuned. Still, CTAB has to be present, for example in the case of BDAC [93]. Moreover, it was found that the quality of CTAB is very important [116] and $>50 \mathrm{ppm}$ iodide impurity means the difference between obtaining rods or spheres and thus strongly affects the final AuNR yield [130].

Silver ions. Silver ions play an important role in the gold nanorod formation and are required for high yield of monodispersed AuNRs $[44,108]$. Silver ions are combined with CTAB and undergo under-potential deposition on either $\{100\}$ or $\{110\}$ facets and thus promote anisotropic growth as it is displayed in Fig. 5. The presence of silver also slows down the growth process with the aforementioned benefit of higher AuNRs yield and enhanced monodispersity. While $\mathrm{Ag}^{+}$is essential to quantitatively form the single-crystal structure (Fig. 6 (right)), the formation of pentatwinned rods is obstructed in its presence. Therefore, pentatwinned rods are synthesized at lower temperature of ca. $20^{\circ} \mathrm{C}$ [108] or by multi-step procedure as reported by Jana et al. [44, 94] (Fig. 4, Fig. 6(left)).

Reducing agent. The reduction of the seeds is undertaken exclusively by sodium borohydride to ensure quick and complete reduction of $\mathrm{HAuCl}_{4}$ to $\mathrm{Au}^{0}$ although they can be capped by sodium citrate [44,94] or CTAB [93] to produce penta-twinned [131] or single-crystal rods [93], respectively. However, a milder reducing agent is required to slowly reduce the growth solution. Ascorbic acid is the prevailing mild reducing agent for the growth solution which reduces $\mathrm{HAuCl}_{4}$ to $\mathrm{Au}^{1}$ [108], although other compounds such as dihydroxybenzenes [111] (e.g. hydroquinone [118]), glucose [111], salicylic acid [119] or acetylacetone [121] were successfully utilised to produce rods.

Halide. Although bromide is the most suitable halide ion to promote the formation of the gold nanorods $[63,113,117,122-124]$, other anions such as chloride $[117,124]$ 

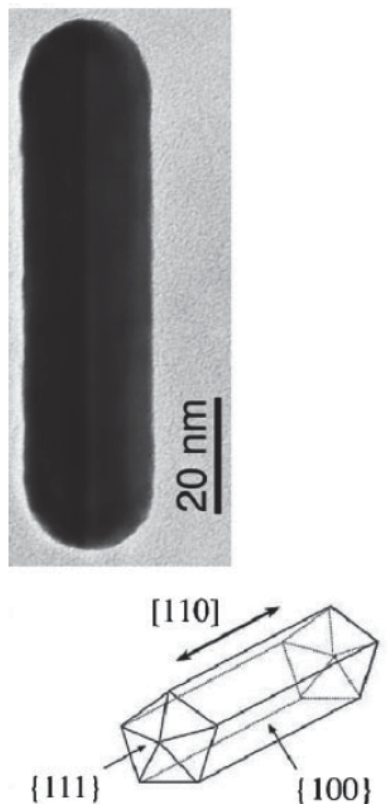

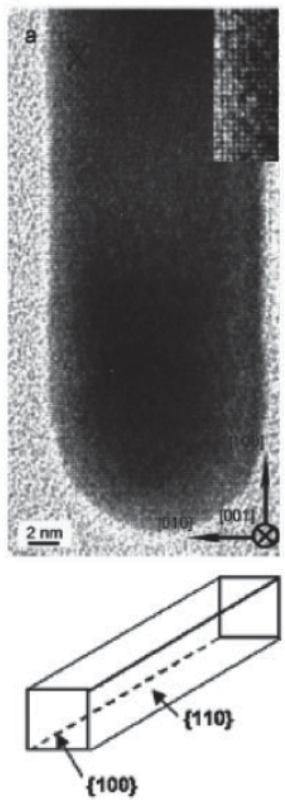

Fig. 6. TEM images (top) and schematic representations (bottom) of the penta-twinned (left) [133] and single-crystal (right) [107] gold nanorods prepared from citrate-capped seeds without and CTAB-capped seeds with using silver, respectively [52]. Reproduced with permission from the American Chemical Society and Wiley-VCH Verlag GmbH \& Co. KGaA, Weinheim, Copyright 2004, 2005 and 2009, respectively.

or iodide $[117,130]$ have been studied. The interaction strength of the halide series follows the Hofmeister series [132]: $\mathrm{F}^{-}<\mathrm{Cl}^{-}$ $<\mathrm{Br}^{-}<\mathrm{I}^{-}$. It was shown that the interaction of iodide and gold is too strong hindering the nanorod growth $[117,130]$, while that of chloride alone is too weak [117] and should quantitatively produce rods only in the presence of bromide [124]. Nevertheless, controlled and tunable bromide-free synthesis of AuNRs was presented by Ye et al. [113] using CTAC and sodium oleate surfactant mixture who showed it's much less susceptible to iodide impurities and produced $\{310\}$ facets at the tips of the rods. Also, the higher importance of bromide compared to CTAB was demonstrated [124]. CTAB at as low as or even at lower than critical micelle concentration (ca. $1 \mathrm{mM}$ ) can be used to form rods if the bromide anions are supplied in another form, e.g. $\mathrm{NaBr}$ [124]. Again, concentrations of the compounds used are substantial for the controlled growth kinetics of the rods [123].

Seeds. It was elucidated that the nature of the seed influenced the final form of the gold rods [131]. While citrate-capped seeds grown without $\mathrm{Ag}^{+}$produce penta-twinned rods [131,133], CTAB-capped seeds grown in the presence of $\mathrm{AgNO}_{3}$ give single crystal rods [52,107] (Fig. 6). Gole and co-workers [125] studied the effect of different size seeds (3.5 to $18 \mathrm{~nm}$ ) and their capping agent (uncapped, citrate, glucose, CTAB, 4-mercaptobenzoic acid) in the three-step method $[44,94]$. They found that the aspect ratio of the AuNRs depends linearly on the size of the seeds. Also, positively charged seeds (e.g. CTAB-capped) produced narrower aspect ratio distribution as explained by better compatibility of the solutions and faster capping agent exchange.

pH. In the general seed-mediated gold nanorods syntheses, no specific pH control was initially applied $[44,93,94]$. However, it was later found that the lower the $\mathrm{pH}$, the longer rods could be produced due to the decrease in the reaction rate as long as the other parameters were adjusted accordingly $[111,127,128]$. Generally, the optimum $\mathrm{pH}$ lies below the $\mathrm{p} K_{\mathrm{a}}$ value of the reducing agent. As the reduction potential of the reducing agent is $\mathrm{pH}$ dependent, careful manipulation of the parameters influencing $\mathrm{pH}$ is needed and high $\mathrm{pH}$ values should be avoided as these impede the growth of the nanorods completely [127].

\subsubsection{Synthesis of gold nanostars}

The traditional heterogeneous catalyst scientist might be sceptical about the possible application of even more complex (and larger) morphologies. However, one must consider that those working in photocatalysis will be more appreciative of their optical properties. Indeed, the application of gold nanoparticles with multiple tips is of high interest in sensing applications and SERS to the point that the concept "nanostars shine bright" is widely accepted [59]. This is due to the plasmon resonance coming from the tips of these particles $[46,49,73,78,134,135]$. The recent review from the group of Liz-Marzán [59] focuses solely on the synthesis and aspects of branched nanoparticles with extended interest in gold, whereas other reviews on different shapes of gold nanocrystals examine stars and other similar shapes among variety of other anisotropic nanoparticles [56,58,62]. Also, branched gold nanoparticles are perhaps the most studied anisotropic gold nanoparticles after nanorods due to their enhanced interaction with light [59].

Chen and co-workers [136] were the first to show room temperature and water-based reduction synthesis of branched gold nanocrystals (Fig. 7), closely followed by Hao et al. [137] using dipotassium bis(p-sulfonatophenyl) phenylphosphine dihydrate and Sau et al. [138] using CTAB as a surfactant. All of these methods used different components and surfactants to achieve the same goal-to create branched gold nanoparticles. These works stimulated further synthetic efforts to obtain star-shaped AuNP [139-144]. It was shown (Fig. 7) that the growth of the tripod occurs preferentially on the (220) planes in three of $<110\rangle$ directions compared to tetrapod where the growth takes place on the (200) planes also in the $<110>$ direction [136]. However, it was demonstrated that this depended both on the preparation method as well as surfactant used $[137,139,140]$.

Since then, many variations on the solvents, reducing agents or surfactants have been reported to be able to tune the size, number of tips, yield and stability of the formed branched particles to various extent [143,145-149]. For example, various surfactants [59] such as CTAB [136,138], BDAC [150], sodium dodecyl sulphate (SDS) [140], PVP [139,143], dipotassium bis( $p$-sulfonatophenyl) phenylphosphine dihydrate [137], gelatin [151] or lysine [148] can all lead to the branched morphologies. Unlike various single crystals such as rods [87] or various polyhedra [152], branched morphologies were shown to exhibit either single-crystal structure [153] or two different single-crystals of seed and branches $[143,154]$ or single-crystal 

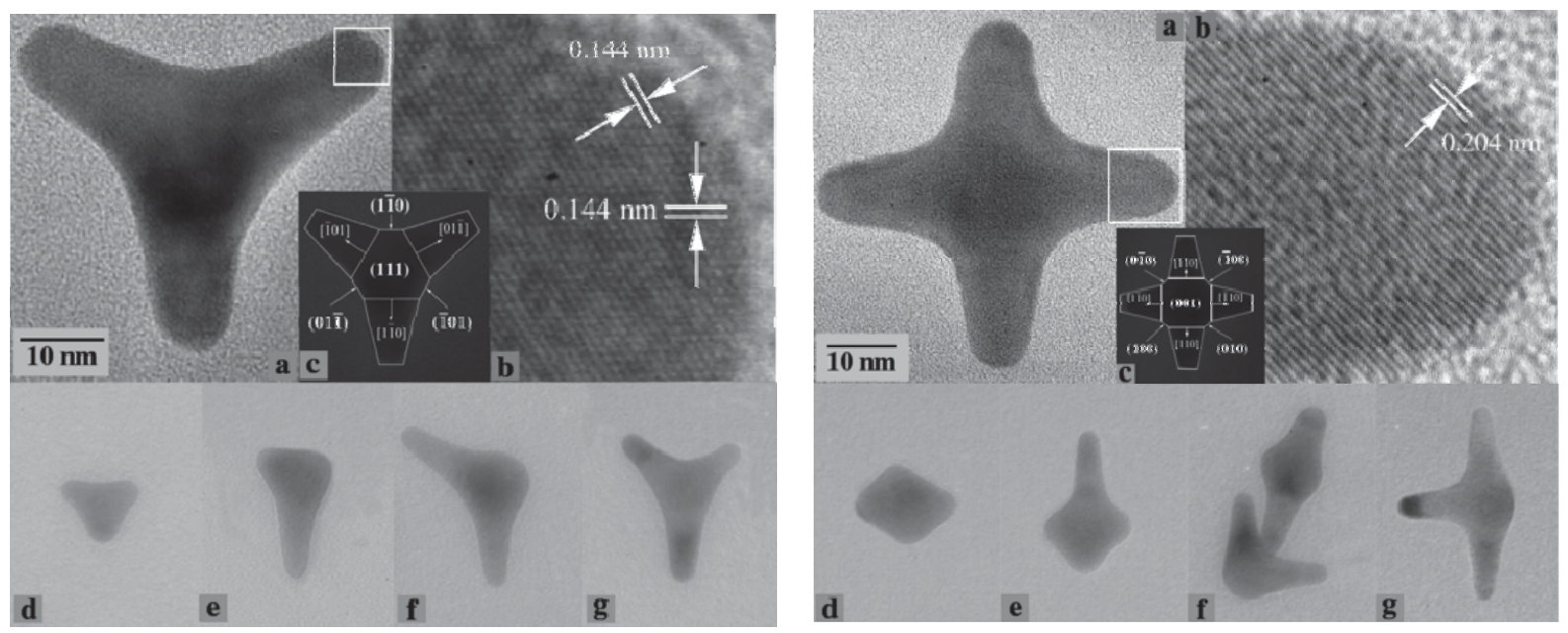

Fig. 7. TEM images of different multipod-shaped gold nanoparticles prepared by solution-phase chemical reduction method at room temperature [136]. Reproduced with permission from the American Chemical Society, Copyright 2003.

seed and polycrystalline branches [142].

Two main pathways for the synthesis of branched Au nanoparticles can be shown [59]: seeded $[136,138,140,142,143,145,147]$ and seedless growth [153-157]. In a typical synthesis solution of $\mathrm{HAuCl}_{4}$ was mixed with other components (seeds, surfactant and reducing agent) and temperature and/or stirring was adjusted to obtain the branched nanoparticles [140]. Sau et al. [138] had shown that simple procedure using CTAB as the only surfactant was able to produce different morphologies in high yield (Fig. 8) by varying the concentrations of $\mathrm{CTAB}, \mathrm{HAuCl}_{4}$, ascorbic acid, silver nitrate and seeds.

Increasing the concentration of ascorbic acid changes the morphology from hexagonal to cubic while the addition of small quantity of silver nitrate produces rods instead of cubes
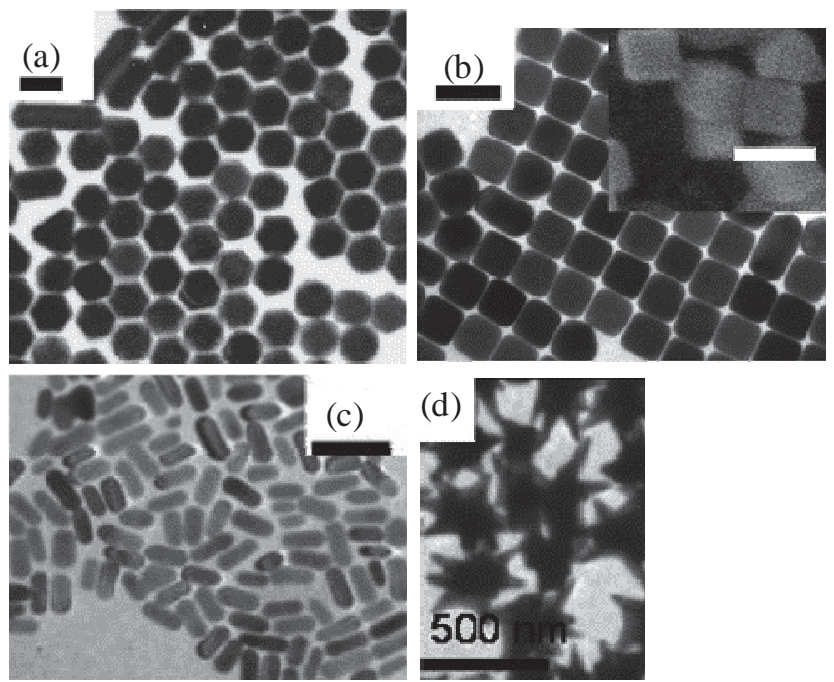

Fig. 8. TEM micrographs of the examples of different morphologies (a, hexagons; b, cubes; c, rods; d, multipods) produced from the aqueous solution of Au seeds, chloroauric acid, CTAB, ascorbic acid and silver nitrate by varying the concentrations of these components [138]. Scale bar in (a), (b) and (c) is $100 \mathrm{~nm}$. Reproduced with permission from the American Chemical Society, Copyright 2004. at low concentration of ascorbic acid. Finally, decreasing the concentration ratio between seeds and $\mathrm{HAuCl}_{4}$ and increasing the concentration of ascorbic acid gives branched nanoparticles. This happens even in the absence of $\mathrm{AgNO}_{3}$ although silver ions can improve the yield and shape of the star-shaped NPs due to their under-potential deposition on specific crystal facets of gold seeds $[138,141]$. Moreover, as it is shown in Fig. 9 increasing concentration of $\mathrm{Ag}^{+}$can increase the amount of branches during the surfactant-free seeded-growth synthesis of nanostars [147,158].

\subsubsection{Synthesis of nanoflowers, urchins and dendritic nanostructures}

Other star-like morphologies have been synthesized such as nanoflowers (Fig. 10) [153,159-161], urchins (Fig. 10) [151,162] or dendrites/dendrimers (Fig. 11) [163,164]. Early flower-like structures were synthesized by electrochemically induced growth on the metal oxide/glass electrode [159,160]. These nanoflowers were $>1 \mu \mathrm{m}$ in diameter and composed mainly of (111) planes, which is expected as Au(111) was identified as the lowest energy and therefore most stable gold plane also present predominantly in spherical gold nanoparticles [47]. The advantage of the electrochemical method seemed to be the absence of template or surfactant and narrow particle size distribution [160].

Wet chemical methods were also employed in the synthesis of nanoflowers [153,165-167] and offered smaller particle sizes (a few hundreds of nanometres and $<100 \mathrm{~nm}$ ) and tunability of the particle size and its distribution [166,167]. This was due to the same variability of synthesis parameters [167] and surfactants, such as $N$-2-hydroxyethylpiperazine$\mathrm{N}$-2-ethanesulphonic acid $[165,166], 5$-hydroxyindole-3-acetic acid [153], caffeine [168] or surfactant-free [167,169]. Wet chemical syntheses also showed $\mathrm{Au}(111)$ planes as the most dominant in nanoflowers [153,169].

Recently, microwave-assisted nanoflowers synthesis was reported to decrease the synthesis time ca. 10 times from 30 min and more to 2-3 $\min$ [161]. However, further optimisation 


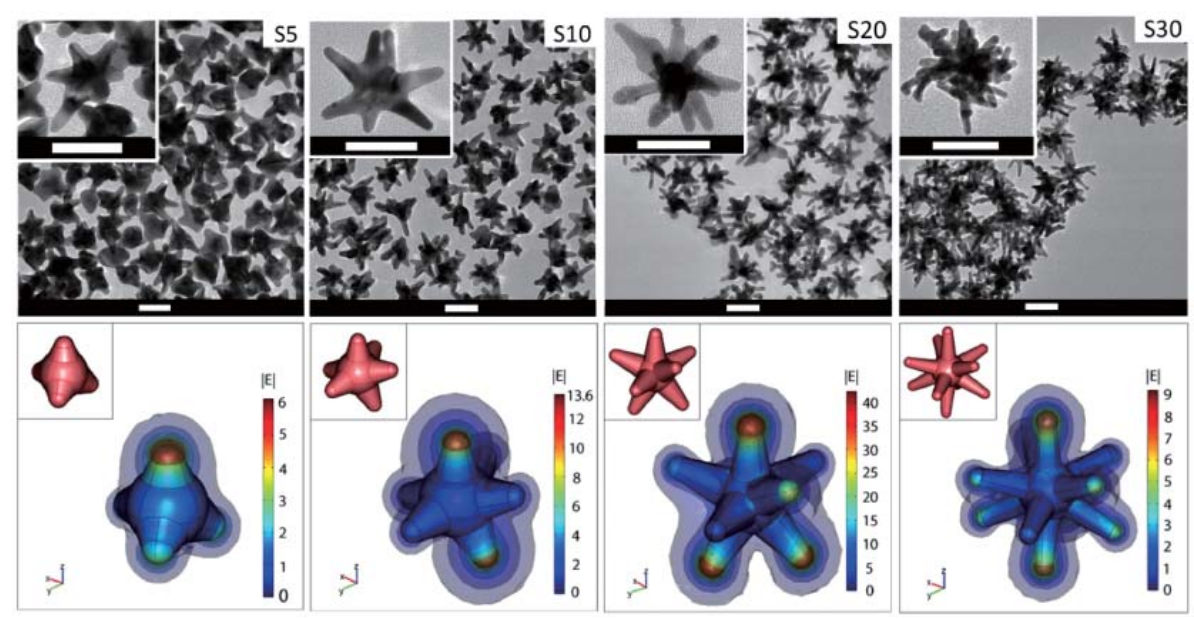

Fig. 9. TEM images (top) and shape simulation (bottom) with E-field enhancement due to the interaction with light. 3D geometry of the stars (bottom) is depicted in the insets [147]. Scale bar is $50 \mathrm{~nm}$. Reproduced with permission from IOP Publishing Ltd., Copyright 2012.
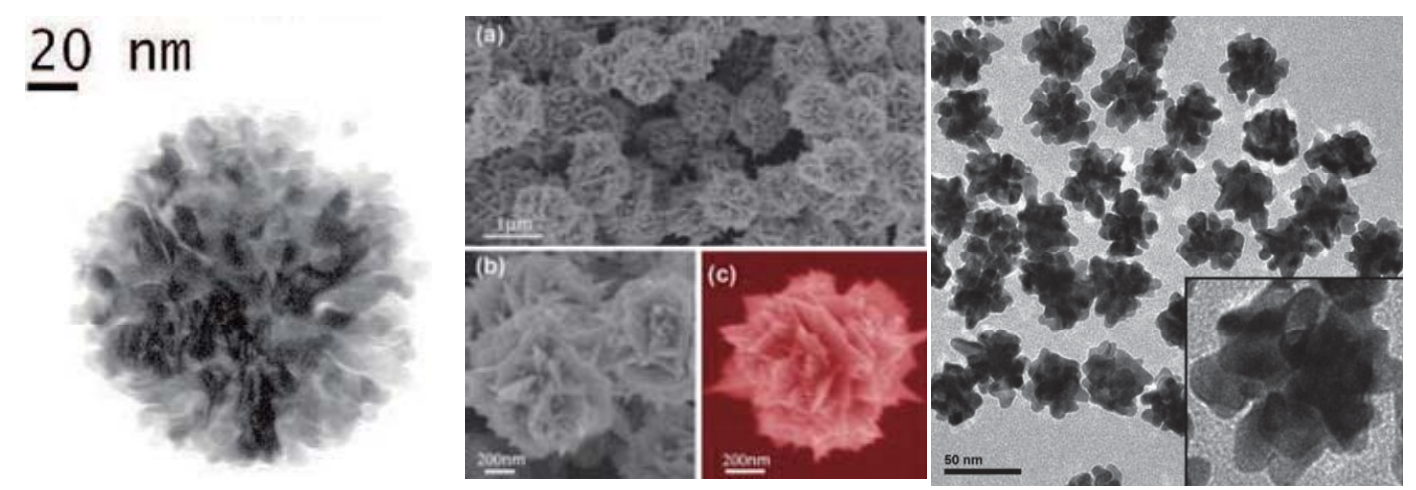

Fig. 10. TEM image of flower-shaped nanoparticle synthesized electrochemically (left) [153], SEM images of flower-shaped nanoparticle synthesized by wet chemical method (middle) [159] and TEM image of urchin-like nanostructure (right) [151]. Reproduced with permission from the (left to right) American Chemical Society, American Institute of Physics, American Chemical Society. Copyright, 2008, 2006 and 2008, respectively.
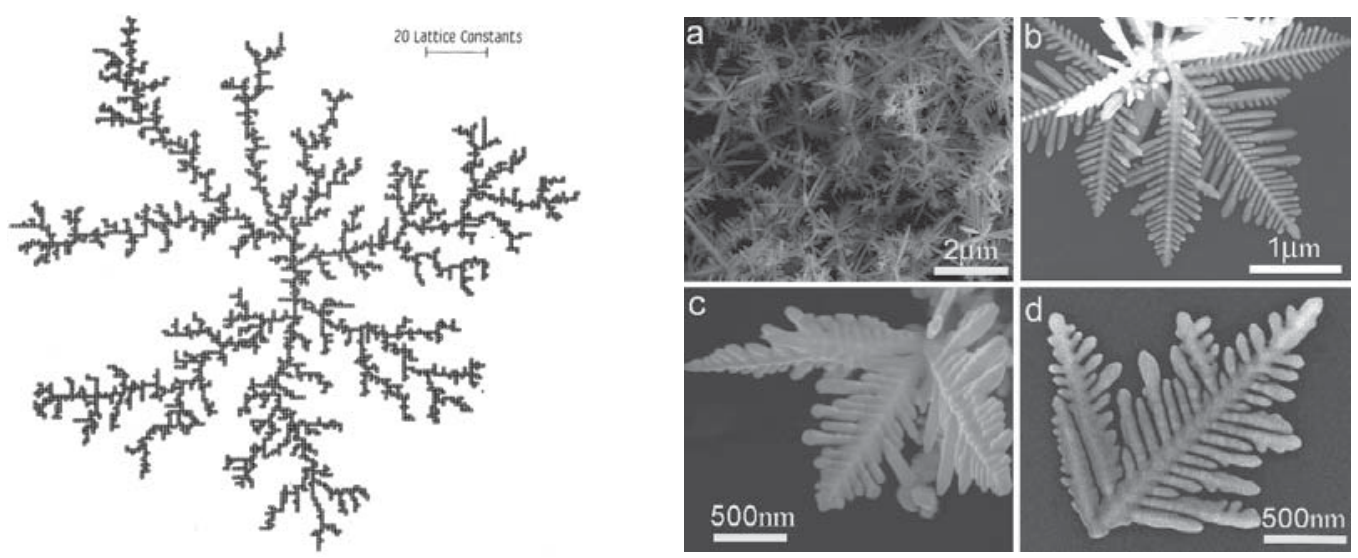

Fig. 11. Example of the simulation of the dendritic structure consisting of 3600 particles (left) [175] and TEM images of the real Au dendrite (right) [173]. Reproduced with permission from the American Physical Society and the American Chemical Society, Copyright 1981 and 2010 , respectively.

is needed to obtain narrow particle size distribution at sub-micron range. To enhance the resonance effect for use in sensing or SERS, chains of branched nanoparticles were synthesized recently by one-step wet chemical methods [168,169].

Dendritic nanostructures are governed by diffusion-controlled aggregation [170] (Fig. 11) which in the case of gold was achieved for example by an aqueous/organic interfacial reaction of chloroauric acid and 3,4-ethylenedioxythiophene, respectively [171]; the reaction between a zinc plate and $\mathrm{HAuCl}_{4}$ in the ionic liquid [BMIM][PF6] producing AuZn dendrites [172]; reduction of chloroauric acid in the solution of supermolecular complexes of dodecyltrimethylammonium bromide and $\beta$-cyclodextrin [173]; simple and fast electrochemical reduction of gold precursor only in $\mathrm{HCl}+\mathrm{KCl}$ solution [174]; triggering oxidative polymerization of pyrrole with chloroauric acid creating Au@pyrrole core-shell 
dendrites [164] or by simultaneous growth, reduction and deposition of $\mathrm{HAuCl}_{4}$ and $\mathrm{H}_{2} \mathrm{PtCl}_{6}$ with ascorbic acid and polydopamine functionalised graphene oxide [163] (Fig. 11).

It should be noted it might be sometimes hard to discern between flower, urchin and some dendritic nanostructures due to their structural similarities and not perfectly developed shapes (Fig. 10).

\subsubsection{Synthesis of hollow gold nanostructures}

Hollow gold nanostructures produced to this date can be classified as nanocages or nanoframes (Fig. 14) and hollow nanospheres although the latter is not strictly speaking an anisotropic morphology. A good introduction into the synthesis of $\mathrm{Au}$ nanocages and nanoframes by galvanic replacement and their properties was reported by the group of Xia [85] but the synthetic strategies for nanocage-based gold crystals were also presented in several reviews on anisotropic nanoparticles $[62,66]$. Nevertheless, the aforementioned group is still recognised as a pioneer in the synthesis of the cubic nanostructures, especially by galvanic replacement [85,176-181].

The synthesis of cubic Au nanostructures was described by the group of Xia $[176,177,179]$ whereby silver nanocubes were synthesized by polyol reduction of silver precursor in ethylene glycol with PVP and sodium sulphide, which is responsible for promoting the formation of cubic structure (Fig. 14). In a second step, the silver in these nanocubes are exchanged for gold due to the difference in the electrochemical potentials between $\mathrm{Au}$ and silver (Fig. 12). This can readily be done because the reduction potential of $\mathrm{AuCl}_{4}^{-} / \mathrm{Au}(0.99 \mathrm{~V}$ vs. the standard hydrogen electrode (SHE)) is more positive than that of $\mathrm{AgCl} / \mathrm{Ag}$ ( $0.22 \mathrm{~V}$ vs. SHE). The exchange proceeds as described by the overall reaction:

\section{$3 \mathrm{Ag}(\mathrm{s})+\mathrm{HAuCl}_{4} \rightarrow \mathrm{Au}(\mathrm{s})+3 \mathrm{AgCl}(\mathrm{s})+\mathrm{HCl}(\mathrm{l})$}

This is achieved by the controlled addition of chloroauric acid solution into the boiling solution of Ag nanocubes with PVP until the desired extent of replacement is attained as con-

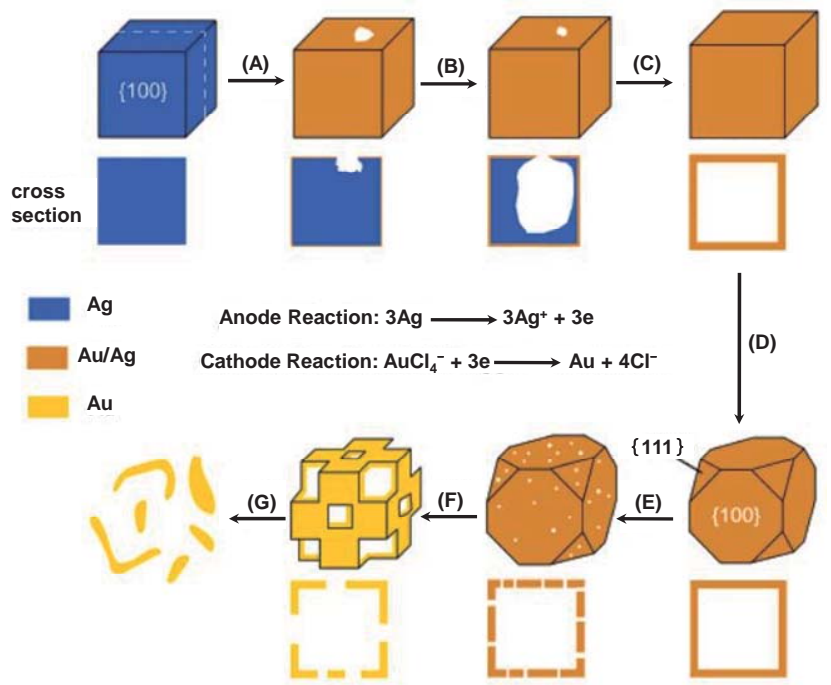

Fig. 12. Schematic representation of the galvanic replacement reaction starting from silver nanocube and ending in gold nanocage or nanoframe or truncated hollow polyhedral shape [177]. Reproduced with permission from the American Chemical Society, Copyright 2004. firmed by the colour of the solution which is correlated with the position of the surface plasmon resonance band (Fig. 13).

By adjusting reaction parameters such as temperature [177], size of the starting Ag nanocubes [176], amount of gold added [179] or etching agent [178] variations on the porosity of the final structure, size of the Au nanocages or amount of $\mathrm{Au} / \mathrm{Ag}$ alloying can be achieved [177]. It was shown that this methodology can be applied to almost any starting shape, for example nanowires [177] or nanotriangles [84] to create nanotubes or nanorings (Fig. 14), respectively. As mentioned at the beginning of this chapter, although not strictly anisotropic nanoparticles, nanoshells or nanorattles can be synthesized by galvanic replacement or dealloying [83]. The cubic structures based on the synthesis by this etching strategy prevalently expose $\{100\}$ facet which forms the 6 main cube planes [176] (Fig. 1) although excessive silver etching can promote the most stable (111) plane formation at the corners of the cube. To increase the amount of high-index facets, CTAC-modified seed-mediated method was employed to create concave cubic gold nanocrystals enclosed by 24 high-index $\{720\}$ facets (Fig. 14). The catalytic activity of several of these cubic nanostructures has recently been demonstrated by several research groups [182-186].

\subsubsection{Synthesis of gold nanowires, nanotubes and nanobelts}

The lithographic synthesis of gold nanowires of $8 \mathrm{~nm}$ diameter was demonstrated already more than 30 years ago [187] and was originally used for preparation of Sn, In and $\mathrm{Zn}$ wires with the diameter of $40 \mathrm{~nm}$ and lengths up to $15 \mu \mathrm{m}$ [188]. A similar method (with modifications developed over time [82])
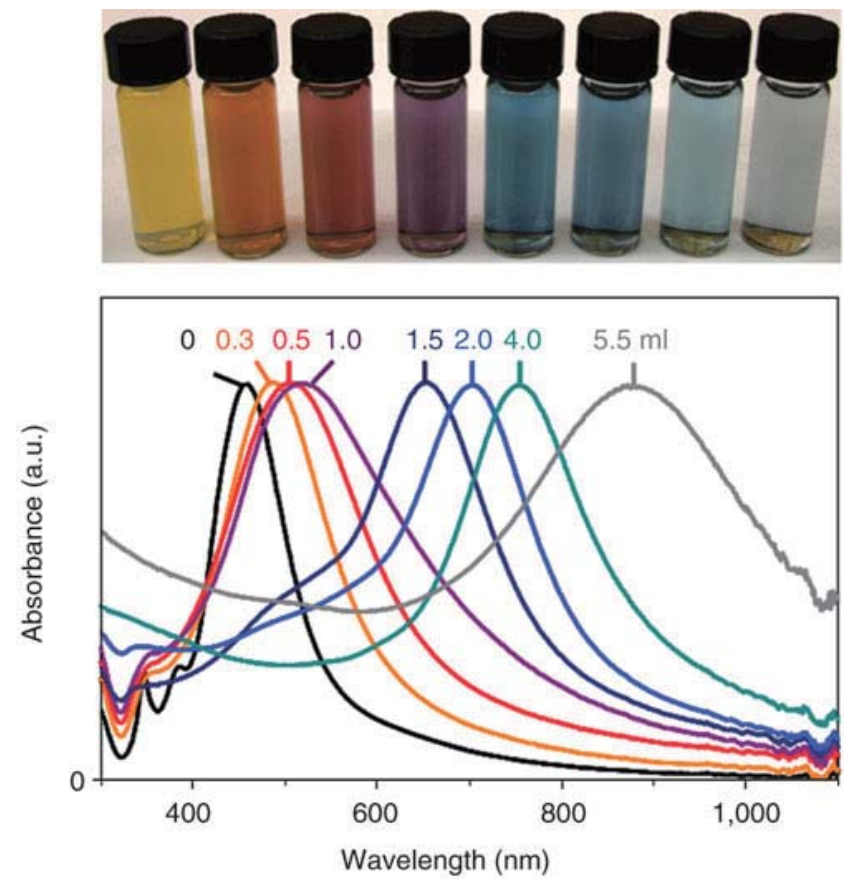

Fig. 13. Photograph of the vials containing solutions of the $\mathrm{Ag}$ nanocubes to $\mathrm{Au}$ nanocages at different amounts of $0.1 \mathrm{mM} \mathrm{HAuCl}_{4}$ solution added to the solution of silver nanocages and PVP (top). UV-vis-NIR spectra corresponding to the formed $\mathrm{Ag} / \mathrm{Au}$ nanoparticles with corresponding colours (bottom) [179]. Reproduced with permission from the Nature Publishing Group, Copyright 2007. 



Fig. 14. TEM images of Au nanoframes (a) [178], Au nanocages (b) [177], Au triangular nanorings (c) [84], mix of SEM and TEM micrographs of concave Au nanocubes with their schematic representations (bottom right) [86]. Scale bars for the bottom right set of images are: (d), (h), (i), (j), (k) 500 nm; (e), (f), (g) $200 \mathrm{~nm}$; inset in (h) $40 \mathrm{~nm}$. Reproduced with permission from the American Chemical Society and Wiley-VCH Verlag GmbH \& Co. KGaA, Weinheim, Copyright 2007, 2004, 2003 and 2010, respectively.

can be used for the synthesis of both nanowires [187,189] and nanotubes [106] and it is mostly based on the controlled deposition of the metal on a suitable template, such as porous polycarbonate [106] or alumina [190], followed by selective dissolution or etching of the template [82]. The general diagram showing the example of the synthesis procedure and an example of the Au nanotubes is displayed in the Fig. 15 (left and right, respectively).

The deposition of the gold was initially done by electrochemical-plating [192] but was later changed to electroless plating which offered higher uniformity of the gold layer deposition [193]. It was also shown that the nanotubes can be used as-synthesized, i.e. without the removal of the original template $[106,194]$. The potential of the gold nanotubes was demonstrated to be mostly in molecular filtration [106], ion transport [194] and sensing [81]. However, both gold wires and tubes have demonstrated their catalytic activity, for example in electrocatalytic oxidation of glucose [195] or CO oxidation [191,196].

Using a different approach, multi-shell helical gold nanowires [197] and single-wall helical gold nanotubes [198] were synthesized by electron beam thinning of a gold thin foil in ultra-high vacuum inside the electron microscope. These single-wall $\mathrm{Au}$ nanotubes were later modelled for the catalytic oxidation of carbon monoxide [196]. In another approach from the group of Qi [199] ascorbic acid induced the reduction of chloroauric acid in the mixed aqueous solution of CTAB, whereas sodium dodecylsulfonate was used to obtain nanobelts. It was shown that just by changing the temperature of the solution from 4 to $27^{\circ} \mathrm{C}$ the preferential growth was changed from $<110>$ to $<211>$ direction (Fig. 16).

Porous gold nanowires [200,201] and nanotubes [202] were prepared by electrochemical methods not too dissimilar to the abovementioned electrochemical plating and etching and by galvanic replacement of less noble metals such as Te [203] or $\mathrm{Ni}$ [204]. On the other hand, a wet chemical method utilising only dodecane-1,12-bis(trimethylammonium bromide) and chloroauric acid was able to provide high yields of porous nanobelts exhibiting enhanced catalytic activity towards the reduction of 4-nitrophenol [205]. For an interested reader, Hong and co-workers [61] have produced in 2015 an excellent review dedicated exclusively to the synthesis and properties of one-dimensional gold nanostructures such as nanowires or nanobelts.

\subsubsection{Synthesis of $2 D$ (plate-like) nanostructures}

Typical examples of the shapes of gold nanoplate morphologies are the hexagon, triangle or truncated hexagon as an in- 

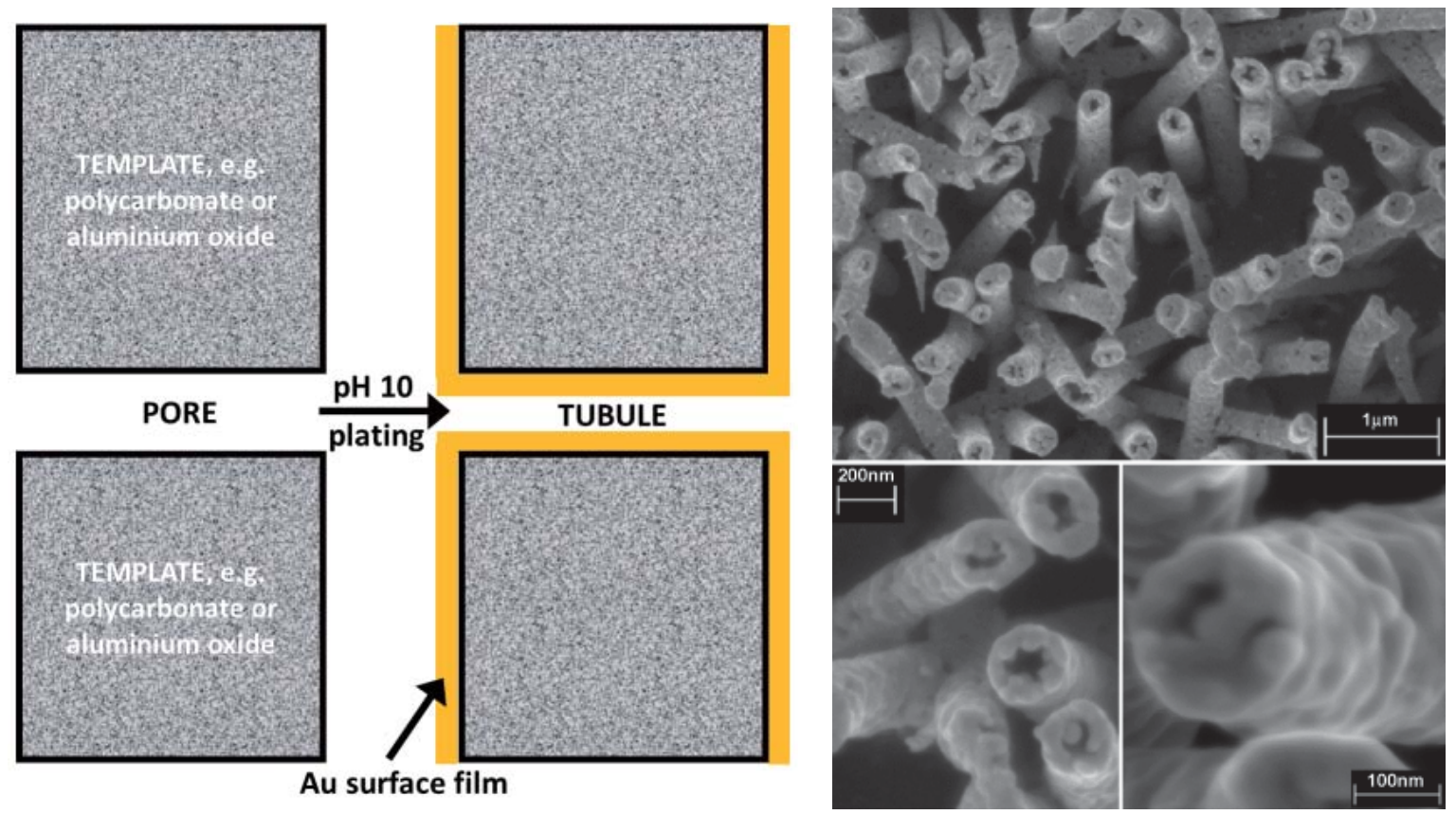

Fig. 15. The example diagram showing the synthesis procedure for gold nanotubes (left) [106] and SEM images of Au nanotubes (right) [191]. Reproduced with permission from the Wiley-VCH Verlag GmbH \& Co. KGaA, Weinheim, Copyright 2004.
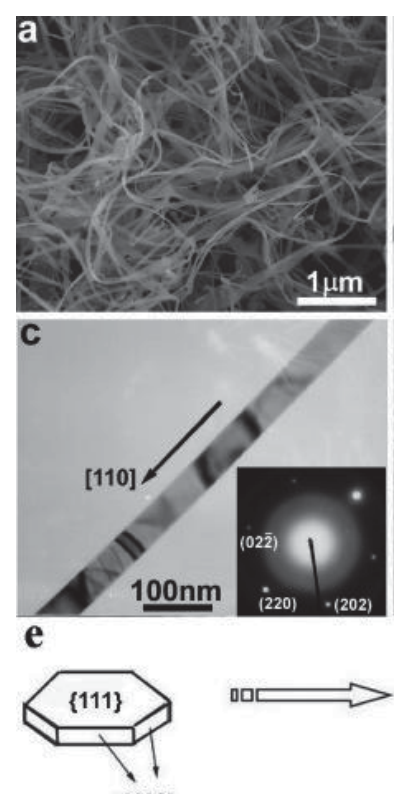

$\{110\}$
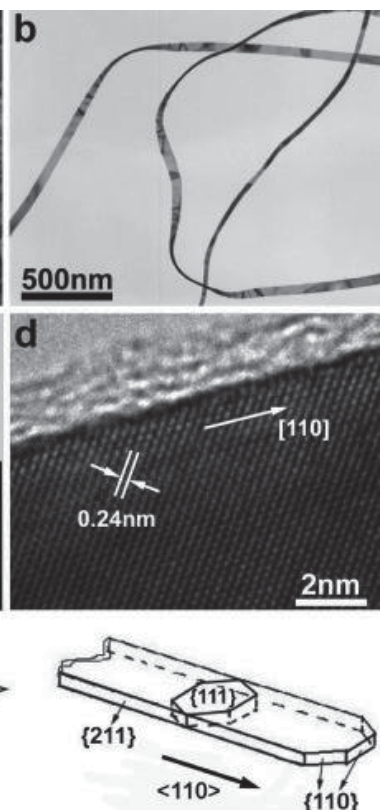
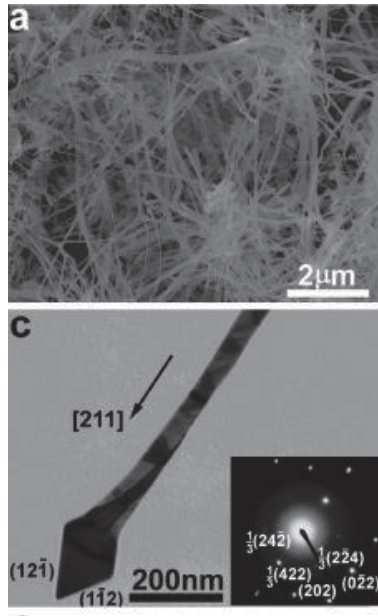

e
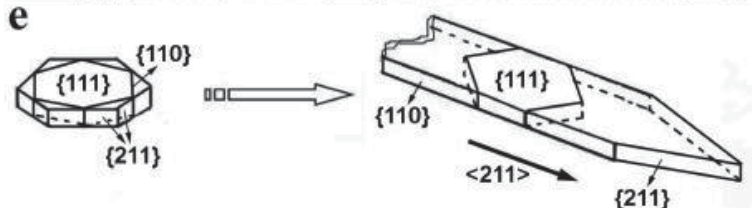

Fig. 16. SEM (a), TEM (b, c, d) and schematic illustration (e) of the gold nanobelts prepared by the reduction of $\mathrm{HAuCl}_{4}$ with ascorbic acid in the solution of CTAB and sodium dodecylsulfonate at $4{ }^{\circ} \mathrm{C}$ (left) and $27^{\circ} \mathrm{C}$ (right) [199]. Reproduced with permission from the American Chemical Society, Copyright 2008.

termediate between these two shapes [61,64] (Fig. 17). The synthesis and properties of two-dimensional structures was reviewed specifically for different metals by Pastoriza-Santos et al. [206] and for gold by Hong et al. [61] or Hu et al. [64]. Generally, the three-step seed-mediated synthesis developed by Murphy et al. [207] has shown to produce only nanoprisms (plate-like structure with triangular base) $(144 \pm 30 \mathrm{~nm}, 7.8 \pm$ $0.5 \mathrm{~nm}$ thick) and spherical nanoparticles (size of $35 \pm 2 \mathrm{~nm}$ ) when modified with $\mathrm{NaOH}$ [208]. Even before, simple mixing of aqueous lemongrass leaf extract and an aqueous solution of $\mathrm{HAuCl}_{4}$ provided almost $45 \%$ yield of gold triangular nanoparticles (with an average size of little over $1 \mu \mathrm{m}$ ) preferentially exposing the (111) plane [209]. It was possible to increase the yield of the nanoprisms up to $90 \%$ by centrifugation. Differing from these typical face cubic-centred gold structures, Huang et al. [210] synthesized hexagonal close-packed Au square sheets which were $2.4 \mathrm{~nm}$ thick and had an edge of 200-500 nm. They had shown the gold sheets were stable under ambient condi- 

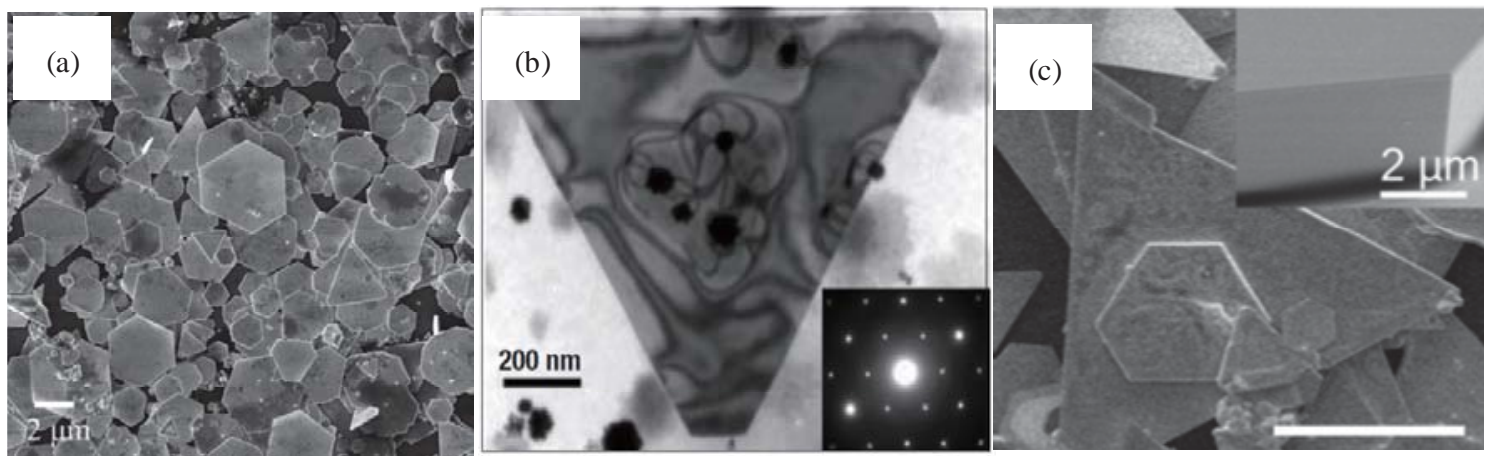

Fig. 17. SEM (a) [218] and TEM (b) [209] and SEM (c) image [217] examples of plate-like gold nanostructures to microstructures. Reproduced with permission from the American Chemical Society, Nature Publishing Group and Elsevier, Copyright 2008, 2004 and 2016, respectively.

tions but transformed into fcc structures upon exposure to the electron beam. 1-amino-9-octadecene in hexane/ethanol solution of chloroauric acid with dispersed graphene oxide was heated to $55{ }^{\circ} \mathrm{C}$ for $16 \mathrm{~h}$ to form gold nanostructures. Apart from using CTAB [211] or other surfactant (e.g. PVP [139,212]), other strategies were employed to prepare plate-like nanostructures, such as the use of polymer templates [213-216]. However, it should be mentioned that in most of the aforementioned studies the size of the formed 2D nanostructures was in order of $>1 \mu \mathrm{m}$ up to hundreds of micrometres [217] (Fig. 17).

\subsubsection{Synthesis of polyhedral gold nanoparticles}

Polyhedral nanoparticles include the octahedron [219-224], cuboctahedron [219,221,224], tetrahedron [223], tetrahexahedron [225], icosahedron [223,226-232], decahedron [233], dodecahedron [222,224,234], bipyramid [107,235], ditetragonal prism [222] or the cube [86,176,219,221-223]. The synthesis of these polyhedral nanostructures of gold were examined in the following reviews $[62,91,236,237]$ and their representative images are shown in Fig. 18.

Polyhedral shapes are generally synthesized by modifying the seed-mediated method which in itself produced a mix of shapes [138]. For example, tetrahexahedral gold nanocrystals (Fig. 18(d)) were prepared this way with $\mathrm{HCl}$ and $\mathrm{AgNO}_{3}$ in the growth solution [225]. On the other hand, CTAC was used to synthesize nanocubes (Fig. 14(f)) and rhombic dodecahedra (Fig. 18(c)) with addition of $\mathrm{NaBr}$, while KI promoted the growth of octahedra [238]. Also, CTAC and $\mathrm{HCl}$ was used in another study in which increasing amount of silver gave octa- hedra with $\{111\}$ facets < rhombic dodecahedra with $\{110\}$ facets < ditetragonal prisms with $\{310\}$ facets < concave cubes with $\{720\}$ facets [222]. Icosahedra were selectively prepared by mixing an aqueous solution of chloroauric acid with $N$-vinyl pyrrolidone to get $94 \%$ yield of monodisperse gold nanoparticles [228].

From the above sections it seems clear that a wide number of techniques have been demonstrated to selectively produce anisotropic gold nanoparticles with certain ease, although it is also evident that such syntheses are extremely sensitive to small modifications in the synthesis and preparation conditions, including impurities or exposure to the light among other environmental factors. On the other hand, many of the mentioned colloidal nanoparticles have demonstrated their catalytic properties. We must now note that catalysis requires robust and stable catalysts that can easily be separated from the reaction media, and this is typically achieved by dispersing and stabilising the active phase (gold) on a porous solid support. In the next section we will introduce the two approaches that have been studied for this purpose, namely the formation of a protective external shell (typically an oxide) around the metal nanoparticle and the direct immobilisation of the metal nanoparticle on/within a porous support.

\subsection{Preparation of supported anisotropic gold catalysts}

Pioneering work in heterogeneous gold catalysis highlighted the crucial role played by the preparation method of the supported gold catalysts on their overall activity for particular reactions such as oxidations, hydrogenations or nucleophilic
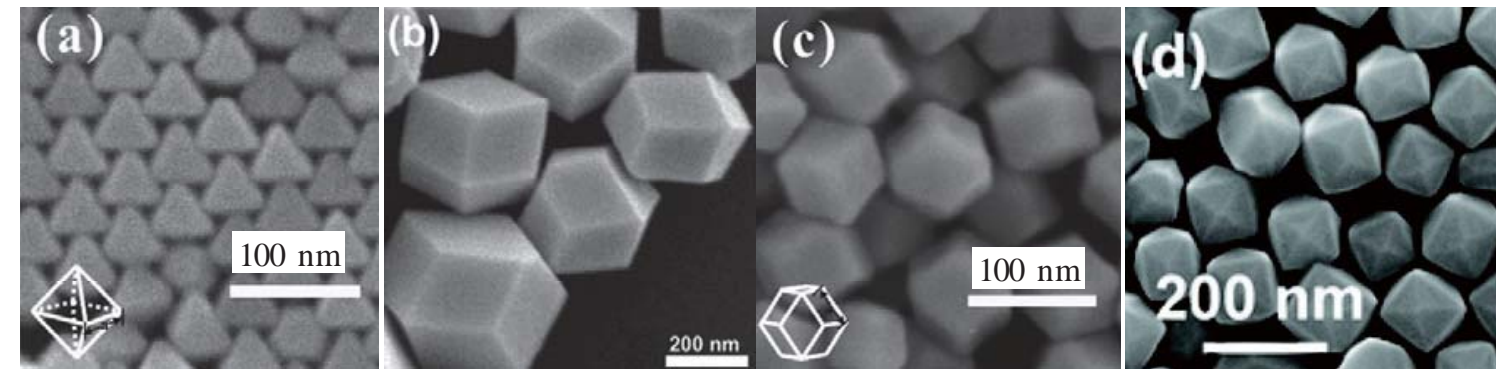

Fig. 18. SEM images of octahedra (a) [238], icosahedra (b) [234], dodecahedra (c) [238], tetrahexahedra (d) [225]. Reproduced with permission from the American Chemical Society, Copyright 2012, 2009, 2012 and 2009, respectively. 
additions [7,9,12,13,239,240]. The more traditional methods include impregnation $[9,13]$ or deposition-precipitation $[7,9,13,241]$, whereas co-precipitation is also used and particularly in the seminal work by Haruta in gold catalysis for CO oxidation [242,243]. All of the above-mentioned techniques, require at some stage the direct interaction of the metal salt with the support, so that the metal nanoparticles are formed after a reduction treatment of the metal surface, or their formation is coupled with their deposition step in the deposition-precipitation method while both components are mixed in a suspension. More recently, the concept of preforming the metal nanoparticles in a colloidal suspension in a controlled synthesis, followed by the immobilisation of the nanoparticle has attracted a lot of interest and produced some exceptional catalytic results and termed colloids immobilisation [244] or sol immobilisation [32,34-36,245-247]. The obvious advantage of the two step immobilisation of the colloid is that preferably monodisperse nanoparticles of specific size can be prepared and then selectively supported as opposed to one step during which both particles are formed and supported (impregnation, deposition-precipitation and co-precipitation) as this leads to higher polydispersity of the nanoparticles. Nevertheless, the challenge lies in the ability to maximise the effectiveness of the most active component by designing catalyst preparation methodologies that yield robust heterogeneous catalysts with anisotropic morphologies (Fig. 19) which has been little so far.

\subsubsection{Core@shell method or encapsulation by a layer of the support}

The encapsulation of the gold nanoparticle within a stabilising material is a promising strategy to produce robust nanoparticles for catalysis $[249,250]$, typically comprising oxides in the outer shell, usually titania [249,251-254], ceria [250] or silica $[255,256]$ although other oxide shells were reported, such as iron [257,258] or copper [259] oxides. In particular, the integration of gold and titania to create a core@shell structure has been explored aiming to minimize the problem of aggregation and loss of shape of the metal nanocrystal core as well as to increase the active metal/semiconductor interfacial areas $[248,260,261]$. Nevertheless, most of the work done in literature has been based on the use of spherical Au nanoparticles and only a few have made use of colloidal or templated Au na-

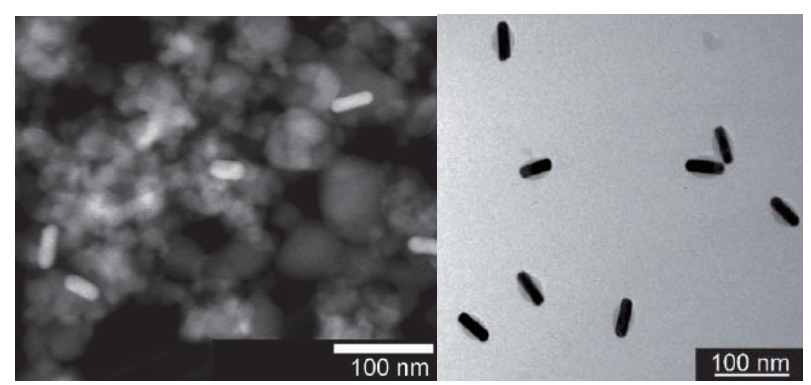

Fig. 19. Comparison of gold nanorods supported on $\mathrm{TiO}_{2}$ by the immobilisation of the colloidal solution (left) [248] and gold nanorods coated by $\mathrm{TiO}_{2}$ layer (right) [249]. Reproduced with permission from Wiley-VCH Verlag GmbH \& Co. KGaA, Weinheim, Copyright 2013, 2011, respectively. norods integrated with $\mathrm{TiO}_{2}[248,260,262-265]$.

The core@shell method adopted by multiple authors $[249,252,253,266,267]$ (schematically depicted in Fig. 20) relies on coating the metal nanoparticles by a layer of metal oxide (e.g. titania) which both protects nanoparticles from agglomeration, dilutes the amount of metal and is expected to couple with the surface plasmon resonance of the nanoparticle as these are mostly used for photocatalytic applications [251-253]. This core-shell structure was pioneered by the group of Liz-Marzán [268] and consisted of one-pot simultaneous formation of spherical silver nanoparticles and their coating by a thin layer of polymerised $\mathrm{TiO}_{2}$ via controlled hydrolysis of titanium butoxide as reported in the late $1990 \mathrm{~s}$ $[269,270]$. In this case, titanium dioxide is the most widely used support $[254,266,271]$ due to its structural, optical properties and interaction with light $[254,271]$.

In a typical synthesis of these layered or core-shell structures the preformed gold nanoparticles are treated to remove the excess of surfactant generally by centrifugation. A chemical agent is introduced in order to facilitate the growth of metal oxide on the surface of nanoparticle, such as poly(sodium-4-styrenesulfonate) [253], cetyltrimethylammonium chloride [252] or hydroxypropyl cellulose [249] among others. Subsequently, the source of titanium is added and hydrolysed to form a titanium dioxide layer and finally, core@shell nanoparticles are purified to remove residual chemicals used during the synthesis.

\subsubsection{Immobilisation of preformed colloidal nanoparticles}

The preparation of gold heterogeneous catalysts via immobilisation of colloidal nanoparticles has recently attracted a great amount of interest [16,27,247,272-274] and demonstrated to typically produce more active catalysts to more traditional impregnation or deposition-precipitation [33-36,244,246,275-279]. However, the relevance of such routes to prepare heterogeneous catalysts offers even more advantages in some catalytic systems by producing more homogeneous systems, particularly relevant when alloyed nanoparticles are considered, when a narrow distribution is required or a precise core@shell bimetallic nanoparticle is desired [37,247,280-282]. Such systems can potentially bridge the gap between model and real heterogeneous systems when aiming to generate structure-activity relationships. Exploring the preparation of homogeneous distributions of anisotropic nanoparticles to form heterogeneous catalysts is the logical consequence of such advances. Simple electrostatic immobilisation is the common procedure to immobilise spherical col-

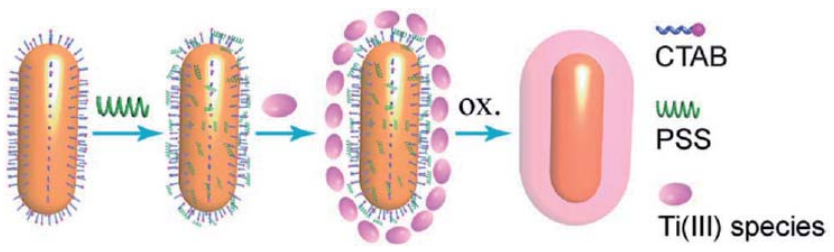

Fig. 20. Schematic representation of an example of the preparation of core-shell Au@ $\mathrm{TiO}_{2}$ [253]. PSS, poly(sodium-4-styrenesulfonate); ox., oxidation. Reproduced with permission from the Royal Society of Chemistry, Copyright 2014. 
loids on a range of supports [37,280]. It is important to highlight that anisotropic nanoparticles are also typically prepared as a colloidal solution and that, in principle, the same methodology should apply. Indeed, the colloid or sol two step immobilisation approach can be applied to the preparation of supported anisotropic nanostructures [248,264]. During the preparation of the colloidal gold solution the stable gold nanoparticles can be obtained by a variety of synthetic techniques $[55,58,62,66,283]$. Support of choice (usually metal oxides or carbon) is then added to the solution which can be acidified below the isoelectric point of the support to facilitate the interaction of the nanoparticles with surface groups of the support. After adsorption of the colloidal particles is achieved, the solvent is evaporated or filtered and catalyst washed and eventually treated to remove unwanted molecules (surfactants, protecting agents, etc.) $[35,248,264]$. On the other hand, it was shown that the immobilisation of the colloid can be achieved by simple time-induced electrostatic adsorption of the solution of gold nanoparticles from organic/aqueous media such as $\mathrm{Au}$ nanorice supported on $\mathrm{ZnO}$ nanowires from ethanol solution [263] or gold nanorods supported on $\mathrm{CeO}_{2}$ from water [265] followed by filtration, washing and $100-200{ }^{\circ} \mathrm{C}$ heat treatment [263,265].

Although this method has been used extensively for spherical nanoparticles, it has not been largely explored yet for anisotropic nanocrystals and the majority of the "supported" gold anisotropic nanoparticles refer essentially to core-shell nanoparticles [249] as described in the previous section. We would expect that the higher the interest in the application of anisotropic gold nanoparticles for catalysis that more that the direct immobilisation onto supports will be utilised, possibly in combination of mesoporous materials as supports that would fur-

Table 1

Summary of the catalytic studies performed on free colloidal anisotropic gold nanoparticles.

\begin{tabular}{|c|c|c|c|}
\hline No. & Metal(s) and nanoshape & Reaction system & Ref. \\
\hline 1 & Au rods & Hydrogenation of 4-nitrobenzaldehyde with $\mathrm{H}_{2}$ & [293] \\
\hline 2 & Au rods & Reduction of 4-NP and 4-NA by $\mathrm{KBH}_{4}$ & [296] \\
\hline 3 & Au rods & Reduction of 4-NP by $\mathrm{NaBH}_{4}$ & [297] \\
\hline 4 & Au,Au@Ag multiple core@shell rods (up to 6 layers) & Reduction of 4-NP by $\mathrm{NaBH}_{4}$ & [298] \\
\hline 5 & Au rods, prisms & Reduction of nitro compounds (e.g. 4-NP) by $\mathrm{NaBH}_{4}$ & [294] \\
\hline 6 & Au@Au and Au@Pd rattles (rod-shaped), rods & Reduction of 4-NP by $\mathrm{NaBH}_{4}$ & [299] \\
\hline 7 & AuAg rods, decahedra, bipyramids & Reduction of 4-NP by $\mathrm{NaBH}_{4}$ & [291] \\
\hline 8 & Au rods, cubes, triangles, polygons & Reduction of 4-NP by $\mathrm{NaBH}_{4}$ & {$[300]$} \\
\hline 9 & $\begin{array}{l}\text { Au elongated tetrahexahedral, concave cubic, } \\
\text { trisoctahedral and quasi-spherical NPs }\end{array}$ & Hydrogenation of 4-NTP & {$[301]$} \\
\hline 10 & Au@Ag cubes and pyramids & Reduction of 4-NP by $\mathrm{NaBH}_{4}$ & [302] \\
\hline 11 & Au cages, boxes, spheres & Reduction of 4-NP by $\mathrm{NaBH}_{4}$ & [303] \\
\hline 12 & Au@Ag cubic, octahedral crystals & Reduction of 2-amino-5-NP by $\mathrm{NaBH}_{4}$ & [304] \\
\hline 13 & Au and AuPt cages & Reduction of 4-NP by $\mathrm{NaBH}_{4}$ & [182] \\
\hline 14 & Au cubes, octahedra, rhombic dodecahedra & Reduction of 4-NA by $\mathrm{NaBH}_{4}$ & [238] \\
\hline 15 & AuPt cubes & Reduction of 4-NP by $\mathrm{NaBH}_{4}$ & [305] \\
\hline 16 & $\mathrm{Au}$ polygons & Reduction of 4-NP by $\mathrm{NaBH}_{4}$; oxidation of D-hexoses & [292] \\
\hline 17 & Au stars, shells & Reduction of 4 -NTP by $\mathrm{NaBH}_{4}$ & [306] \\
\hline 18 & Au stars & Reduction of 4-NP, 4-NA by $\mathrm{NaBH}_{4}$ & [307] \\
\hline 19 & flower-like Au chains & Reduction of 4-NP by $\mathrm{NaBH}_{4}$ & [168] \\
\hline 20 & Au flowers & Reduction of 4-NP by $\mathrm{NaBH}_{4}$ & [161] \\
\hline 21 & Au dendrites & Reduction of 4-NP by $\mathrm{NaBH}_{4}$ & [308] \\
\hline 22 & Au porous belts and solid belts & Reduction of 4-NP by $\mathrm{NaBH}_{4}$ & [205] \\
\hline 23 & Au nanowire networks & Reduction of 4-NP by $\mathrm{NaBH}_{4}$ & [309] \\
\hline 24 & Au nanoparticle networks & Reduction of 4-NP by $\mathrm{NaBH}_{4}$ & {$[310]$} \\
\hline 25 & Au foam (network) & Reduction of 4-NA by $\mathrm{KBH}_{4}$ & [311] \\
\hline $26^{a}$ & Au rod, dodecahedron & Oxidation of ascorbic acid & [284] \\
\hline $27^{b}$ & single-walled Au tube & Oxidation of CO & [196] \\
\hline $28^{b}$ & Au porous network & Oxidative $\mathrm{MeOH}$ coupling in gas-phase & {$[312]$} \\
\hline 29 & Au and Au@Pt octahedra & Hydrogen generation from hydrolysis of $\mathrm{NH}_{3} \mathrm{BH}_{3}$ & [313] \\
\hline 30 & Au cubes, octahedra, rhombic dodecahedra & {$[3+2]$ azide-alkyne cycloaddition (e.g. of benzyl azide and ethynylbenzene) } & [314] \\
\hline $31^{c}$ & Au rods & Photocatalytic oxidation of salicylic acid & [297] \\
\hline $32^{c}$ & Au rods, cubes, triangles, polygons & Photocatalytic oxidation of benzaldehyde & [185] \\
\hline 33 & AuNR@Cu $\mathrm{Cu}_{2} \mathrm{O}$ truncated octahedra & Photocatalytic degradation of methyl orange & [259] \\
\hline 34 & Pd- and Pt-tipped Au rods & Photocatalytic dehydrogenation of formic acid & [315] \\
\hline 35 & Au and Au@Pt porous and solid tubes & Electrocatalytic oxidation of $\mathrm{MeOH}$ with $\mathrm{H}_{2} \mathrm{SO}_{4}$ & [202] \\
\hline 36 & Au rods & Electrocatalytic oxidation of glucose & [316] \\
\hline 37 & Au rods with PdAg alloys & Electrocatalytic oxidation of ethanol & [317] \\
\hline
\end{tabular}

References are sorted on the basis of the activation type (thermo-, photo- and electrocatalytic), reaction system (reduction, oxidation, C-C forming and other) and nanoparticles shape (rods, polyhedra, star-like, tubes and networks, wires). NP is nitrophenol; 4-NP, 4-nitrophenol; 4-NA, 4-nitroaniline; 4-NTP, 4-nitrothiophenol; $\mathrm{MeOH}$, methanol.

a single particle experiment

${ }^{\mathrm{b}}$ unsupported (gas phase)

c colloidal mix with $\mathrm{TiO}_{2}$ in solution. 
ther stabilise the typically larger anisotropic nanoparticles.

\section{Catalytic applications of anisotropic gold nanoparticles}

The size and shape of noble metal nanoparticles play a key role in their catalytic activity and selectivity. Therefore the ability to control their morphology can be crucial in tailoring them as anisotropic nanoparticle catalysts or in pursue of generating structure-activity relationships with real catalyst and therefore avoiding working with model catalysts in some instances. It is important to note that for a given metal catalytic system, the active sites responsible for activity might result from the contribution of a unique crystal phase or a combination of them and this is key in understanding the potential of anisotropic nanoparticles in catalysis. The pioneering study of Novo and co-workers [284] showed that single Au nanoparticles of different shape can be directly observed during the catalytic oxidation of ascorbic acid. Through the combination of dark-field microscopy and surface plasmon spectroscopy the authors were able to show for the first time electron injection, build up and discharge on the single gold dodecahedron as a direct measure of both oxidation and reduction of ascorbic acid and oxygen, respectively. This study opened up the possibility of the investigations of catalytic reactions on single nanoparticles with a view for later applications in the research of quantum reaction regime and single electron transfer. As another example of crystallographic particle effect, tetrahedral platinum nanoparticles with average diameter of $5 \mathrm{~nm}$ were shown to possess the $\{100\}$ facets as their only active facet [285]. Results from the work of Narayanan and El-Sayed [285,286] showed that as a result of involvement of surface coordination in the rate limiting step of the reaction, there was an exponential increase in the average rate constant of the Pt NPs when the percentage of surface atoms at their corners and edges were increased. Similar facet dependent catalytic activities were demonstrated for other non-gold anisotropic nanoparticles [287-290]. Yoshihara et al. [287] showed higher water-gas shift reactivities for $\mathrm{Cu}(110)$ when compared to both $\mathrm{Cu}(100)$ and polycrystalline Cu. Choudary and co-workers [288] demonstrated that hexagonal nanoplatelet-shaped $\mathrm{MgO}$ with the most (100) planes exposed was more active in benzylation of aromatics than other irregular shapes showing a mixture of planes. Also, (001) and (110) planes of $\mathrm{CeO}_{2}$ nanorods were shown to be more reactive than the most stable (111) plane in the oxidation of CO [289] and silver nanocubes with $\{100\}$ facets displayed significantly higher activity in the oxidation of styrene than truncated triangular nanoplates and near-spherical nanoparticles with $\{111\}$ facets [290].

On the other hand, the synthesis of metal nanocrystals with high energy facets is crucial and has proven to be a challenge in catalytic applications since it is believed that these facets promote crystals with high catalytic activity [62]. Amongst low-index faceted nanocrystals, the $\{110\}$ facets found in dodecahedral nanocrystals possess the highest energy. This is as a result of the occurrence of sharp corners and edges in NPs of such morphology. Examples of this can be found in the use of gold nanopyramids, gold nanotubes and polygonal gold in catalysis [285,291,292].

In Table 1-3 we have systematically categorised catalytic studies performed on free colloidal, core@shell and supported anisotropic gold nanoparticles, respectively. These will be discussed in the following chapters. The majority of the published catalytic research work as displayed in Table 1 corresponds to the use of the metal as a nanoparticle (with and without a protecting shell) rather than the more industrially relevant supported heterogeneous catalysts. We agree with the common justification given by many authors based on that the unsupported anisotropic nanoparticles are more suitable to study intrinsic catalytic activity without introducing the effect of the support [293-295]. However, we foresee this as a limitation towards the application of these materials which eventually needs to be overcome.

\subsection{Thermocatalytic reactions}

Somewhat surprisingly, the oxidation of CO [336-338] and

Table 2

Summary of the catalytic studies performed on anisotropic gold nanoparticles coated with oxide shell (generally core@shell).

\begin{tabular}{|c|c|c|c|c|}
\hline No. & Metal(s) and nanoshape & Core@shell structure & Reaction system & Ref. \\
\hline 38 & Au dendrites & Au@polypyrrole & Degradation of methylene blue by $\mathrm{NaBH}_{4}$ & {$[164]$} \\
\hline 39 & Au rods & $\mathrm{Au} @ \mathrm{TiO}_{2}$ & Reduction of 4-NP by $\mathrm{NaBH}_{4}$ & [249] \\
\hline 40 & Au rods & $\mathrm{Au} @ \mathrm{SiO}_{2}$ & Hydrogenation of cinnamaldehyde with $\mathrm{H}_{2}$ & [255] \\
\hline 41 & AuPt alloy icosahedra & AuPt@SiO 2 (hollow) & Ullmann homocoupling of iodobenzene & [318] \\
\hline 42 & $\mathrm{Au} / \mathrm{TiO}_{2}$ dumbbells & Au with $\mathrm{TiO}_{2}$ on tips & Photocatalytic water splitting and degradation of methylene blue & [319] \\
\hline 43 & Au cages & $\mathrm{Au} @ \mathrm{TiO}_{2}$ & Photocatalytic decomposition of acetaldehyde & {$[184]$} \\
\hline 44 & Au cages & Au@C-TiO 2 hybrid (Janus type) & Photocatalytic oxidation of propan-2-ol & {$[186]$} \\
\hline 45 & Au rods & $\mathrm{Au} @ \mathrm{TiO}_{2}$ & $\begin{array}{l}\text { Photocatalytic generation of reactive oxygen species (e.g. } \mathrm{O}, \mathrm{OH} \\
\text { radicals) and oxidation of } \mathrm{ABDA}^{*}\end{array}$ & $H[253]$ \\
\hline 46 & Au rods & AuNR@mesoporous $\mathrm{TiO}_{2}$ & Photocatalytic oxidation of ABDA* & [320] \\
\hline 47 & $\mathrm{Au}$ and $\mathrm{AuAg}$ rods & $\mathrm{Au}(\mathrm{Ag}) @ \mathrm{TiO}_{2}$ & Photocatalytic degradation of methylene blue & [251] \\
\hline 48 & Au@Ag rods & Au@Ag@TiO 2 tri-layered & Photocatalytic oxidation of propan-2-ol & [252] \\
\hline 49 & Au rods & $\mathrm{AuNR@CeO} 2$ & Photocatalytic oxidation of benzyl alcohol & [321] \\
\hline 50 & Au rods & $\mathrm{AuNR} @ \mathrm{TiO}_{2}$ & Photocatalytic oxidation of benzyl alcohol & [322] \\
\hline
\end{tabular}

Works are sorted on the basis of the activation type (thermo- or photo-), reaction system (reduction, oxidation, C-C forming and other) and nanoparticles shape (rods, polyhedra, star-like, tubes and networks, wires). Thermo and photo are abbreviations for thermocatalytic and photocatalytic, respectively.

*9,10-anthracenediyl-bis(methylene)dimalonic acid. 
Table 3

Summary of the catalytic studies performed on supported anisotropic gold nanoparticles.

\begin{tabular}{|c|c|c|c|c|}
\hline No. & Metal(s) and nanoshape & Metal/support & Reaction system & Ref. \\
\hline 51 & $\begin{array}{l}\text { biicosahedral } A_{25} \text { rods, icosahedral } \\
\mathrm{Au}_{25} \text { nanospheres }\end{array}$ & $\mathrm{Au} / \mathrm{CeO}_{2}$ & $\begin{array}{l}\text { Hydrogenation of alpha,beta-unsaturated ben- } \\
\text { zalacetone with } \mathrm{H}_{2}\end{array}$ & [264] \\
\hline 52 & Au rods, AuPt dumbbells & $\begin{array}{l}\mathrm{Au}(\mathrm{Pt}) / \text { poly}(\mathrm{N} \text {-isopropylacrylamide }) \\
\text { microgel spheres }\end{array}$ & Reduction of $4-\mathrm{NP}$ by $\mathrm{NaBH}_{4}$ & {$[323]$} \\
\hline 53 & PtAu dendrimer-like particles & PtAu/reduced graphene oxide & Reduction of 4-NP by $\mathrm{NaBH}_{4}$ & [163] \\
\hline 54 & Au tubes & $\mathrm{Au}$ /anodic aluminium oxide membrane & Reduction of $4-\mathrm{NP}$ by $\mathrm{NaBH}_{4}$ & [324] \\
\hline 55 & $\begin{array}{l}\text { Au@Pd triangular plate, icosahedra, } \\
\text { decahedra }\end{array}$ & $\begin{array}{l}\text { single particle } \mathrm{Au} /<100>\text { Si wafer } \\
\text { (oxide-coated p-type) }\end{array}$ & Adsorption/desorption of $\mathrm{H}_{2}$ & [325] \\
\hline 56 & Au rods & $\mathrm{AuNR} / \mathrm{CeO}_{2}$ & $\begin{array}{l}\text { Sonogashira cross-coupling of phenylacetylene and } \\
\text { 4-iodoanisole }\end{array}$ & {$[265]$} \\
\hline 57 & $\mathrm{Au}_{38}$ cubooctahedral shape and $\mathrm{Au}_{13}$ & single $\mathrm{Au}$ particle $/ \mathrm{TiO}_{2}$ & Theoretical/DFT/activation of molecular oxygen & [326] \\
\hline 58 & Au rice (rod-like) & $\mathrm{Au} / \mathrm{ZnO}$ nanowires & Oxidation of $\mathrm{CO}$ & [263] \\
\hline 59 & Au tubes & $\mathrm{Au} /$ polycarbonate membrane & Oxidation of $\mathrm{CO}$ & [191] \\
\hline 60 & Au@Ag cubes and pyramids & Au@Ag@SiO $2 / \mathrm{TiO}_{2}$ P25/glass anode & Photocatalytic water splitting & [183] \\
\hline 61 & Au rods & $\mathrm{Au} / \mathrm{TiO}_{2}$ nanowire arrays & Photo- and electrocatalytic water oxidation & [260] \\
\hline 62 & Au@Ag rods & Au@AgNR/Pt/n-Si/Ag photodiode & Photocatalytic degradation of nitrobenzene & [327] \\
\hline 64 & Au stars & $\mathrm{Au} / \mathrm{GCE}$ & Electrocatalytic reduction of hydrogen peroxide & [149] \\
\hline 65 & Au dendrites & $\mathrm{Au} /$ indium tin oxide electrode & Electrocatalytic reduction of oxygen & {$[174]$} \\
\hline 66 & Au prisms and flowers (periwinkles) & $\begin{array}{l}\mathrm{Au} / \text { thiol- functionalised silicate 3D } \\
\text { network self-assembled on Au electrode }\end{array}$ & $\begin{array}{l}\text { Electrocatalytic reduction of oxygen in phosphate } \\
\text { buffer and oxidation of } \mathrm{MeOH} \text { with } \mathrm{KOH}\end{array}$ & [328] \\
\hline 67 & Au@Pd core-shell bricks (rod-shaped) & $\mathrm{Au} / \mathrm{GCE}$ & Electrocatalytic oxidation of EtOH with $\mathrm{KOH}$ & [329] \\
\hline 68 & Au porous network & pure Au porous network electrode & Electrocatalytic oxidation of $\mathrm{MeOH}$ with $\mathrm{KOH}$ & [330] \\
\hline 69 & Au dendrites & $\mathrm{Au} / \mathrm{GCE}$ & Electrocatalytic oxidation of $\mathrm{MeOH}$ with $\mathrm{KOH}$ & [172] \\
\hline 70 & Au dendrites & $\mathrm{Au} / \mathrm{GCE}$ & Electrocatalytic oxidation of $\mathrm{MeOH}$ with $\mathrm{KOH}$ & [173] \\
\hline 71 & Au dendrites & $\mathrm{Au} /$ indium tin oxide substrate & Electrocatalytic oxidation of EtOH with $\mathrm{NaOH}$ & [331] \\
\hline 72 & Au dendrites & Au/GCE or polycrystalline Au electrode & Electrocatalytic oxidation of $\mathrm{MeOH}$ with $\mathrm{KOH}$ & [332] \\
\hline 73 & Au dendrites & $\mathrm{Au} / \mathrm{GCE}$ & Electrocatalytic oxidation of EtOH with $\mathrm{NaOH}$ & [333] \\
\hline 74 & Au multipods (star-shaped) & $\mathrm{Au} /$ amine functionalised GCE & oxidation of EtOH with $\mathrm{KOH}$ & [334] \\
\hline 75 & Au stars-like, sea urchin-like particles & $\mathrm{Au} / \mathrm{GCE}$ & Electrocatalytic oxidation of EtOH with $\mathrm{NaOH}$ & [335] \\
\hline 76 & Au flowers & $\begin{array}{l}\mathrm{Au} / \text { thiol functionalised silicate 3D net- } \\
\text { work self-assembled on Au electrode }\end{array}$ & $\begin{array}{l}\text { Electrocatalytic oxidation of } \mathrm{MeOH} \text { and reduction of } \\
\text { oxygen with } \mathrm{KOH}\end{array}$ & [165] \\
\hline 78 & Au belts and combs & $\mathrm{Au} / \mathrm{GCE}$ & Electrocatalytic oxidation of $\mathrm{MeOH}$ with $\mathrm{KOH}$ & [199] \\
\hline 79 & AuPt wires & $\begin{array}{l}\mathrm{AuPt} / \mathrm{IrO}_{x} \text { coated screen printed elec- } \\
\text { trode }\end{array}$ & $\begin{array}{l}\text { Electrocatalytic oxidation of glucose, real-time } \\
\text { non-enzymatic impedancimetric detection of glucose }\end{array}$ & {$[195]$} \\
\hline
\end{tabular}

4-nitrophenol reduction [339] are the most common thermocatalytic probe reactions utilised to evaluate the activity of anisotropic gold nanoparticles despite the fact that, for conventional spherical supported gold liquid phase selective oxidations are the most predominantly studied [16,31-33]. Recently, Garcia et al. [20] published an excellent review on "Catalysis by Supported Gold Nanoparticles: Beyond Aerobic Oxidative Processes", which further emphasises the pre-eminence that oxidative processes have taken in gold nanoparticle catalytic studies.

\subsubsection{Oxidation reactions}

Ever since the pioneering studies of Haruta on the low temperature oxidation of $\mathrm{CO}$, this reaction has fascinated the scientific community $[7,243]$. Despite the ongoing discrepancies regarding the precise mechanism of this reaction on the gold nanoparticle and the effect of the support, it is widely accepted that there is a preferential adsorption of CO molecules at the surface edges and steps of non-spherical AuNPs as opposed to the facets [340,341]. Kuwauchi et al. [342] recently showed evidence by using environmental transmission electron microscopy at operando conditions that the active sites for CO oxidation were the perimeter interfaces surrounding AuNPs (Fig. 21) such as edges parallel to the $<110>$ directions. These perimeter interfaces have been suggested as a possible active catalytic sites not long ago by several authors [343-348]. It has been shown that side facets of gold nanorods are either $\{110\}$ or $\{100\}$ depending on the shape of their cross-section $[55,87,107]$.

It was Dumesic and collaborators in 2004 who demonstrated that anisotropic gold nanoparticles in the form of gold supported nanotubes showed high efficiency when used as a catalyst for CO oxidation at room temperature [191,196]. Their deposition within the pores of polycarbonate membranes resulted in higher catalytic efficiency when compared with supported spherical AuNPs [191] and demonstrated the promoting effect of $\mathrm{H}_{2} \mathrm{O}$ in this reaction. An et al. [196] reported computational study on the use of single-walled helical gold nanotubes as catalysts for $\mathrm{CO}$ oxidation at room temperature. The high catalytic activity of the $\mathrm{Au}(5,3)$ nanotubes (where notation in 


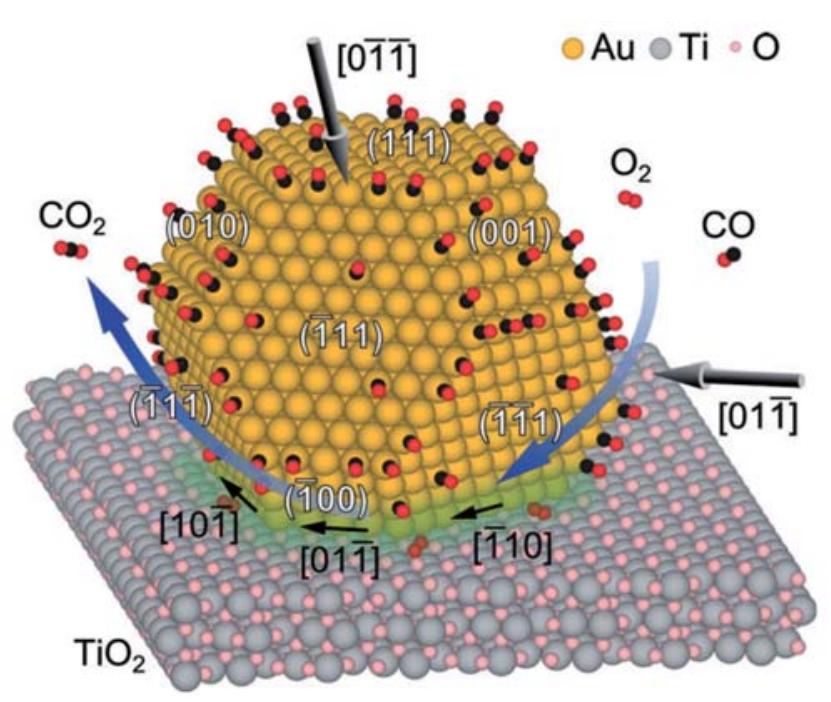

Fig. 21. View of the supported gold nanoparticle on $\mathrm{TiO}_{2}$. Green colour represents possible catalytic active sites [342]. Reproduced with permission from Wiley-VCH Verlag GmbH \& Co. KGaA, Weinheim, Copyright 2012 .

bracket follows the chiral vector notation for carbon nanotubes $\mathrm{C}(\mathrm{n}, \mathrm{m})$ ) may be attributed to the under-coordinated Au sites present in the helical geometry. On the other hand, the microscopic level analysis of the nanotube showed that this high catalytic activity may be due to electronic resonance between the $\mathrm{d}$ state of the $\mathrm{Au}$ atom at the reaction site and the antibonding $2 \mathrm{p}^{*}$ state of $\mathrm{CO}$ and $\mathrm{O}_{2}$ and the synergistic partial charge transfer [196]. Recently a CO oxidation study of PVP-capped Au nanorice supported on $\mathrm{ZnO}$ nanowires compared the activity of high-index $\{611\}$ faceted truncated nanorice crystals with \{111\} spherical particles [263]. It was demonstrated that while anisotropic gold was able to reach $100 \%$ CO conversion at $280^{\circ} \mathrm{C}$, spherical nanoparticles (either capped with PVP or citrate) only at $340{ }^{\circ} \mathrm{C}$. They attributed this improvement in catalytic activity to the exposure of high-energy facets in the nanorice catalyst. In view of this encouraging reports, it is surprising to realise the little development of methods to effectively utilise supported anisotropic gold nanoparticles for this reaction.

The utilisation of anisotropic gold catalysts was demonstrated in the aerobic oxidation of D-hexoses (glucose, fructose, mannose) over colloidal polygonal gold nanoparticles of different sizes (100 to $158 \mathrm{~nm}$ ) [292]. These were hexagonally-shaped with fcc structure and bound by $\{111\}$ facets. Although authors were not able to determine the exact shape, the data suggest either plate-like structure for bigger crystals and possibility of partial decahedral shape for smaller ones, however the presence of bigger triangular plates suggests plate-like structures. In all cases the polygonal nanoparticles were significantly more active than their spherical counterpart although no explanation for the observed trend was given.

In 2010, a landmark pioneering study by Wittstock et al. [312] finally demonstrated the potential of nanoporous gold in catalysis and reported $100 \%$ selectivity to methyl formate at $10 \%$ conversion of methanol during oxidative coupling of methanol at room temperature and 1 bar pressure. Authors had shown that catalytic characteristics were similar to $\mathrm{Au}$ single crystals and that residual silver regulated the availability of reactive oxygen. Overall TOFs of $0.26 \mathrm{~s}^{-1}$ were achieved although it was estimated that these could be two to five times higher.

Regarding the catalytic influence of perimeter interfaces between nanoparticle and support, many studies confirm shape-dependent catalytic activity for a range of reactions [238,265,291,294,301,314,318]. However, each catalytic system and the interaction of each nanoparticle is different (e.g. colloidal vs. supported vs. core@shell structure) which means each case has to be considered separately.

\subsubsection{Reduction reactions}

Despite the fact that a couple of hundreds of scientific publications are dedicated to gold nanoparticles for oxidation catalysis each year whereas only a few to reduction reactions in comparison, it seems almost ironic that the amount of catalytic studies on anisotropic Au is so much more favoured for reduction reactions. This is probably due to the ease of the evaluation of catalytic activity in the reduction of nitro group containing compounds with borohydride by simple analysis of UV-vis absorption spectra. The majority of these studies were performed on anisotropic gold catalysts which appeared as colloidal nanoparticles [161,168,182,205,238,291-294,296-311], but also as core@shell structures [249,255] and as supported systems [163,264,323-325].

The work of Rashid et al. [292] previously mentioned in the oxidation (Section (3.1.1)) also reports that their colloidal hexagonal nanoparticles were more active than spherical nanoparticles in the reduction of nitrophenols by sodium borohydride to corresponding amines by two orders of magnitude. However, their hexagonal nanoparticles deactivated within 4-7 consecutive runs with steadily decreasing activity. Although the authors did not explain the increase in the catalytic activity, shape-dependent effect spurs to mind.

This work was shortly followed by Khalavka et al. [299] and Kundu et al. [294]. The former synthesized $\mathrm{Au}$ nanorattles, which are gold nanorods within a gold nanorod shell obtained by galvanic replacement which exhibited $50 \%$ increased plasmon sensitivity when compared to bare AuNRs and 6x than spherical NPs. Also, this colloidal catalyst gave $4 \mathrm{x}$ enhanced 4-nitrophenol reduction activity against simple AuNRs. This activity improvement agreed with the same order of the increase of surface area of rattles vs. rods. On the other hand, Kundu et al. [294] observed a decreasing reduction activity for all substituted nitrobenzenes with spherical NPs > prisms > long NRs $>$ short NRs. Such trend appears counterintuitive at first, and control experiments in CTAB revealed much slower reaction rates, but the trend did not change. It was suggested that close packing of the rods and more active facets in prisms were responsible for the trend although no explanation was provided for higher activity of the spheres and how longer NRs would be more active than the short rods when a spherical morphology is preferred. Quite the opposite was observed by Li et al. [293] who reported the hydrogenation of 4-nitrobenzaldehyde to 4-nitrobenzyl alcohol using unsup- 
ported Au nanorods. When compared with spherical Au NPs, the unsupported Au nanorods showed higher activity with the achievement of $>99 \%$ conversion and $100 \%$ selectivity after $8 \mathrm{~h}$ reaction at $80{ }^{\circ} \mathrm{C}$ as compared to $53 \%$ conversion and $100 \%$ selectivity of $\mathrm{Au} /$ citrate spherical nanoparticles. Also, samples of nanorods were shown to be recyclable with stable activity for 5 reaction cycles in comparison with spherical nanoparticles which agglomerated after first run. Although authors had shown different aspect ratio of three samples of nanorods, the aspect ratio effect on their catalytic activity was not shown as they all exhibited the same activity and selectivity [293].

In order to adequately investigate the facet-dependent catalytic activity of the gold nanocrystals, Chiu et al. [238] used the seed-mediated growth approach to successfully synthesize octahedral, cubic and rhombic dodecahedral gold nanoparticles exhibiting exclusively $\{100\},\{111\}$ and $\{110\}$ facets with excellent size and shape control, respectively. They subsequently used colloidal solutions of these anisotropic gold nanoparticles as catalysts in $\mathrm{NaBH}_{4}$ reduction of $p$-nitroaniline to $p$-phenylenediamine at different temperatures. By using the samples of nanocrystal solutions containing particles with the same total surface area, they found that the best catalytic activity was from the rhombic dodecahedra at all temperatures examined $\left(25-40^{\circ} \mathrm{C}\right)$. The rhombic dodecahedra also exhibited the lowest activation energy and DFT calculations supported their highest activity showing the highest binding energy of $p$-nitroaniline on $\mathrm{Au}(110)$ plane as compared to (100) and (111) planes of octahedra and cubes, respectively. However, binding energies for octahedra and cubes were close and while octahedral particles were less active in the $25-36{ }^{\circ} \mathrm{C}$ range, they became slighty more active at $40{ }^{\circ} \mathrm{C}$. The reason for this remains unclear. Overall, the catalytic activity for the reduction reaction followed the order of $(110)>(100)>(111)$ for the three facets (rhombic dodecahedra, cubes, octahedral, respectively).

Similarly, Li and co-workers [291] synthesized different sizes of AuAg decahedra $(\{111\}$ facets and small area $\{100\}$ facets on crystal edges due to the imperfect crystallisation), bipyramids $(\{11 \mathrm{n}\}$ with $\mathrm{n}$ of e.g. 7 [107] which are high-index facets and penta-twinned rods $(\{111\}$ facets at tips and side
$\{100\}$ facets) and compared their catalytic performances in the reduction of 4-nitrophenol by $\mathrm{NaBH}_{4}$ (Fig. 22). They found that smaller decahedra were more active than bigger ones (Fig. 22(a)) and suggested that this could be a combined effect of the amount of edge atoms and surface area when the total mass of $\mathrm{Au}$ NPs is kept constant. Moreover, when bipyramids and rods were compared, it was shown that high-index facets containing bipyramids converted $p$-nitrophenol more effectively than truncated bipyramids and rod-like nanocrystals (Fig. 22(b)) in which the amount of high-index facets decreased in favour of the low-index ones. On top of that, relatively big bipyramids (average length of $144 \mathrm{~nm}$; sample 1 in Fig. 22(b)) showed even higher activity when compared to the smallest decahedra (edge size of $21 \mathrm{~nm}$; Fig. 22(a)).

Zarick and co-workers [302] made an effort to discern the active facets in the reduction of 4-nitrophenol by $\mathrm{NaBH}_{4}$ over colloidal CTAC-capped Au@Ag nanocubes and nanopyramids mixture synthesized at $35{ }^{\circ} \mathrm{C}(\{100\}$ facets for cubes, $\{111\}$ for pyramids and lower energy $\{110\}$ at rounded edges for both) and $65^{\circ} \mathrm{C}(\{100\}$ for cubes, $\{111\}$ for pyramids) and compared them with commercial citrate-capped Ag nanospheres. Higher activity of the cubes/pyramids mixture in comparison with $\mathrm{Ag}$ spheres was attributed to the electronic effect of $\mathrm{Au}-\mathrm{Ag}$ interaction, while shorter induction period of Ag spheres to that of Au@Ag NPs was suggested to be due to the ligand which presents a diffusion barrier for 4-nitrophenol (smaller citrate vs. bulkier CTAC, respectively). Higher apparent rate of the reaction of Au@Ag NPs synthesized at $35{ }^{\circ} \mathrm{C}$ compared to $65{ }^{\circ} \mathrm{C}$ could be due to the higher Au:Ag ratio in $35{ }^{\circ} \mathrm{C}$ sample. The Au@Ag sample prepared at $35^{\circ} \mathrm{C}$ exhibited also longer induction period than the sample prepared at $65{ }^{\circ} \mathrm{C}$ and this was attributed to the rounded edges of the former which contained lower energy $\{110\}$ facets.

To bring more light to the shape-dependent catalytic activity on anisotropic colloidal nanoparticles, Zhang and co-workers [301] made a comparison of $\mathrm{Au}$ elongated tetrahexahedral (ETHH), concave cubic (CC), and trisoctahedral (TOH) structures against quasi-spherical nanoparticles (QS). It was shown that elongated tetrahexahedral, concave cubic and trisoctahedral nanoparticles expose mainly $\{730\},\{520\}$ and $\{221\}$ facets,
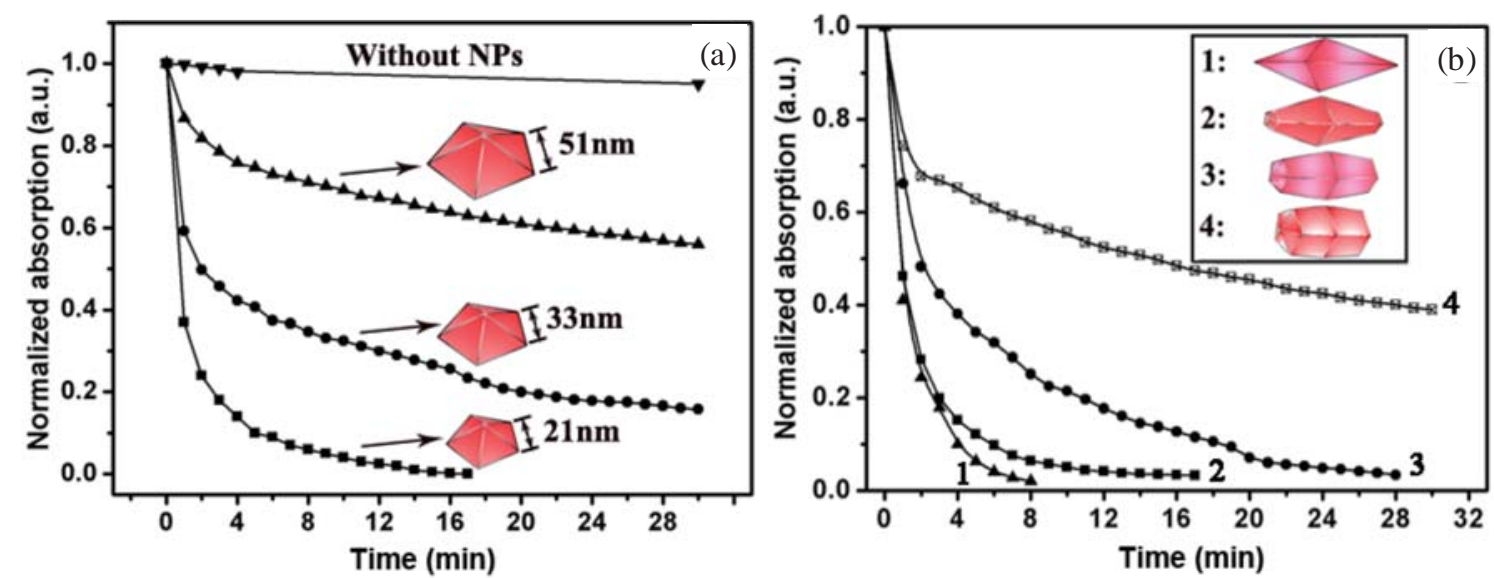

Fig. 22. Progress of the reduction of 4-nitrophenol determined from the normalized UV-vis absorption spectra of $p$-nitrophenol as a function of time over various sized Au decahedra (a) and bipyramids and rods (b) as catalysts [291]. Reproduced with permission from the Royal Society of Chemistry Copyright 2013. 
respectively, while quasi-spherical nanoparticles expose $\{111\}+\{100\}$ facets. The catalytic rates for the reduction of 4-nitrophenol decrease from of high to low index planes (730) $>(520)>(221)>(111)+(110)$ as expected, and in agreement with a decrease in the number of coordinatively unsaturated surface atoms.

Among studies performed with supported anisotropic catalysts, the reduction of 4-nitrophenol (4-NP) to 4-aminophenol (4-AP) was reported by Yu and co-workers [324] using gold nanotubes supported on porous anodic aluminium oxide. They found that the smaller gold nanotubes (prepared at $\mathrm{pH}$ 8) reduced all of the reactant nitrophenol in $<15$ minutes while larger NTs (prepared at $\mathrm{pH}>9.5$ ) took $>40 \mathrm{~min}$. Using SEM, they confirmed that the characteristic nanoclustered morphology of the gold nanotubes formed inside the anodic aluminium oxide pores was as a result of nucleation process during the gold deposition, highlighting the importance of developing suitable procedures to efficiently support anisotropic nanoparticles. This correlation between the catalytic activity and size of the gold nanoclusters makes it possible to control and improve the catalytic properties of gold nanotube membranes.

Very importantly, Tang et al. [325] studied $\mathrm{H}_{2}$ adsorption and desorption from $\mathrm{Au} @ \mathrm{Pd} / \mathrm{SiO}_{x} / \mathrm{Si}$ at single-particle level and highlighted the importance of carrying out investigations of single particles as multiparticle studies of non-uniform particles of different morphologies can mask their mixed response. Two other interesting approaches to supporting gold nanoparticles were shown by Lu et al. [323] and Ye et al. [163]. Firstly, Au nanorods were grown in-situ onto microgel particles by first preforming seeds on these polymeric nanoparticles and then growing the seeds into rods. Also, selective deposition of Pt at the tips to create dumbbell structures was demonstrated. This bimetallic structures were more active in the reduction of nitrophenol than bare Au NRs which was unsurprisingly attributed to the bimetallic effect [323]. Similar effects will be also shown in the photocatalytic section [349]. Secondly, PtAu alloyed dendrimers were supported on reduced graphene oxide via polydopamine linkages [163]. PtAu/graphene oxide 3:1 and 1:1 alloys showed increased performance over all other tested systems (supported Pt or Au alone; commercial Pt/C) due to the increased surface area and electronic effects, both between metals and due to the metal-support interaction. Moreover, supported PtAu catalyst had shown no deterioration of $100 \%$ conversion over 6 consecutive runs and demonstrated visible clearing of the water from nitrophenol in $8 \mathrm{~s}$ to colourless. We will note here that also non-anisotropic AuPt bimetallic or even trimetallic AuPdPt alloyed nanoparticles prepared via colloidal methods have recently been attracting a lot of interest although typically in oxidation reaction or $\mathrm{H}_{2} \mathrm{O}_{2}$ synthesis [350-352].

Another anisotropic AuNPs that have attracted increasing interest due to their exceptional field enhancement for SERS are branched nanostructures [161,168,308], such as nanostars (AuNSs) [306,307]. These anisotropic gold nanoparticles possess several sharp tips on their surface and this has been known to promote their catalytic activity [195,353]. To examine the catalytic performance of AuNSs in reduction reactions,
Cui et al. [307] synthesized AuNSs using a one-step facile method and used them as catalysts for the reduction of aromatic nitro compounds, namely 4-nitrophenol (4-NP), 4-nitroaniline (4-NA), and 4-nitrothiophenol (4-NTP). They also investigated the adsorption behaviour of the molecules on gold surfaces using SERS, with a view of correlating the catalytic activity of the gold nanoparticles with their molecular orientation. Their results showed that the AuNSs had high catalytic activity towards the reduction of 4-NA and 4-NP. They attributed the high catalytic activity to the use of a weakly binding agent in the synthesis and the large defect to volume ratio of the NPs [307]. In the case of 4-NTP an efficient reduction reaction was not observed. This result was in contrast to the reduction abilities of small AuNPs for 4-NTP molecules [354]. To justify their results, they associated the catalytic behaviour to the orientation of the molecules when they are adsorbed on the gold surface. Electron transfer between the gold atoms and the nitro group takes place when there is a direct contact between the nitro group and the gold surface which leads to the reduction reaction. This explains the rapid reduction of the 4-NP and 4-NA molecules by borohydride when absorbed onto the gold surface.

In contrast to the above synthesis method, Ndokoye et al. [150] synthesised uniform sharp pointed AuNSs through the use of BDAC and CTAB at low BDAC/CTAB ratios. The catalytic activity of the synthesised AuNSs in the reduction of 4-nitrophenol to 4-aminophenol was shown to be high and this can be linked to the corners, stepped surfaces and high electron density at their tips [150].

Gold nanoparticles often lose their catalytic activity as a result of sintering when dispersed on a support material [355]. To address this problem Arnal et al. [356] developed highly stable gold catalysts by enclosing the gold particles inside a thin shell of zirconia. The resulting catalysts showed high temperature stability. In order to ascertain the thermal stability and catalytic activity of gold nanorods when enclosed within a mesoporous silica shell, van de Glind et al. [255] prepared AuNR coated with a MCM-41-like mesoporous silica layer and compared their thermal stability with uncoated AuNRs by heating in an oven up to $500{ }^{\circ} \mathrm{C}$. Their results showed the stabilizing ability of the mesoporous silica layer for anisotropic AuNRs while the uncoated AuNRs sintered at temperatures exceeding $500{ }^{\circ} \mathrm{C}$. When used as catalyst in selective hydrogenation of cinnamaldehyde, the coated AuNRs maintained their stability even after consecutive catalytic reactions, as opposed to the uncoated rods which sintered even at low temperatures. They also showed that despite the relative low turnover frequency of the anisotropic nanoparticles for this reaction their improved stability remains an advantageous property [255].

\subsubsection{Other reactions}

Other interesting reactions carried out with various gold shapes have appeared in the literature in the last five years, such as [3+2] azide-alkyne cycloaddition [314], Ullmann homocoupling of iodobenzene [318], hydrogen generation from hydrolysis of $\mathrm{NH}_{3} \mathrm{BH}_{3}$ [313] or Sonogashira cross-coupling of 
phenylacetylene and 4-iodoanisole [265].

Gold nanocubes, octahedra, and rhombic dodecahedra colloids were compared in [3+2] azide-alkyne cycloaddition for formation of triazoles [314]. It was shown that rhombic dodecahedra were $100 \%$ regioselective towards 1,4-triazole whereas cubes and octahedra produced lower yields of mixture of 1,4- and 1,5-triazoles. This was due to the exposure of $\{110\}$ facets with the lowest Au density and largest unsaturation degree for dodecahedra which promoted terminal binding mode of reactants as compared to $\{100\}$ and $\{111\}$ facets exposed in cubes and octahedra, respectively. Also, the smallest-sized dodecahedra were the most active.

Shape-dependent activity was also evidenced in Ullmann homocoupling of iodobenzene over AuPt icosahedra encapsulated in hollow silica shells when compared to spherical $\mathrm{Au}$ enclosed the same way [318]. The increase in yield of biphenyl from $53.6 \%$ to $99.2 \%$ was attributed to the higher exposure of $\{111\}$ facets in icosahedra. However, it is known that spherical gold nanoparticles are mostly covered with (111) planes so the question of Pt contribution when in contact with gold or the effect of sharp edges in icosahedra arises.

Haruta and co-workers [265] synthesized well-defined $\mathrm{AuNR} / \mathrm{CeO}_{2}$ enclosed by $\mathrm{Au}(111)$ and $\mathrm{Au}(100)$ surfaces for the Sonogashira cross-coupling reaction between phenylacetylene and 4-iodoanisole traditionally performed with palladium complexes. Shorter nanorods with higher percentage of $\mathrm{Au}(111)$ surface gave higher selectivity towards the cross-coupling product when compared to longer nanorods. DFT simulations confirmed the roles played by the $\mathrm{Au}(100)$ and $\mathrm{Au}(111)$ surfaces and showed that the coupling reactions, reactant surface diffusion as well as bond dissociation is more favoured on $\mathrm{Au}(111)$ than on $\mathrm{Au}(100)$.

\subsection{Photocatalytic reactions}

The potential application of solar energy to drive chemical reactions under mild conditions is a tantalising prospect for many of us, and the realisation of the potential of photocatalysis can lead us to a scenario where reactions such as water splitting [183,260], the production of fuels and reduction of greenhouse gases and organic pollutants [251,327,357] via photocatalysis [358-361] would be implemented bringing many benefits to society. Chemical inertness, non-toxicity and high activity of $\mathrm{TiO}_{2}$ makes it a promising photocatalyst in such practical applications. However, $\mathrm{TiO}_{2}$ lacks the ability to fully utilize visible light due to its large band gap which is around 3.2 $\mathrm{eV}$. This inability, coupled with the fast recombination of photo-generated electron-hole pairs, limits the photocatalytic efficiency of $\mathrm{TiO}_{2}$ under solar light [362-364]. Since visible light contributes to ca. $50 \%$ of the solar radiation energy, compared to $4 \%$ for UV light, there is a strong focus on developing photocatalytic systems capable of utilizing visible light irradiation for practical applications to meet future energy demands $[30,251,322,365,366]$. Plasmonic nanoparticles such as gold have been used to enhance this photocatalytic efficiency when depositing them onto $\mathrm{TiO}_{2}$ [364]. The improved efficiency has been attributed to the plasmon resonance enhanced local elec- tric field of the incident light, as well as the generation of hot electrons by visible light excitation of localized surface plasmon resonance (SPR) [367]. In addition, the electron storage properties of noble metal nanoparticles promote the separation of charge in semiconductor-metal complex systems [363].

Isotropic noble metal nanoparticles have been widely reported in literature for preparing metal- $\mathrm{TiO}_{2}$ composites [30,261,365,368,369] and until recently [327], only spherical nanoparticles were used to prepare photocatalytic materials within the field of gold catalysis [370,371]. However, these spherical nanoparticles have limited absorption of solar light due to their relatively narrow SPR band. This further highlights the challenge to design and prepare noble metal- $\mathrm{TiO}_{2}$ composites with tunable SPR capable of fully utilizing visible light $[30,251]$. In this regard, anisotropic gold nanoparticles show enhanced and tailored optical properties such as surface plasmon resonance and electric field enhancement $[46,49,78,134,135,141,372]$ which should be beneficial especially for photocatalytically-driven reactions. This is because their surface plasmon resonance band can be tuned from the UV to near-infrared region by careful control of their size and aspect ratio [373,374]. In the next section, we will introduce these optical properties so determinant in photocatalytic activity.

\subsubsection{Optical properties of anisotropic gold nanoparticles}

Noble metal nanoparticles absorb light of diverse wavelength on their surface. This is as a result of resonance between the incident electromagnetic wave and the collective motion of free electrons on the metal surfaces. This phenomenon known as localized surface plasmon resonance effect (LSPR) [375]. An

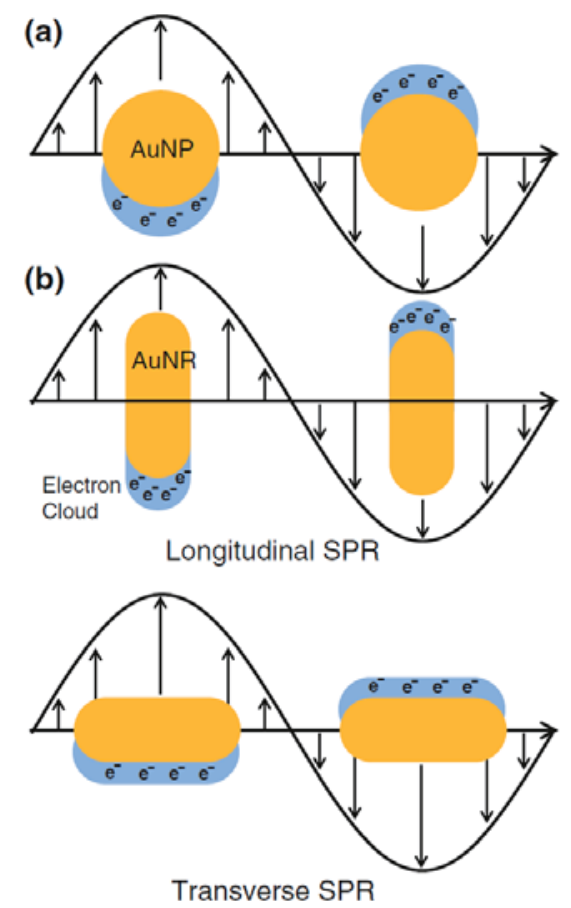

Fig. 23. Illustration of the plasmon oscillation for a metal sphere (a) and rod (b) [66]. The black wave and arrows show the direction of electric field. Reproduced with permission from the Springer International Publishing Switzerland, Copyright 2015. 
illustration of this is shown in Fig. 23. A theoretical explanation of this phenomenon was first given by Mie et al. [5] when he solved Maxwell's equations for radiation field interacting with a spherical metal particle under the appropriate boundary conditions.

This explains the fact that when the colloidal gold nanoparticles are dispersed in water, they display colours varying from blue to red, depending on the size and shape of the nanoparticles as well as the environment or media $[3,76,78,135]$, which makes it very simple to monitor their formation in the solution using UV-vis-NIR spectroscopy or even by visual inspection in some circumstances. Importantly, for anisotropic gold nanoparticles the LSPR effect is enhanced as a result of the combined contribution from the remarkably high electric field intensities at their hollow structure or tips and substantial absorptions in the near IR region [376-378]. For example, the unique optical properties of gold nanorods (AuNRs) depend strongly on their size and aspect ratio (ratio of length to width) as it was confirmed by the following quantitative relationship, in which in aqueous solution the SPR absorption maximum $\left(\lambda_{\max }\right)$ of the nanorods is linearly proportional to their aspect ratio (AR) and dielectric constant of the surrounding medium ( $\left.\varepsilon_{\mathrm{m}}\right)$ [379-382]:

$$
\lambda_{\max }=(53.71 \mathrm{AR}-42.29) \varepsilon_{\mathrm{m}}+495.14
$$

This is also the basis of their tunability (Fig. 24) [52] and its translation to photocatalysis [248].

Nanorods differ from spherical gold nanoparticles by the appearance of two distinct surface plasmon bands in the visible region-the transverse surface plasmon band (TSPR) and the longitudinal surface plasmon band (LSPR). Both of these bands correspond to light absorption and scattering along the long and short axis of the particle, respectively. While TSPR is usually at the same wavelength as that of nanospheres, with no dependence on the aspect ratio, the LSPR of gold nanorods is dependent on their overall size and aspect ratio. Careful control of synthesis conditions has made it possible to design single crystalline gold nanorods with LSPR ranging from the 600 to $1100 \mathrm{~nm}$ [383], covering both the visible and near IR range of the electromagnetic spectrum and this achieved by varying the amount of silver ions used during the synthesis (Fig. 24) [52]. The unique ability to tune the surface plasmon resonance band of gold nanorods and other anisotropic nanoparticles from the UV to near-infrared region continues to attract the interest in these materials for photocatalytic applications [183,184,248,251,259,315,322,327].

Although nanorods have been the most studied gold anisotropic nanocrystals for photocatalysis, most of the other abovementioned shapes exhibit surface plasmon resonance and show absorption in the UV-vis-NIR spectrum $[3,46,47,49,59,73,78,134,135,141,384]$, and particularly stars [59,141,147] (Fig. 25). Interestingly, it was demonstrated that when two bipyramids form a dimer by connecting through the tips, their plasmon red-shifts corresponding to the elongated particle of that length and width [235].

The enhancement of the electric field of the nanoparticle must also be taken in careful consideration $[49,71,135,370,375,385]$. It translates into the surface plasmon band and its intensity and eventually gives the electron density
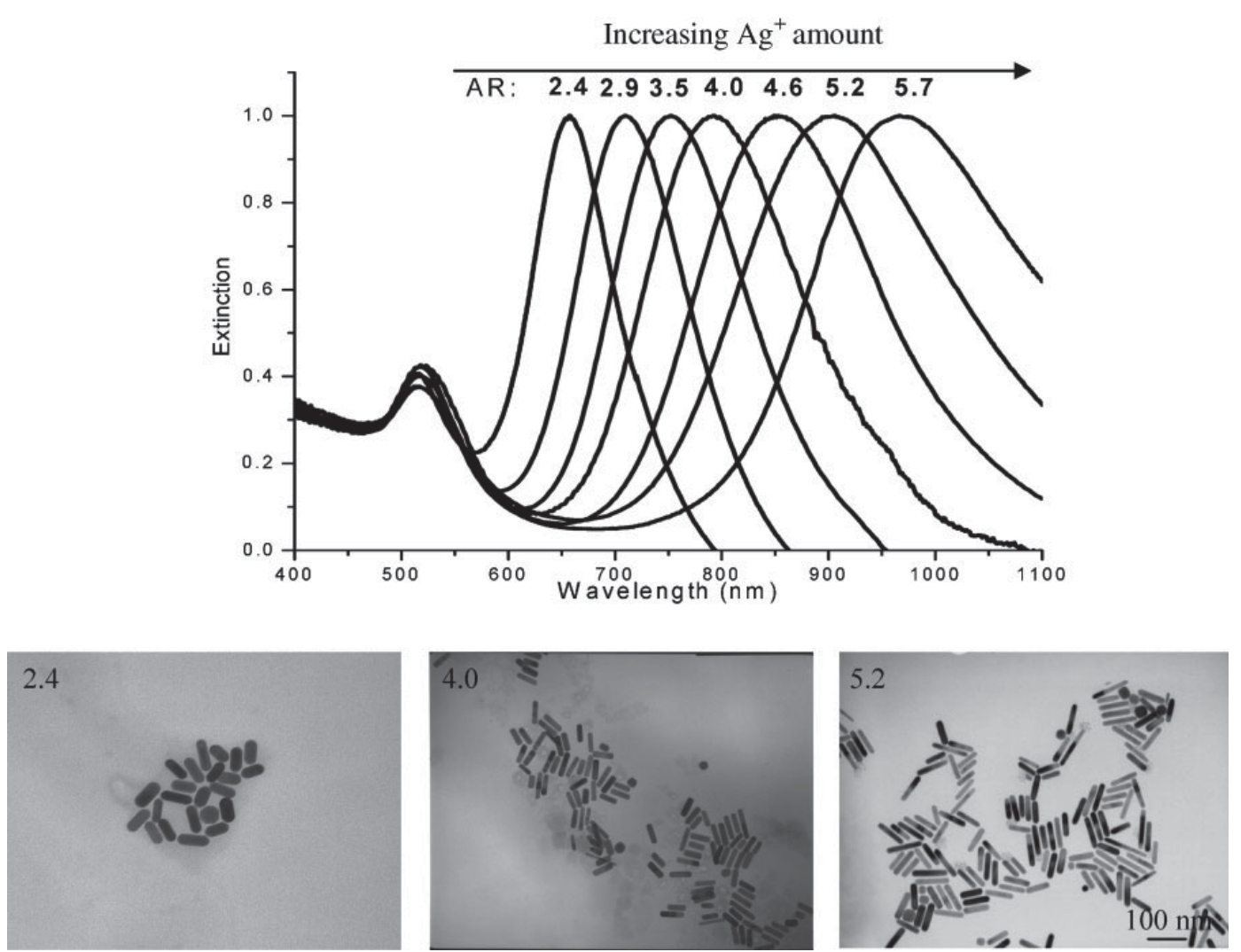

Fig. 24. Red-shifting of the longitudinal surface plasmon resonance band of colloidal gold nanorods across the visible and near-IR region of the electromagnetic spectra [52]. Reproduced with permission from Wiley-VCH Verlag GmbH \& Co. KGaA, Weinheim, Copyright 2009. 


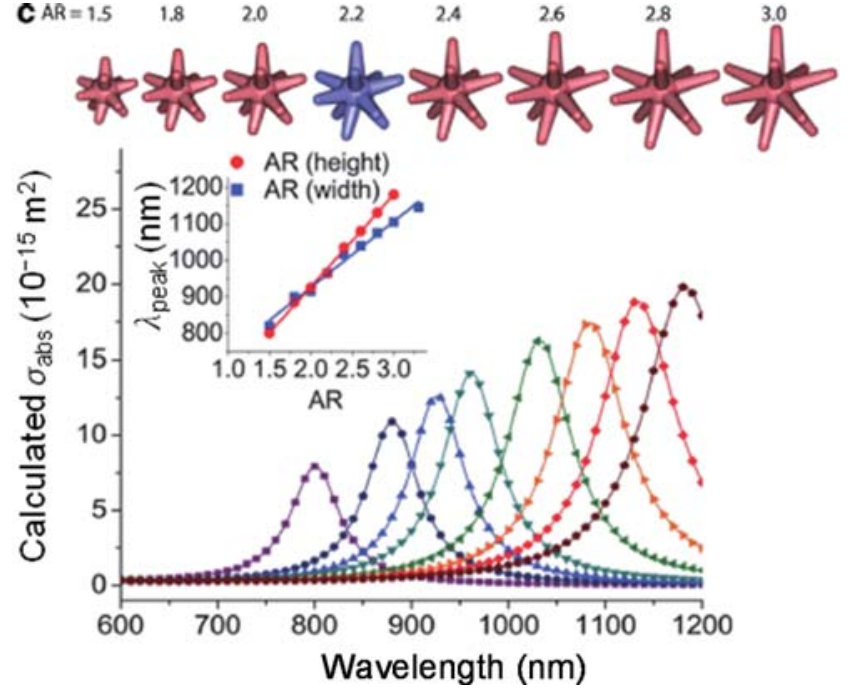

Fig. 25. Calculated UV-vis spectra of nanostars of different aspect ratios (keeping other parameters such as width of the base, diameters of core and tips and number of branches constant) [147]. Reproduced with permission from IOP Publishing Ltd., Copyright 2012.

excited by the incident light. Noguez et al. [135] produced in 2007 a comprehensive and detailed discussion of the SPR and interactions within metal nanoparticles of different shapes, sizes and with different physical environments. Calculation of the enhancement of the electric field of the nanosphere, triangular nanoplate and nanorod presented in Fig. 26 demonstrates that simple elongation of the gold nanoparticle from spherical to rod shape is able to increase the electron density at the tips by an order of magnitude [375,384] (logarithmic scale in Fig. 26). Furthermore, synthesis of the anisotropic nanoparticles can be tailored in this way to use the same or lower amount of gold atoms to produce the particles which will utilise the light in a much more efficient manner. Both of these parameters are eventually sought for in photocatalysis.

\subsubsection{Photocatalytic oxidations}

Catalytic oxidations are the most important class of the reactions performed over supported gold catalysts $[25,28,31,370,371]$. In addition to CO oxidation, they find applications for the production of platform chemicals [185, 252, $321,322]$, degradation of pollutants [251,259,327] or for medicinal use $[253,320]$. Among photooxidation studies on anisotropic gold nanoparticles the rod-shaped catalysts are the most common [185,251-253,259,297,320-322,327], but other shapes such as cubes, triangles, polygons [185], cages
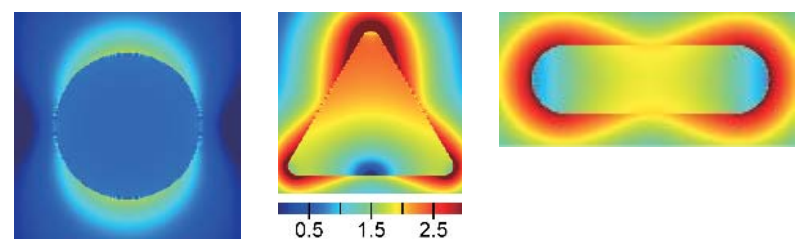

Fig. 26. Contours of the electric field enhancement of nanosphere (left; $50 \mathrm{~nm}$ diameter), triangular nanoplate (middle; edge length of $87 \mathrm{~nm}$ and thickness of $10 \mathrm{~nm}$ ) and nanorod (right, length of $102 \mathrm{~nm}$ and width of $30 \mathrm{~nm}$ ) in logarithmic scale [384]. Reproduced with permission from Wiley-VCH Verlag GmbH \& Co. KGaA, Weinheim, Copyright 2014.
$[184,186]$ or dumbbells [319] were reported as well.

To the best of our knowledge, the first report on photocatalytic use of anisotropic gold nanoparticles is the work of Qu and co-workers [327] who studied Au and Au@Ag core@shell nanorods supported on $\mathrm{Pt} / \mathrm{n}-\mathrm{Si} / \mathrm{Ag}$ nanowire photodiodes using (3-mercaptopropyl)trimethoxysilane as the coupling agent. They found that while pristine gold nanorods showed no catalytic activity in UV-vis photodegradation of nitrobenzene, supported Au@Ag rods were superior to both photodiodes alone and AuNRs/photodiodes. The higher activity of the bimetallic nanorods was attributed to the $d$-band centre of bimetallic nanoparticles which can be adjusted by varying the chemical composition. At the same time, the more active sample among supported Au@AgNRs was the catalyst with higher Ag/Au ratio (2.58 compared to 0.86 ) which produced smaller aspect ratio particles with more apparent edges and exposed planes than those of more regular rod shape. Also, the more active Au@AgNRs exhibited broader SPR in the range 400-600 nm compared to the second Au@Ag sample with plasmon centred at $600 \mathrm{~nm}$. This was followed closely by Kong et al. [259] who studied visible light photodegradation of methyl orange dye catalysed by gold nanorods encapsulated in $\mathrm{Cu}_{2} \mathrm{O}$ octahedra of different sizes. They found that generally the smaller the size of the nanoparticle the faster the degradation of methyl orange, although the size effect alone could not explain the catalytic trend. Even though the authors could not give a final explanation they suggested this could be connected to the balance between the size vs. surface area and size vs. recombination of photo-reduced carriers.

Among other reported studies on rods it was shown that colloidal solutions of $\mathrm{Au}$ nanorods tend to agglomerate under UV light and when exposed to various solvents such as chloroform, dimethylsulphoxide, propan-2-ol, methanol or dimethylformamide when compared to water under catalytic conditions [297]. However, oxidation of salicylic acid in UV was improved over bare $\mathrm{TiO}_{2}$ even when the rods were simply mixed with $\mathrm{TiO}_{2}$ in the reaction mixture which suggests an interaction of the nanorods and titania in the solution. The same trend was noted when Au rods were transformed into multifaceted polygonal spheres, low aspect ratio rods, oval egg shapes, squares, pentagons and nanocapsules of varying sizes after laser exposure [185], all of which showed $20-25 \%$ increase in activity to that of the initial rods. The smaller size and corresponding higher surface area of the formed nanoparticles was found to be responsible for the activity.

Amidst the few photocatalytic studies on supported systems Liu et al. [248] presented a comprehensive research and compared gold nanorods of different aspect ratios (ca. $40 \mathrm{~nm}$ long with varied width corresponding to aspect ratios from 1.8 to 2.3, 2.7, 3.3 and 4.0) supported on $\mathrm{TiO}_{2}$ in the transverse band activating visible range (400-650 $\mathrm{nm}$ ), both longitudinal and transverse band activating visible range (400-820(910) $\mathrm{nm}$ ) and monochromatic light (660 $\mathrm{nm}$ ). A 5-fold increase in propan-2-ol conversion to acetone was shown for the nanorod sample treated with $\mathrm{HClO}_{4}$ to remove the CTAB. An increase in activity was also observed when varying the light source to activating both plasmon bands, however, no dependence was 
found to the nanorods aspect ratio. Also, the comparison of gold nanorods with "spherical" Au nanoparticles produced the same yield of acetone under 400-820 nm irradiation. However, the aforementioned Au nanoparticles were created by a $200{ }^{\circ} \mathrm{C}$ argon heat treatment of the said nanorod sample and the final shape of the nanoparticles was not shown. Nevertheless, this work marked a milestone in the studies of real heterogeneous catalysts with controlled anisotropic gold morphologies in photocatalysis.

On the other hand, most of the photooxidation research on anisotropic gold nanocrystals is based on (gold or bimetallic core)@(metal oxide shell) [184,186,251-253,320-322] (e.g. Fig. 27 (left bottom)). Reports mentioning Au@Ag nanorods agree that silver increases photocatalytic activity owing to electron- and energy-transfer mechanisms [251,252], however there is a limit to the $\mathrm{Ag} / \mathrm{Au}$ ratio which provides the maximum interaction (e.g. 5 [252]). Also, coating the nanoparticles with a layer of metal oxide such as $\mathrm{TiO}_{2}$ [322] or $\mathrm{CeO}_{2}$ [321] can improve the stability and activity of the nanostructures (e.g. 10 nm optimum layer thickness [252]), but care must be taken when the shell thickness is concerned not to decrease the activity at the expense of the outer layer [322].

Worth highlighting is the study of Li and co-workers [322] who demonstrated a better utilisation of the visible light by $\mathrm{Au}$ nanorods encapsulated in the hollow titania shells when compared to spherical nanoparticles. The authors had shown that nanorods expose more of the high-index (100) and (110) planes when compared to low-energy (111) planes and therefore utilise the visible light better in selective benzyl alcohol photooxidation. Also, they found the optimum aspect ratio of 4.2 when compared to 2.4 and 5.4 which confirmed the previous finding and showed that if the aspect ratio is too big, the
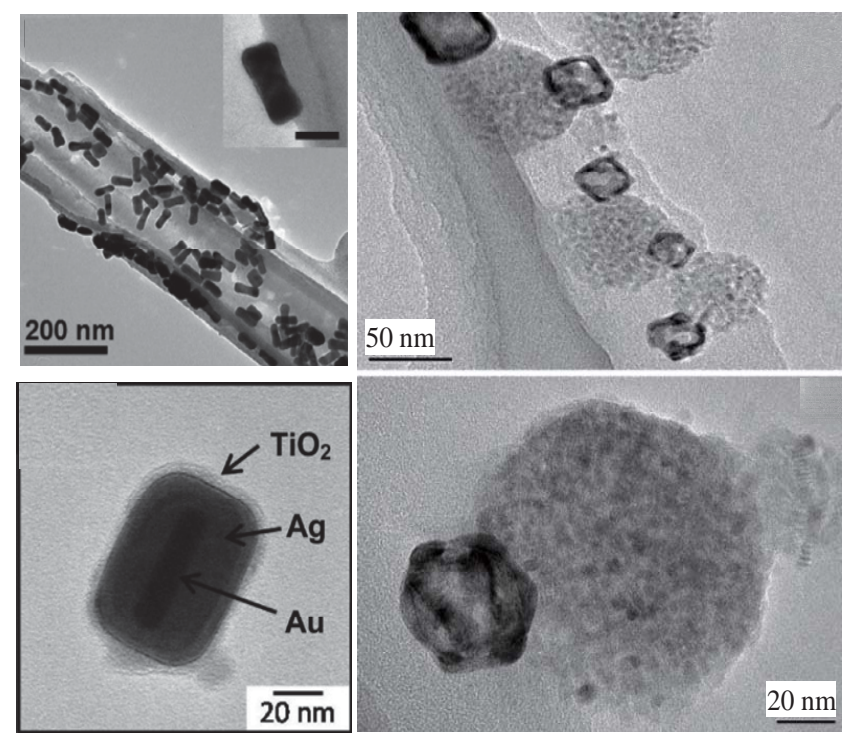

Fig. 27. TEM images of gold nanorods supported on $\mathrm{Pt} / \mathrm{n}-\mathrm{Si} / \mathrm{Ag}$ nanowire photodiodes using (3-mercaptopropyl)trimethoxysilane as the coupling agent (left top) [327]; Au@Ag@TiO multi-core@shell nanorod (left bottom) [252]; gold nanocage supported on $\mathrm{TiO}_{2}$ Janus nanostructures (right) [186]. Reproduced with permission from the American Chemical Society and Wiley-VCH Verlag GmbH \& Co. KGaA, Weinheim, Copyright 2011, 2014 and 2014, respectively. longitudinal plasmon band is too much red-shifted to provide enough chemical energy from the light conversion, again highlighting the potential offered by anisotropic nanoparticles to tune photocatalytic activity.

Finally, anisotropic non-centrosymmetric Janus nanostructures such as gold nanocubes@C-TiO2 composites were able to significantly enhance plasmon-photon coupling improving the visible light-driven oxidation of propan-2-ol by $100 \%$ or more when compared to either symmetrical Au nanocages or spherical nanoparticle@C- $\mathrm{TiO}_{2}$ core@shell structures or the supports alone [186].

In conclusion, it seems that the photocatalytic activity of the anisotropic gold nanoparticles strongly depends on the reaction conditions and catalytic system chosen along with its controlled design and synthesis. However, gold combined with silver, palladium or platinum especially in core@shell structures can significantly improve utilisation of the light and either addition of the suitable metal oxide layer or supporting (e.g. $\mathrm{TiO}_{2}$ or $\mathrm{CeO}_{2}$ ) can both improve the nanoparticles stability and promote the charge-separation thus enhancing the oxidation/reduction activity.

\subsubsection{Other photocatalytic reactions}

This section aims to cover recent advances in photocatalytic hydrogen production over anisotropic gold catalysts, which were undertaken to the best of our knowledge over the past 3 years $[260,319,349]$. One of these reports which is truly photocatalytic is the work of Zheng and co-workers [349] who prepared gold nanorods coated with palladium either only at the tips or as proper Au@Pd core@shell and compared them in colloidal form in visible light-driven hydrogen generation from formic acid dehydrogenation. They demonstrated that Au@Pd tips nanorods were $>50 \%$ more active than their full Au@Pd core@shell counterparts and that the activity increased with increasing temperature up to $40{ }^{\circ} \mathrm{C}$. However, the emphasis was placed on the fact that the catalysts were photocatalytically active at $5{ }^{\circ} \mathrm{C}$ and were comparable to the thermally-catalysed reaction rates at $40{ }^{\circ} \mathrm{C}$ which demonstrates the future prospect of these materials. Moreover, supported by finite-difference-time-domain calculations it was suggested that the increase in the activity was due to the selective deposition of the palladium only at the field-enhanced sites of the Au nanorods (i.e. their tips).

$\mathrm{H}_{2}$ generation from photo-electro-catalysed water splitting was also studied [260,319]. Initially, Pu et al. [260] evidenced enhancement of the water splitting activity for both spherical gold nanoparticles and nanorods supported on $\mathrm{TiO}_{2}$ nanowires. While the enhancement was shown in both UV and visible range for spherical nanoparticles, hydrogen generation was improved only in the visible range for Au nanorods with maximum boost by light irradiation at $710 \mathrm{~nm}$ which coincides with the maximum of the plasmon band of the rods. Authors proved this to be due to the both effective surface passivation as well as effect of the electric-field enhancement in the case of the spherical nanoparticles and generation of the hot electrons from excitation of the surface plasmon and electric field enhancement. However, by combining both spherical particles 
and rods, increase in the photocatalytic activity in the whole UV-vis range could be achieved.

In comparison, the very recent study of $\mathrm{Wu}$ and co-workers [319] used similar approach to Zheng et al. [349] and coated selectively the tips of the Au nanorods with a layer of titania to create $\mathrm{Au}-\mathrm{TiO}_{2}$ nanodumbbells (Fig. 28).

Owing to the specific structure of the dumbbell as depicted in the Fig. 28 (right bottom) when compared to the full AuNR@TiO2 core@shell, it was shown that the surface area made accessible this way provided enhanced charge separation due to the surface plasmon resonance induced hot electron transfer instead of plasmon-induced resonance energy transfer as proved by the inactivity of the core@shell structure.

\subsection{Electrocatalytic reactions}

One of the other thriving areas for anisotropic nanoparticles is electrocatalysis. This is due to the fact that mainly branched $[149,153,165,172-174,328,330-335]$ and porous [202,330] structures could to some extent utilise the enhanced electric field. While several studies employed colloidal nanoparticles [202,316,317], the majority opted for supporting the nanoparticle on glassy carbon [149,172,173,199,332-335], Au $[153,165,328,330]$, indium tin oxide $[174,331]$ or iridium oxide electrode [195]. Although most of the aforementioned studies investigated alkaline-enhanced electro-oxidation of methanol or ethanol, a few focused on the oxidation of glucose [195,316], nicotinamide adenine dinucleotide [153] or reduction of oxy- gen $[174,328]$ or hydrogen peroxide [149].

The first studies appeared in 2007 [165,328,330]. For example, Zhang and co-workers [330] prepared nanoporous gold slices by de-alloying AuAg material or alternatively coating it with Pt and used the slice instead of standard Au electrode. When the authors compared the nanoporous gold electrode to the classic polycrystalline one, they found enhanced methanol oxidation activity attributable to the porous structure which is able to trap $\mathrm{OH}^{-}$. However, structural stability was not acceptable. After submonolayer Pt coating, not only the catalytic activity but also stability significantly improved, which was ascribed to the charge-transfer induced synergistic effect between gold and platinum.

Other examples are the works of Jena et al. [165,328] who have shown both reduction of oxygen and oxidation of methanol with gold nanoprisms, nanoperiwinkles (nanoflowers-like shape) [328] and nanoflowers [165] immobilised on porous silicate network supported on the polycrystalline Au electrode and compared these to spherical gold nanoparticles. Decreasing order of methanol oxidation activity for studied shapes was found to be nanoperiwinkles > nanoflowers > nanoprisms > nanospheres. It was demonstrated that the difference is not due to the surface area. Authors had shown that periwinkles contained more high-index $\{220\}$ and $\{311\}$ facets than prisms. Even though it's not clear why smaller nanoflowers with relatively more high-index facets were not superior to the nanoperiwinkles, it was proved that anisotropic morphologies offer enhanced electroactivity.
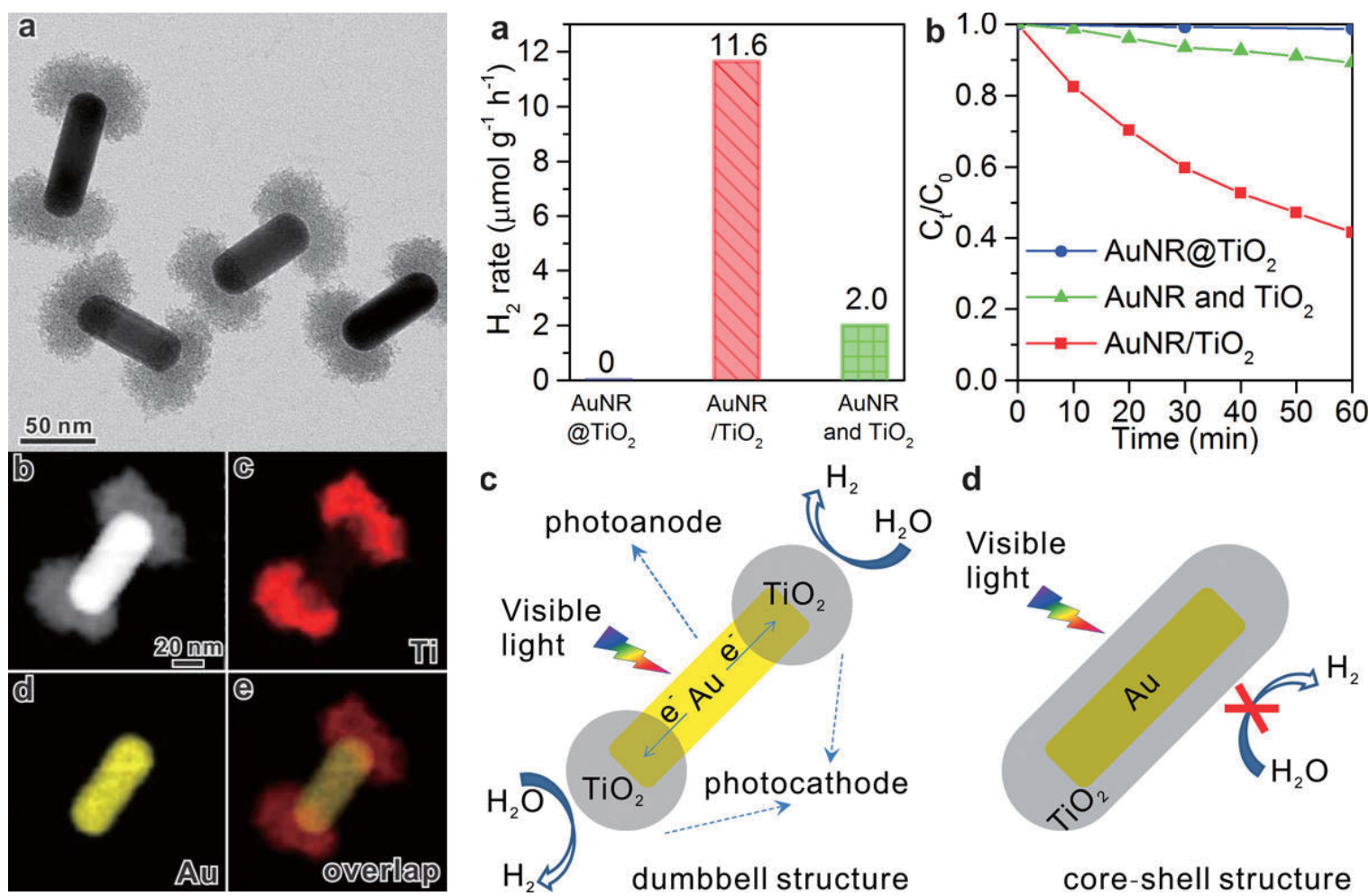

d

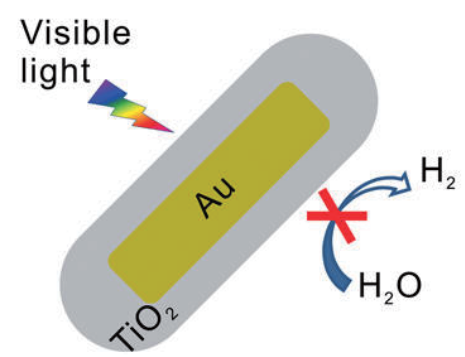

core-shell structure

Fig. 28. Representations of the $\mathrm{Au}^{-\mathrm{TiO}_{2}}$ nanobumbbells and their photocatalytic activity. TEM image of the $\mathrm{Au}^{-\mathrm{TiO}_{2}}$ nanodumbbells (left top); EDX maps of the dumbbell showing $\mathrm{Au}$, Ti and overlap distribution map (left bottom); photocatalytic $\mathrm{H}_{2}$ generation rate for AuNR@TiO $\mathrm{Aur}_{2}$ coreshell, $\mathrm{AuNR} / \mathrm{TiO}_{2}$ dumbbell and $\mathrm{AuNR}$ and $\mathrm{TiO}_{2}$ mixture in the solution (right top); schematic representation of the proposed working mechanism of the two compared AuNR coupled with $\mathrm{TiO}_{2}$ structures (right bottom) [319]. Reproduced with permission from the American Chemical Society, Copyright 2016. 
Many authors investigated electrode-supported various dendritic gold nanostructures [172-174,331-335]. However, most of the time the dendrites were only compared to the polycrystalline metal counterpart, i.e. normal polycrystalline Au or indium tin oxide electrode [172-174,331]. Dendrite-supported electrodes in these cases exhibited enhanced electrocatalytic activities, which was expected as branched nanocrystals show both higher surface area, more high-index facets and strong electric field enhancement when compared to the surface of the normal gold electrode. However, more evolved dendritic shapes [174] were shown to improve the oxygen reduction activity of the previously reported nanoflowers [165]. This could be due to the three-dimensional crystal structure which helps to expose more high-index facets [149,173].

Other gold shapes such as nanobelts, nanocombs [199], porous and solid nanotubes [202] or nanowires [195] were shown to exhibit enhanced electrocatalytic performance. Both single-crystalline nanobelts and nanocombs exposed (110) and (211) planes previously identified as exhibiting higher-energy than (111) plane in spherical nanoparticles and were more active when compared to the normal gold electrode. Also, porous nanotubes performed better than solid ones demonstrating the importance of higher surface area and easier transport of reactants [202]. Moreover, AuPt nanowires deposited on iridium oxide-coated screen-printed electrode demonstrated high electrocatalytic efficiency for non-enzymatic impedancimetric detection of glucose along with good stability and reproducibility [195]. Overall, anisotropic gold nanoparticles generally offered enhanced catalytic performances and tunability as compared with spherical nanoparticles as observed in many instances in photocatalysis and thermocatalysis.

\section{Conclusions and outlook}

Catalysis by gold nanoparticles forms an indispensable part of the catalytic research worldwide and many research groups have dedicated their time and effort to advance the synthetic, physico-chemical or mechanistic aspects of the gold nanoparticles supported on solid materials via traditional impregnation techniques, or more recently, via preforming the gold metal nanoparticles as colloidal solutions prior to immobilisation. As a consequence, catalysts based on gold and its alloys in spherical form are now recognised as highly active and promising catalytic materials. On the other hand, a great opportunity arises in the utilisation of anisotropic gold nanoparticles which potential and application in other fields has been extensively demonstrated. The developments and advances made in the past decade or so made it possible to prepare various gold shapes (rods, tubes, polyhedra, cubes, stars, flowers, wires, platelets, bipyramids, javelins, hollow shapes, etc.) in high yield and selectively. This enabled the studies of specific shapes and the corresponding exposed or preferential crystallographic planes that can display different properties. Although the major application area for anisotropic nanoparticles has so far been in sensing and medicine due to their enhanced plasmon resonance and its tunability, this review highlights a strong evidence emerging for their potential in catalysis. This is now slowly attracting the catalytic community as evidenced by the exciting new developments demonstrated by Dumesic in CO oxidation, or Haruta in carbon forming reactions among many others.

Optical properties of the differently shaped gold nanocrystals (especially those with multiple tips, such as stars) predestine them initially for photocatalytic reactions as the light can be harvested effectively and enhance photochemical transformations. Although many of the anisotropic AuNPs show enhanced resistance to sintering, it might be beneficial to couple them with suitable support material (e.g. $\mathrm{TiO}_{2}, \mathrm{CeO}_{2}$ ). This brings another level of stability and increase the efficiency of the utilisation of the incident light as for example titania and ceria are photocatalysts on their own, albeit with bandgap in the UV region. However, tuning the properties, interaction and exposed planes of both support and anisotropic nanocrystals can provide a bridge to obtain long sought utilisation of visible light in photocatalysis. It was already shown that interaction between AuNPs and support can be achieved not only by forming Au@support core-shell structures but also by the immobilisation of preformed colloidal solution of gold. Nevertheless, the materials produced by the first method are still comparable in size to the original gold nanoparticles and therefore would require similar separation after the catalytic run (e.g. centrifugation). That makes their potential catalytic application limited although either solution to this or a more suitable application might present itself in future. It can be only expected that differently shaped supported metal nanocrystals will attract more attention in the near future which will hopefully bring more answers on the interaction between anisotropic AuNPs, supports and chemicals employed in the chemical transformations used in gold catalysis.

In summary, we have found enough scientific evidence to predict an exponential increase in catalytic applications for anisotropic gold nanoparticles and their alloys with Pt, Ag and other metals as more catalyst scientists become more familiar with the materials and methods that have been generated by scientists in other areas of nanotechnology, such as the work by Murphy, El-Sayed or Liz-Marzan to mention a few. The ability to tune the preferentially exposed crystallographic planes and plasmon properties make them particularly exciting in the development of structure-activity relationships in conventional chemocatalysis and in photocatalysis in particular.

\section{Acknowledgments}

Peter Priecel and Jose Antonio Lopez-Sanchez thank the EPSRC (grant EP/K014773/1) and the UK Department of Business Skills and Innovation (Regional Growth Fund, MicroBioRefinery). Hammed Adekunle Salami thanks the Tertiary Education Trust Fund Nigeria for the academic staff training and development scholarship and University of Abuja, Nigeria for the study fellowship award. Romen Herrera Padilla and Ziyi Zhong thank financial support of the project from ICES (ICES/15-1G4B01) and Drs. Carpenter and Borgna for their kind support of this collaboration with University of Liverpool in the UK. 


\section{Nomenclature}

4-ATP 4-Aminothiophenol

4-NA 4-Nitroaniline

4-NP 4-Nitrophenol

4-NTP 4-Nitrothiophenol

ABDA 9,10-Anthracenediyl-bis(methylene)dimalonic acid

AR Aspect ratio

BDAC Benzyldimethylcetylammonium chloride

CC Concave cubic

CTAB Cetyltrimethylammonium bromide

CTAC Cetyltrimethylammonium chloride

EtOH Ethanol

ETHH Elongated tetrahexahedral

GCE Glassy carbon electrode

IR Infrared

LSPR Longitudinal surface plasmon resonance

$\mathrm{MeOH}$ Methanol

NADH Nicotinamide adenine dinucleotide

NIR Near infrared

NP Nanoparticles

NR Nanorods

NS Nanostars

NT Nanotubes

PVP Poly(vinylpyrrolidone)

QS Quasi-spherical

SDS Sodium dodecyl sulphate

SEM Scanning electron microscopy

SERS Surface-enhanced Raman spectroscopy

SHE Standard hydrogen electrode
SPR Surface plasmon resonance

TEM Transmission electron microscopy

TOH Trisoctahedral

TSPR Transverse surface plasmon resonance

\section{References}

[1] D. B. Harden, J. M. C. Toynbee, Archaeologia (Second Series), 1959, 97, 179-212.

[2] R. H. Brill, The Chemistry of the Lycurgus Cup, in: Proceedings of the VIIth International Congress on Glass, paper 223, I.C.G., Brussels, 1965.

[3] H. Jing, L. Zhang, H. Wang, Geometrically Tunable Optical Properties of Metal Nanoparticles, in: UV-VIS and Photoluminescence Spectroscopy for Nanomaterials Characterization, C. Kumar ed. Springer Berlin Heidelberg, Berlin, Heidelberg, 2013, 1-74.

[4] M. Faraday, Philos. Trans. Royal Soc. London, 1857, 147, 145-181.

[5] G. Mie, Ann. Phys., 1908, 330, 377-445.

[6] G. C. Bond, P. A. Sermon, G. Webb, D. A. Buchanan, P. B. Wells, J. Chem. Soc., Chem. Commun., 1973, (13), 444-445.

[7] M. Haruta, T. Kobayashi, H. Sano, N. Yamada, Chem. Lett., 1987, (2), 405-408.

[8] G. J. Hutchings, J. Catal., 1985, 96, 292-295.

[9] M. Haruta, Catal. Today, 1997, 36, 153-166.

[10] G. C. Bond, Catal. Today, 2002, 72, 5-9.

[11] G. J. Hutchings, Catal. Today, 2002, 72, 11-17.

[12] M. Haruta, Gold Bull., 2004, 37, 27-36.

[13] A. Stephen, K. Hashmi, G. J. Hutchings, Angew. Chem. Int. Ed., 2006, 45, 7896-7936.

[14] S. Eustis, M. A. El-Sayed, Chem. Soc. Rev., 2006, 35, 209-217.

[15] A. S. K. Hashmi, M. Rudolph, Chem. Soc. Rev., 2008, 37, 1766-1775.

[16] A. Corma, H. Garcia, Chem. Soc. Rev., 2008, 37, 2096-2126.

\section{Graphical Abstract}

Chin. J. Catal., 2016, 37: 1619-1650 doi: 10.1016/S1872-2067(16)62475-0

Anisotropic gold nanoparticles: Preparation and applications in catalysis

Peter Priecel, Hammed Adekunle Salami, Romen Herrera Padilla, Ziyi Zhong*, Jose Antonio Lopez-Sanchez*

University of Liverpool, United Kingdom; Agency for Science, Technology and Research (A*STAR), Singapore
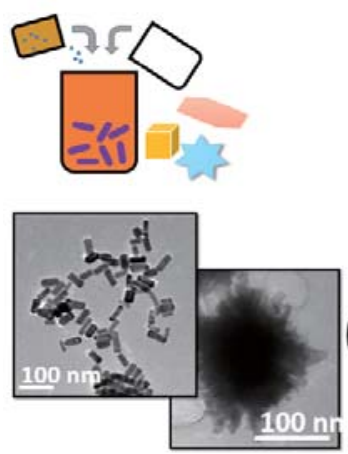

COLLOIDAL GOLD NANOPARTICLES

\section{ANISOTROPIC GOLD NANOPARTICLES FOR CATALYSIS}

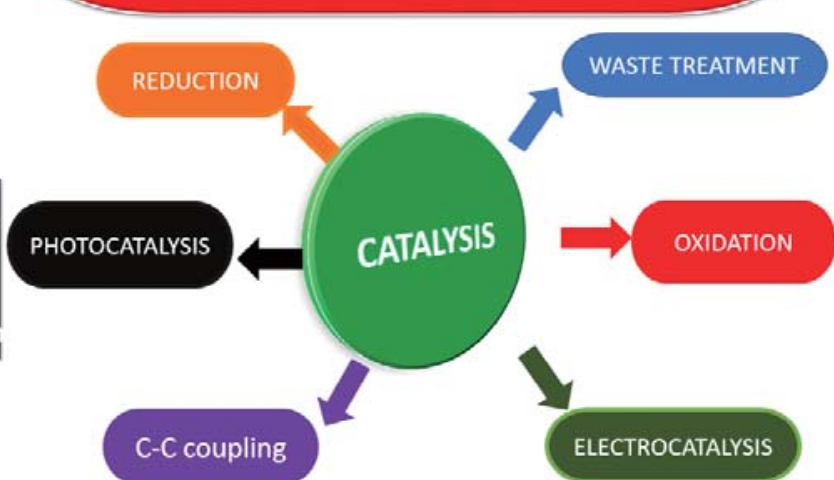

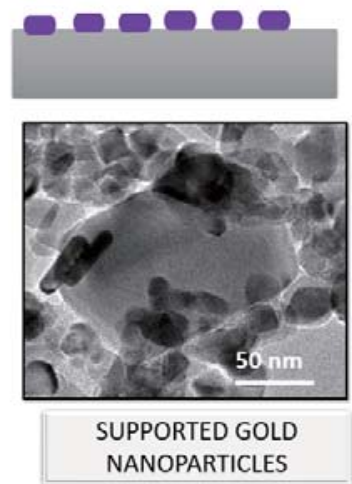

Preparation and applications of gold nanorods and other anisotropic gold nanoparticles in catalysis as free colloidal solutions, as core@shell composite nanostructures and immobilised as supported heterogeneous catalysts and future outlook in chemo-, electro- and photocatalysis. 
[17] R. Sardar, A. M. Funston, P. Mulvaney, R.W. Murray, Langmuir, 2009, 25, 13840-13851.

[18] A. I. Kozlov, A. P. Kozlova, H. C. Liu, Y. Iwasawa, Appl. Catal. A, 1999, 182, 9-28.

[19] T. V. Choudhary, D. W. Goodman, Top. Catal., 2002, 21, 25-34.

[20] M. Stratakis, H. Garcia, Chem. Rev., 2012, 112, 4469-4506.

[21] Z. G. Li, C. Brouwer, C. He, Chem. Rev., 2008, 108, 3239-3265.

[22] A. Corma, A. Leyva-Pérez, M. J. Sabater, Chem. Rev., 2011, 111, 1657-1712.

[23] M. Haruta, Nature, 2005, 437, 1098-1099.

[24] A. S. K. Hashmi, Chem. Rev., 2007, 107, 3180-3211.

[25] X. Chen, H. Zhu, R. J. Groarke, Catalysis by Supported Gold Nanoparticles, in: S. Hashmi ed., Reference Module in Materials Science and Materials Engineering, Elsevier, Amsterdam, 2016.

[26] T. A. Baker, X. Liu, C. M. Friend, Phys. Chem. Chem. Phys., 2011, 13, 34-46.

[27] N. Dimitratos, C. Hammond, C. J. Kiely, G. J. Hutchings, Appl. Petrochem. Res., 2014, 4, 85-94.

[28] N. Dimitratos, J. K. Edwards, C. J. Kiely, G. J. Hutchings, Appl. Petrochem. Res., 2012, 2, 7-14.

[29] A. S. K. Hashmi, Gold. Bull., 2004, 37, 51-65.

[30] A. Primo, A. Corma, H. Garcia, Phys. Chem. Chem. Phys., 2011, 13, 886-910.

[31] C. Della Pina, E. Falletta, M. Rossi, Chem. Soc. Rev., 2012, 41, 350-369.

[32] C. Della Pina, E. Falletta, L. Prati, M. Rossi, Chem. Soc. Rev., 2008, 37, 2077-2095.

[33] N. Dimitratos, J. A. Lopez-Sanchez, G. J. Hutchings, Chem. Sci., 2012, 3, 20-44.

[34] L. Kesavan, R. Tiruvalam, M. H. Ab Rahim, M. I. bin Saiman, D. I. Enache, R. L. Jenkins, N. Dimitratos, J. A. Lopez-Sanchez, S. H. Taylor, D. W. Knight, C. J. Kiely, G. J. Hutchings, Science, 2011, 331, 195-199.

[35] J. A. Lopez-Sanchez, N. Dimitratos, C. Hammond, G. L. Brett, L. Kesavan, S. White, P. Miedziak, R. Tiruvalam, R. L. Jenkins, A. F. Carley, D. Knight, C. J. Kiely, G. J. Hutchings, Nat. Chem., 2011, 3, 551-556.

[36] J. A. Lopez-Sanchez, N. Dimitratos, P. Miedziak, E. Ntainjua, J. K. Edwards, D. Morgan, A. F. Carley, R. Tiruvalam, C. J. Kiely, G. J. Hutchings, Phys. Chem. Chem. Phys., 2008, 10, 1921-1930.

[37] C. E. Chan-Thaw, A. Villa, L. Prati, Immobilization of Preformed Gold Nanoparticles, in: L. Prati, A. Villa eds., Gold Catalysis: Preparation, Characterization, and Applications, Pan Stanford Publishing CRC Press, Boca Raton, FL, 2015, 39-71.

[38] R. Zsigmondy, J. Alexander, Colloids and the Ultramicroscope: A Manual of Colloid Chemistry and Ultramicroscopy, Wiley \& sons, New York, 1909, 129-152.

[39] R. Gans, Ann. Phys., 1912, 37, 881-900.

[40] J. Turkevich, P. C. Stevenson, J. Hillier, Discuss. Faraday Soc., 1951, 55-75.

[41] J. Wiesner, A. Wokaun, Chem. Phys. Lett., 1989, 157, 569-575.

[42] K. Esumi, K. Matsuhisa, K. Torigoe, Langmuir, 1995, 11, 3285-3287.

[43] Y. Yu, S. S. Chang, C. L. Lee, C. R. C. Wang, J. Phys. Chem. B, 1997, 101, 6661-6664.

[44] N. R. Jana, L. Gearheart, C. J. Murphy, Adv. Mater., 2001, 13, 1389-1393.

[45] B. Nikoobakht, M. A. El-Sayed, Langmuir, 2001, 17, 6368-6374.

[46] M. A. El-Sayed, Acc. Chem. Res., 2001, 34, 257-264.

[47] Y. Xia, N.J. Halas, MRS Bull., 2005, 30, 338-348.

[48] C. J. Murphy, A. M. Gole, S. E. Hunyadi, J. W. Stone, P. N. Sisco, A. Alkilany, B. E. Kinard, P. Hankins, Chem. Commun., 2008, 544-557.
[49] L. Judith, S. M. Novikov, L. M. Luis-Marzan, Nanotechnology, 2015, 26, 322001.

[50] P. K. Jain, W. Huang, M. A. El-Sayed, Nano Lett., 2007, 7, 2080-2088.

[51] L. A. Bauer, N. S. Birenbaum, G. J. Meyer, J. Mater. Chem., 2004, 14, 517-526.

[52] X. Huang, S. Neretina, M.A. El-Sayed, Adv. Mater., 2009, 21, 4880-4910.

[53] B. Pelaz, V. Grazu, A. Ibarra, C. Magen, P. del Pino, J. M. de la Fuente, Langmuir, 2012, 28, 8965-8970.

[54] C. Lofton, W. Sigmund, Adv. Funct. Mater., 2005, 15, 1197-1208.

[55] C. J. Murphy, T. K. Sau, A. M. Gole, C. J. Orendorff, J. Gao, L. Gou, S. E. Hunyadi, T. Li, J. Phys. Chem. B, 2005, 109, 13857-13870.

[56] M. Grzelczak, J. Perez-Juste, P. Mulvaney, L. M. Liz-Marzan, Chem. Soc. Rev., 2008, 37, 1783-1791.

[57] A. R. Tao, S. Habas, P. D. Yang, Small, 2008, 4, 310-325.

[58] T. K. Sau, A. L. Rogach, Adv. Mater., 2010, 22, 1781-1804.

[59] A. Guerrero-Martínez, S. Barbosa, I. Pastoriza-Santos, L. M. Liz-Marzán, Curr. Opin. Colloid Interface Sci., 2011, 16, 118-127.

[60] S. E. Lohse, C. J. Murphy, Chem. Mater., 2013, 25, 1250-1261.

[61] X. Hong, C. L. Tan, J. Z. Chen, Z. C. Xu, H. Zhang, Nano Res., 2015, 8, 40-55.

[62] N. Li, P. Zhao, D. Astruc, Angew. Chem. Int. Ed., 2014, 53, 1756-1789.

[63] S. E. Lohse, N. D. Burrows, L. Scarabelli, L. M. Liz-Marzán, C. J. Murphy, Chem. Mater., 2014, 26, 34-43.

[64] H. Q. Hu, J. Y. Zhou, Q. S. Kong, C. X. Li, Part. Part. Syst. Charact., 2015, 32, 796-808.

[65] J. P. Lai, W. X. Niu, R. Luque, G. B. Xu, Nano Today, 2015, 10, 240-267.

[66] C. Xue, Q. Li, Anisotropic Gold Nanoparticles: Preparation, Properties, and Applications, in: Q. Li ed. Anisotropic Nanomaterials: Preparation, Properties, and Applications, Springer International Publishing, Cham, 2015, 69-118.

[67] N. D. Burrows, A. M. Vartanian, N. S. Abadeer, E. M. Grzincic, L. M. Jacob, W. Lin, J. Li, J. M. Dennison, J. G. Hinman, C. J. Murphy, J. Phys. Chem. Lett., 2016, 7, 632-641.

[68] P. X. Zhao, N. Li, D. Astruc, Coord. Chem. Rev., 2013, 257, 638-665.

[69] P. R. Sajanlal, T. S. Sreeprasad, A.K. Samal, T. Pradeep, Nano Rev. 2011, 2, 10.3402/nano.v2i0.5883.

[70] T. K. Sau, A.L. Rogach, in: Complex-Shaped Metal Nanoparticles, Wiley-VCH Verlag GmbH \& Co. KGaA, 2012, 7-90.

[71] C. Burda, X. Chen, R. Narayanan, M. A. El-Sayed, Chem. Rev., 2005, 105, 1025-1102.

[72] S. Link, M. A. El-Sayed, Int. Rev. Phys. Chem., 2000, 19, 409-453.

[73] Y. H. Peng, B. Xiong, L. Peng, H. Li, Y. He, E. S. Yeung, Anal. Chem., 2015, 87, 200-215.

[74] L. D. Marks, L. Peng, J. Phys.: Cond. Matter, 2016, 28, 053001.

[75] C. J. Murphy, L. B. Thompson, A. M. Alkilany, P. N. Sisco, S. P. Boulos, S. T. Sivapalan, J. A. Yang, D. J. Chernak, J. Huang, J. Phys. Chem. Lett., 2010, 1, 2867-2875.

[76] H. J. Chen, L. Shao, Q. Li, J. F. Wang, Chem. Soc. Rev., 2013, 42, 2679-2724.

[77] E. Carbó-Argibay, S. Mourdikoudis, I. Pastoriza-Santos, J. Pérez-Juste, Chapter 2-Nanocolloids of Noble Metals, in: C.R. Abreu ed., Nanocolloids, Elsevier, Amsterdam, 2016, 37-73.

[78] C. L. Nehl, J.H. Hafner, J. Mater. Chem., 2008, 18, 2415-2419.

[79] J. Pérez-Juste, I. Pastoriza-Santos, L. M. Liz-Marzán, P. Mulvaney, Coord. Chem. Rev., 2005, 249, 1870-1901.

[80] K. Thorkelsson, P. Bai, T. Xu, Nano Today, 2015, 10, 48-66.

[81] M. Wirtz, M. Parker, Y. Kobayashi, C. R. Martin, Chem. Rec., 2002, 2, 259-267. 
[82] M. Wirtz, S. Yu, C. R. Martin, Analyst, 2002, 127, 871-879.

[83] Y. Sun, B. Wiley, Z. Y. Li, Y. N. Xia, J. Am. Chem. Soc., 2004, 126, 9399-9406

[84] Y. G. Sun, Y. N. Xia, Adv. Mater., 2003, 15, 695-699.

[85] S. E. Skrabalak, J. Y. Chen, Y. G. Sun, X. M. Lu, L. Au, C. M. Cobley, Y. N. Xia, Acc. Chem. Res., 2008, 41, 1587-1595.

[86] J. Zhang, M. R. Langille, M. L. Personick, K. Zhang, S. Li, C. A. Mirkin, J. Am. Chem. Soc., 2010, 132, 14012-14014.

[87] Z. L. Wang, M. B. Mohamed, S. Link, M. A. El-Sayed, Surf. Sci., 1999, 440, L809-L814.

[88] Z. L. Wang, R. P. Gao, B. Nikoobakht, M. A. El-Sayed, J. Phys. Chem. $B, 2000,104,5417-5420$.

[89] H. Katz-Boon, M. Walsh, C. Dwyer, P. Mulvaney, A. M. Funston, J. Etheridge, Nano Lett., 2015, 15, 1635-1641.

[90] M. S. Bakshi, Cryst. Growth Des., 2016, 16, 1104-1133.

[91] Y. N. Xia, Y. J. Xiong, B. Lim, S. E. Skrabalak, Angew. Chem. Int. Ed., 2009, 48, 60-103.

[92] T. S. Ahmadi, Z. L. Wang, T. C. Green, A. Henglein, M. A. El-Sayed, Science, 1996, 272, 1924-1925.

[93] B. Nikoobakht, M. A. El-Sayed, Chem. Mater., 2003, 15, 1957-1962.

[94] N. R. Jana, L. Gearheart, C. J. Murphy, J. Phys. Chem. B, 2001, 105, 4065-4067.

[95] Y.Xiong, Y. Xia, Adv. Mater., 2007, 19, 3385-3391.

[96] K. Mitamura, T. Imae, Plasmonics, 2008, 4, 23-30.

[97] V. Sharma, K. Park, M. Srinivasarao, Mater. Sci. Eng. R, 2009, R65, 1-38.

[98] C. J. Murphy, L. B. Thompson, D. J. Chernak, J. A. Yang, S. T. Sivapalan, S. P. Boulos, J. Huang, A. M. Alkilany, P. N. Sisco, Curr. Opin. Colloid Interface Sci., 2011, 16, 128-134.

[99] C. R. Martin, Science, 1994, 266, 1961-1966.

[100] C. R. Martin, Chem. Mater., 1996, 8, 1739-1746.

[101] S. S. Chang, C. W. Shih, C. D. Chen, W. C. Lai, C. R. C. Wang, Langmuir, 1999, 15, 701-709.

[102] C. A. Foss Jr., G. L. Hornyak, J. A. Stockert, C. R. Martin, J. Phys. Chem., 1992, 96, 7497-7499.

[103] V. M. Cepak, C. R. Martin, J. Phys. Chem. B, 1998, 102, 9985-9990.

[104] B. M. I. van der Zande, M. R. Böhmer, L. G. J. Fokkink, C. Schönenberger, Langmuir, 2000, 16, 451-458.

[105] J. C. Hulteen, C. R. Martin, J. Mater. Chem., 1997, 7, 1075-1087.

[106] K. B. Jirage, J. C. Hulteen, C. R. Martin, Science, 1997, 278, 655-658.

[107] M. Zhao, P. Guyot-Sionnest, J. Phys. Chem. B, 2005, 109, 22192-22200.

[108] L. Scarabelli, A. Sánchez-Iglesias, J. Pérez-Juste, L. M. Liz-Marzán, J. Phys. Chem. Lett., 2015, 6, 4270-4279.

[109] Q. F. Zhang, L. L. Han, H. Jing, D. A. Blom, Y. Lin, H. L. Xin, H. Wang, ACS Nano, 2016, 10, 2960-2974.

[110] S. Koeppl, C. Solenthaler, W. Caseri, R. Spolenak, J. Nanomater., 2011, 515049.

[111] S. Koeppl, N. Ghielmetti, W. Caseri, R. Spolenak, J. Nanopart. Res., 2013, 15, 1471/1-1471/11.

[112] J. Gao, C. M. Bender, C. J. Murphy, Langmuir, 2003, 19, 9065-9070.

[113] X. Ye, Y. Gao, J. Chen, D. C. Reifsnyder, C. Zheng, C. B. Murray, Nano Lett., 2013, 13, 2163-2171.

[114] B. N. Khlebtsov, V. A. Khanadeev, J. Ye, G. B. Sukhorukov, N. G. Khlebtsov, Langmuir, 2014, 30, 1696-1703.

[115] F. Hubert, F. Testard, O. Spalla, Langmuir, 2008, 24, 9219-9222.

[116] X. H. Qi, M. Watanabe, T. M. Aida, R. L. Smith, Ind. Eng. Chem. Res., 2008, 47, 9234-9239.

[117] N. Almora-Barrios, G. Novell-Leruth, P. Whiting, L. M. Liz-Marzán,
N. López, Nano Lett., 2014, 14, 871-875.

[118] L. Vigderman, E. R. Zubarev, Chem. Mater., 2013, 25, 1450-1457.

[119] L. Scarabelli, M. Grzelczak, L. M. Liz-Marzán, Chem. Mater., 2013, 25, 4232-4238.

[120] L. Gou, C.J. Murphy, Chem. Mater., 2005, 17, 3668-3672.

[121] C.M. Tollan, J. Echeberria, R. Marcilla, J.A. Pomposo, D. Mecerreyes, J. Nanopart. Res., 2009, 11, 1241-1245.

[122] T. H. Ha, H. J. Koo, B. H. Chung, J. Phys. Chem. C, 2007, 111, 1123-1130.

[123] S. Si, C. Leduc, M. H. Delville, B. Lounis, ChemPhysChem, 2012, 13, 193-202.

[124] N. Garg, C. Scholl, A. Mohanty, R. Jin, Langmuir, 2010, 26, 10271-10276.

[125] A. Gole, C.J. Murphy, Chem. Mater., 2004, 16, 3633-3640.

[126] P. H. Qiu, C. B. Mao, J. Nanopart. Res., 2009, 11, 885-894.

[127] Q. S. Wei, J. Ji, J. C. Shen, J. Nanosci. Nanotechnol., 2008, 8, 5708-5714.

[128] W. M. Park, Y. S. Huh, W. H. Hong, Curr. Appl. Phys., 2009, 9, E140-E143.

[129] F. Kim, J. H. Song, P. D. Yang, J. Am. Chem. Soc., 2002, 124, 14316-14317.

[130] D. K. Smith, N. R. Miller, B. A. Korgel, Langmuir, 2009, 25, 9518-9524.

[131] C. J. Johnson, E. Dujardin, S. A. Davis, C. J. Murphy, S. Mann, J. Mater. Chem., 2002, 12, 1765-1770.

[132] F. Hofmeister, Arch. Exp. Pathol. Pharmakol., 1888, 25, 1-30.

[133] M. Hu, P. Hillyard, G. V. Hartland, T. Kosel, J. Perez-Juste, P. Mulvaney, Nano Lett., 2004, 4, 2493-2497.

[134] L.M. Liz-Marzán, Langmuir, 2006, 22, 32-41.

[135] C. Noguez, J. Phys. Chem. C, 2007, 111, 3806-3819.

[136] S. H. Chen, Z. L. Wang, J. Ballato, S. H. Foulger, D. L. Carroll, J. Am. Chem. Soc., 2003, 125, 16186-16187.

[137] E. Hao, R. C. Bailey, G. C. Schatz, J. T. Hupp, S. Li, Nano Lett., 2004 4, 327-330.

[138] T. K. Sau, C. J. Murphy, J. Am. Chem. Soc., 2004, 126, 8648-8649.

[139] M. Yamamoto, Y. Kashiwagi, T. Sakata, H. Mori, M. Nakamoto, Chem. Mater., 2005, 17, 5391-5393.

[140] C. H. Kuo, M. H. Huang, Langmuir, 2005, 21, 2012-2016.

[141] C. L. Nehl, H. Liao, J. H. Hafner, Nano Lett., 2006, 6, 683-688.

[142] H. Yuan, W. H. Ma, C. C. Chen, J. C. Zhao, J. W. Liu, H. Y. Zhu, X. P. Gao, Chem. Mater., 2007, 19, 1592-1600.

[143] P. S. Kumar, I. Pastoriza-Santos, B. Rodríguez-González, F. Javier García de Abajo, L.M. Liz-Marzán, Nanotechnology, 2008, 19, 015606/1-015606/6.

[144] L. Rodríguez-Lorenzo, R. de la Rica, R. A. Álvarez-Puebla, L. M. Liz-Marzán, M. M. Stevens, Nat. Mater., 2012, 11, 604-607.

[145] C. G. Khoury, T. Vo-Dinh, J. Phys. Chem. C, 2008, 112, 18849-18859.

[146] H. G. Liao, Y. X. Jiang, Z. Y. Zhou, S. P. Chen, S. G. Sun, Angew. Chem. Int. Ed., 2008, 47, 9100-9103.

[147] H. Yuan, C. G. Khoury, H. Hwang, C. M. Wilson, G. A. Grant, T. Vo-Dinh, Nanotechnology, 2012, 23, 075102/1-075102/9.

[148] G. Plascencia-Villa, D. Torrente, M. Marucho, M. José-Yacamán, Langmuir, 2015, 31, 3527-3536.

[149] S. Kumar-Krishnan, E. Prokhorov, O. Arias de Fuentes, M. Ramirez, N. Bogdanchikova, I. C. Sanchez, J. D. Mota-Morales, G. Luna-Barcenas, J. Mater. Chem. A, 2015, 3, 15869-15875.

[150] P. Ndokoye, X. Y. Li, Q. D. Zhao, T. T. Li, M. O. Tade, S. M. Liu, J. Colloid Interface Sci., 2016, 462, 341-350.

[151] L. H. Lu, K. L. Ai, Y. Ozaki, Langmuir, 2008, 24, 1058-1063.

[152] M. R. Langille, M. L. Personick, J. Zhang, C. A. Mirkin, J. Am. Chem. Soc., 2012, 134, 14542-14554. 
[153] B. K. Jena, C. R. Raj, Chem. Mater., 2008, 20, 3546-3548.

[154] S. Umadevi, H. C. Lee, V. Ganesh, X. Feng, T. Hegmann, Liq. Cryst., 2014, 41, 265-276.

[155] H. Y. Wu, M. Liu, M. H. Huang, J. Phys. Chem. B, 2006, 110, 19291-19294.

[156] J. P. Xie, J. Y. Lee, D. I. C. Wang, Chem. Mater., 2007, 19, 2823-2830.

[157] L. C. Cheng, J. H. Huang, H. M. Chen, T. C. Lai, K. Y. Yang, R. S. Liu, M. Hsiao, C. H. Chen, L. J. Her, D. P. Tsai, J. Mater. Chem., 2012, 22, 2244-2253.

[158] H. L. Wu, C. H. Chen, M.H. Huang, Chem. Mater., 2009, 21, 110-114.

[159] G. T. Duan, W. P. Cai, Y. Y. Luo, Z. Li, Y. Li, Appl. Phys. Lett., 2006, 89, 211905/1-211905/3.

[160] S. J. Guo, L. Wang, E. Wang, Chem. Commun., 2007, 3163-3165.

[161] M. A. Bhosale, D. R. Chenna, J. P. Ahire, B. M. Bhanage, RSC Adv., 2015, 5, 52817-52823.

[162] J. Li, J. Wu, X. Zhang, Y. Liu, D. Zhou, H. Sun, H. Zhang, B. Yang, J. Phys. Chem. C, 2011, 115, 3630-3637.

[163] W. C. Ye, J. Yu, Y. X. Zhou, D. Q. Gao, D. A. Wang, C. M. Wang, D. S. Xue, Appl. Catal. B, 2016, 181, 371-378.

[164] W. H. Hu, H. M. Chen, C. M. Li, Colloid Polym. Sci., 2015, 293, 505-512.

[165] B.K. Jena, C.R. Raj, Langmuir, 2007, 23, 4064-4070.

[166] J. P. Xie, Q. B. Zhang, J. Y. Lee, D. I. C. Wang, ACS Nano, 2008, 2, 2473-2480.

[167] Y. Jiang, X. J. Wu, Q. Li, J. Li, D. Xu, Nanotechnology, 2011, 22, 385601/1-385601/6.

[168] A. J. Wang, S. F. Qin, D. L. Zhou, L. Y. Cai, J. R. Chen, J. J. Feng, RSC Adv., 2013, 3, 14766-14773.

[169] L. X. Chen, J. J. Lv, A. J. Wang, H. Huang, J. J. Feng, Sens. Actuators, $B$, 2016, 222, 937-944.

[170] B. Lim, Y. Xia, Angew. Chem. Int. Ed., 2011, 50, 76-85.

[171] G. W. Lu, C. Li, G. Q. Shi, Chem. Mater., 2007, 19, 3433-3440.

[172] Y. Qin, Y. Song, N. Sun, N. Zhao, M. Li, L. Qi, Chem. Mater., 2008, 20, 3965-3972.

[173] T. Huang, F. Meng, L. Qi, Langmuir, 2010, 26, 7582-7589.

[174] X. L. Xu, J. B. Jia, X. R. Yang, S. J. Dong, Langmuir, 2010, 26, 7627-7631.

[175] T. A. Witten, L. M. Sander, Phys. Rev. Lett., 1981, 47, 1400-1403.

[176] Y. G. Sun, Y. N. Xia, Science, 2002, 298, 2176-2179.

[177] Y. G. Sun, Y. N. Xia, J. Am. Chem. Soc., 2004, 126, 3892-3901.

[178] X. Lu, L. Au, J. McLellan, Z. Y. Li, M. Marquez, Y. Xia, Nano Lett., 2007, 7, 1764-1769.

[179] S. E. Skrabalak, L. Au, X. Li, Y. Xia, Nat. Protocols, 2007, 2, 2182-2190.

[180] C. M. Cobley, D. J. Campbell, Y. Xia, Adv. Mater., 2008, 20, 748-752.

[181] L. Au, Y. Chen, F. Zhou, P. H. C. Camargo, B. Lim, Z. Y. Li, D. S. Ginger, Y. Xia, Nano Res., 2008, 1, 441-449.

[182] M. A. Mahmoud, M. A. El-Sayed, Nano Lett., 2011, 11, 946-953.

[183] W. R. Erwin, A. Coppola, H. F. Zarick, P. Arora, K. J. Miller, R. Bardhan, Nanoscale, 2014, 6, 12626-12634.

[184] R. Kodiyath, M. Manikandan, L. Liu, G. V. Ramesh, S. Koyasu, M. Miyauchi, Y. Sakuma, T. Tanabe, T. Gunji, T. Duy Dao, S. Ueda, T. Nagao, J. Ye, H. Abe, Chem. Commun., 2014, 50, 15553-15556.

[185] B. Pal, R. Kaur, Part. Sci. Technol., 2015, 33, 139-144.

[186] L. Liu, T. D. Dao, R. Kodiyath, Q. Kang, H. Abe, T. Nagao, J. Ye, Adv. Funct. Mater., 2014, 24, 7754-7762.

[187] W. D. Williams, N. Giordano, Rev. Sci. Instrum., 1984, 55, 410-412.

[188] G. E. Possin, Rev. Sci. Instrum., 1970, 41, 772-774.
[189] C. Schönenberger, B. M. I. van der Zande, L. G. J. Fokkink, M. Henny, C. Schmid, M. Krüger, A. Bachtold, R. Huber, H. Birk, U. Staufer, J. Phys. Chem. B, 1997, 101, 5497-5505.

[190] G. L. Hornyak, C. J. Patrissi, C. R. Martin, J. Phys. Chem. B, 1997, 101, 1548-1555.

[191] M. A. Sanchez-Castillo, C. Couto, W. B. Kim, J. A. Dumesic, Angew. Chem. Int. Ed., 2004, 43, 1140-1142.

[192] R. M. Penner, C. R. Martin, Anal. Chem., 1987, 59, 2625-2630.

[193] V. P. Menon, C. R. Martin, Anal. Chem., 1995, 67, 1920-1928.

[194] M. Nishizawa, V. P. Menon, C. R. Martin, Science, 1995, 268, 700-702.

[195] C. C. Mayorga-Martinez, M. Guix, R. E. Madrid, A. Merkoci, Chem. Commun., 2012, 48, 1686-1688.

[196] W. An, Y. Pei, X. C. Zeng, Nano Lett., 2008, 8, 195-202.

[197] Y. Kondo, K. Takayanagi, Science, 2000, 289, 606-608.

[198] Y. Oshima, A. Onga, K. Takayanagi, Phys. Rev. Lett., 2003, 91, 205503/1-205503/4.

[199] N. N. Zhao, Y. Wei, N. J. Sun, Q. Chen, J. W. Bai, L. P. Zhou, Y. Qin, M. X. Li, L. M. Qi, Langmuir, 2008, 24, 991-998.

[200] C. Ji, P. C. Searson, J. Phys. Chem. B, 2003, 107, 4494-4499.

[201] R. Laocharoensuk, S. Sattayasamitsathit, J. Burdick, P. Kanatharana, P. Thavarungkul, J. Wang, ACS Nano, 2007, 1, 403-408.

[202] T. Y. Shin, S. H. Yoo, S. Park, Chem. Mater., 2008, 20, 5682-5686.

[203] A. Sanchez-Iglesias, M. Grzelczak, B. Rodríguez-González, R. A. Álvarez-Puebla, L. M. Liz-Marzán, N. A. Kotov, Langmuir, 2009, 25, 11431-11435.

[204] M. Mohl, A. Kumar, A. L. M. Reddy, A. Kukovecz, Z. Konya, I. Kiricsi, R. Vajtai, P. M. Ajayan, J. Phys. Chem. C, 2010, 114, 389-393.

[205] L. S. Li, Z. J. Wang, T. Huang, J. L. Xie, L. M. Qi, Langmuir, 2010, 26, 12330-12335.

[206] I. Pastoriza-Santos, R. A. Alvarez-Puebla, L. M. Liz-Marzán, Eur. J. Inorg. Chem., 2010, 27, 4288-4297.

[207] B. D. Busbee, S. O. Obare, C. J. Murphy, Adv. Mater., 2003, 15, 414-416.

[208] J. E. Millstone, S. Park, K. L. Shuford, L. Qin, G. C. Schatz, C. A. Mirkin, J. Am. Chem. Soc., 2005, 127, 5312-5313.

[209] S. S. Shankar, A. Rai, B. Ankamwar, A. Singh, A. Ahmad, M. Sastry, Nat Mater, 2004, 3, 482-488.

[210] X. Huang, S. Z. Li, Y. Z. Huang, S. X. Wu, X. Z. Zhou, S. Li, C. L. Gan, F. Boey, C. A. Mirkin, H. Zhang, Nat. Commun., 2011, 2, 292.

[211] H. C. Chu, C. H. Kuo, M. H. Huang, Inorg. Chem., 2006, 45, 808-813.

[212] B. Lim, P. H. C. Camargo, Y. Xia, Langmuir, 2008, 24, 10437-10442.

[213] X. P. Sun, S. J. Dong, E. Wang, Langmuir, 2005, 21, 4710-4712.

[214] S. Porel, S. Singh, T. P. Radhakrishnan, Chem. Commun., 2005, 2387-2389.

[215] T. Kida, Langmuir, 2008, 24, 7648-7650.

[216] S. H. Cha, J. U. Kim, K. H. Kim, J. C. Lee, Mater. Sci. Eng.: B, 2007, 140, 182-186.

[217] M. J. Li, X. C. Wu, J. Y. Zhou, Q. S. Kong, C. X. Li, J. Colloid Interface Sci., 2016, 467, 115-120.

[218] Z. R. Guo, Y. Zhang, A. Q. Xu, M. Wang, L. Huang, K. Xu, N. Gu, J. Phys. Chem. C, 2008, 112, 12638-12645.

[219] D. Seo, J. C. Park, H. Song, J. Am. Chem. Soc., 2006, 128, 14863-14870.

[220] C. Li, K. L. Shuford, Q. H. Park, W. Cai, Y. Li, E. J. Lee, S.O. Cho, Angew. Chem. Int. Ed., 2007, 46, 3264-3268.

[221] D. Seo, C. I. Yoo, J. C. Park, S. M. Park, S. Ryu, H. Song, Angew. Chem. Int. Ed., 2008, 47, 763-767.

[222] M. L. Personick, M. R. Langille, J. Zhang, C. A. Mirkin, Nano Lett., 
2011, 11, 3394-3398.

[223] F. Kim, S. Connor, H. Song, T. Kuykendall, P. D. Yang, Angew. Chem. Int. Ed., 2004, 43, 3673-3677.

[224] P. J. Chung, L. M. Lyu, M. H. Huang, Chem. Eur. J., 2011, 17, 9746-9752.

[225] T. Ming, W. Feng, Q. Tang, F. Wang, L. D. Sun, J. F. Wang, C. H. Yan, J. Am. Chem. Soc., 2009, 131, 16350-16351.

[226] K. Kwon, K. Y. Lee, Y. W. Lee, M. Kim, J. Heo, S. J. Ahn, S. W. Han, J. Phys. Chem. C, 2007, 111, 1161-1165.

[227] J. F. Parker, C. A. Fields-Zinna, R. W. Murray, Acc. Chem. Res., 2010, 43, 1289-1296.

[228] M. S. Yavuz, W. Li, Y. Xia, Chem. Eur. J., 2009, 15, 13181-13187.

[229] M. R. Langille, J. Zhang, M. L. Personick, S. Li, C. A. Mirkin, Science, 2012, 337, 954-957.

[230] Y. Y. Li, H. Cheng, T. Yao, Z. H. Sun, W. S. Yan, Y. Jiang, Y. Xie, Y. F. Sun, Y. Y. Huang, S. J. Liu, J. Zhang, Y. N. Xie, T. D. Hu, L. N. Yang, Z. Y. Wu, S. Q. Wei, J. Am. Chem. Soc., 2012, 134, 17997-18003.

[231] O. Guliamov, A. I. Frenkel, L. D. Menard, R. G. Nuzzo, L. Kronik, J. Am. Chem. Soc., 2007, 129, 10978-10979.

[232] M. Zhou, S. H. Chen, S. Y. Zhao, J. Phys. Chem. B, 2006, 110, 4510-4513.

[233] A. Sánchez-Iglesias, I. Pastoriza-Santos, J. Pérez-Juste, B. Rodríguez-González, F. J. García de Abajo, L. M. Liz-Marzán, Adv. Mater., 2006, 18, 2529-2534.

[234] G. H. Jeong, M. Kim, Y. W. Lee, W. Choi, W. T. Oh, Q. H. Park, S. W. Han, J. Am. Chem. Soc., 2009, 131, 1672-1673.

[235] E. W. Malachosky, P. Guyot-Sionnest, J. Phys. Chem. C, 2014, 118, 6405-6412.

[236] W. X. Niu, G. B. Xu, Nano Today, 2011, 6, 265-285.

[237] J. Y. Xiao, L. M. Qi, Nanoscale, 2011, 3, 1383-1396.

[238] C. Y. Chiu, P. J. Chung, K. U. Lao, C. W. Liao, M. H. Huang, J. Phys. Chem. C, 2012, 116, 23757-23763.

[239] M. Haruta, Cattech, 2002, 6, 102-115.

[240] M. Haruta, Chem. Rec., 2003, 3, 75-87.

[241] S. Tsubota, M. Haruta, T. Kobayashi, A. Ueda, Y. Nakahara, Stud. Surf. Sci. Catal., 1991, 63, 695-704.

[242] M. Haruta, H. Kageyama, N. Kamijo, T. Kobayashi, F. Delannay, Stud. Surf. Sci. Catal., 1989, 44, 33-42.

[243] M. Haruta, N. Yamada, T. Kobayashi, S. Iijima, J. Catal., 1989, 115, 301-309.

[244] J. D. Grunwaldt, C. Kiener, C. Wögerbauer, A. Baiker, J. Catal., 1999, 181, 223-232.

[245] L. Prati, M. Rossi, J. Catal., 1998, 176, 552-560.

[246] S. Biella, L. Prati, M. Rossi, J. Catal., 2002, 206, 242-247.

[247] A. Villa, D. Wang, G. M. Veith, F. Vindigni, L. Prati, Catal. Sci. Technol., 2013, 3, 3036-3041.

[248] L. Liu, S. Ouyang, J. Ye, Angew. Chem. Int. Ed., 2013, 52, 6689-6693.

[249] Z. W. Seh, S. Liu, S. Y. Zhang, M. S. Bharathi, H. Ramanarayan, M. Low, K. W. Shah, Y. W. Zhang, M. Y. Han, Angew. Chem. Int. Ed., 2011, 50, 10140-10143.

[250] S. Y. Song, X. Wang, H. J. Zhang, NPG Asia Mater., 2015, 7, e179.

[251] N. Zhou, L. Polavarapu, N. Gao, Y. Pan, P. Yuan, Q. Wang, Q. H. Xu, Nanoscale, 2013, 5, 4236-4241.

[252] Y. Horiguchi, T. Kanda, K. Torigoe, H. Sakai, M. Abe, Langmuir, 2014, 30, 922-928.

[253] C. H. Fang, H. L. Jia, S. Chang, Q. F. Ruan, P. Wang, T. Chen, J. F. Wang, Energy Environ. Sci., 2014, 7, 3431-3438.

[254] Z. W. Seh, S. Liu, M. Y. Han, Chem. Asian J., 2012, 7, 2174-2184.

[255] A. J. van de Glind, P. E. de Jongh, A. Imhof, A. van Blaaderen, K. P. de Jong, in: 23rd North American Catalysis Society Meeting, Nam, 2013.
[256] I. Pastoriza-Santos, J. Pérez-Juste, L. M. Liz-Marzán, Chem. Mater., 2006, 18, 2465-2467.

[257] Z. H. Bao, Z. H. Sun, Z. F. Li, L. W. Tian, T. Ngai, J. F. Wang, Langmuir, 2011, 27, 5071-5075.

[258] A. Gole, J. W. Stone, W. R. Gemmill, H. C. zur Loye, C. J. Murphy, Langmuir, 2008, 24, 6232-6237.

[259] L. N. Kong, W. Chen, D. K. Ma, Y. Yang, S. S. Liu, S. M. Huang, J. Mater. Chem., 2012, 22, 719-724.

[260] Y. C. Pu, G. M. Wang, K. D. Chang, Y. C. Ling, Y. K. Lin, B. C. Fitzmorris, C. M. Liu, X. H. Lu, Y. X. Tong, J. Z. Zhang, Y. I. Hsu, Y. Li, Nano Lett., 2013, 13, 3817-3823.

[261] Z. W. Seh, S. H. Liu, S. Y. Zhang, K. W. Shah, M. Y. Han, Chem. Commun., 2011, 47, 6689-6691.

[262] S. Mubeen, J. Lee, N. Singh, S. Krämer, G. D. Stucky, M. Moskovits, Nat. Nanotechnol., 2013, 8, 247-251.

[263] Y. Q. Zheng, J. Tao, H. Y. Liu, J. Zeng, T. Yu, Y. Y. Ma, C. Moran, L. J. Wu, Y. M. Zhu, J. Y. Liu, Y. N. Xia, Small, 2011, 7, 2307-2312.

[264] Y. Zhu, H. F. Qian, A. Das, R. C. Jin, Chin. J. Catal., 2011, 32, 1149-1155.

[265] J. Z. Lin, H. Abroshan, C. Liu, M. Z. Zhu, G. Li, M. Haruta, J. Catal., 2015, 330, 354-361.

[266] M. M. Gao, L. L. Zhu, W.L. Ong, J. Wang, G.W. Ho, Catal. Sci. Technol., 2015, 5, 4703-4726.

[267] Z. G. Xiong, L. H. Zhang, X. S. Zhao, Chem. Eur. J., 2014, 20, 14715-14720.

[268] I. Pastoriza-Santos, D. S. Koktysh, A. A. Mamedov, M. Giersig, N. A. Kotov, L. M. Liz-Marzán, Langmuir, 2000, 16, 2731-2735.

[269] A. Hanprasopwattana, S. Srinivasan, A. G. Sault, A. K. Datye, Langmuir, 1996, 12, 3173-3179.

[270] E. Scolan, C. Sanchez, Chem. Mater., 1998, 10, 3217-3223.

[271] M. Cargnello, T. R. Gordon, C. B. Murray, Chem. Rev., 2014, 114, 9319-9345.

[272] L. Prati, A. Villa, Catalysts, 2012, 2, 24-37.

[273] Z. Ma, S. Dai, Heterogeneous Gold Catalysts and Catalysis, The Royal Society of Chemistry, Cambridge, 2014, 1-26.

[274] G. C. Bond, C. Louis, D. T. Thompson, Catalysis by Gold, Imperial College Press, London, 2006.

[275] M. Turner, V. B. Golovko, O. P. H. Vaughan, P. Abdulkin, A. Berenguer-Murcia, M. S. Tikhov, B. F. G. Johnson, R. M. Lambert, $\mathrm{Na}$ ture, 2008, 454, 981-983.

[276] Y. Zhang, X. J. Cui, F. Shi, Y. Q. Deng, Chem. Rev., 2012, 112, 2467-2505.

[277] M. H. Ab Rahim, M. M. Forde, R. L. Jenkins, C. Hammond, Q. He, N. Dimitratos, J. A. Lopez-Sanchez, A. F. Carley, S. H. Taylor, D.J. Willock, D. M. Murphy, C. J. Kiely, G. J. Hutchings, Angew. Chem. Int. Ed., 2013, 52, 1280-1284.

[278] M. H. Ab Rahim, Q. He, J. A. Lopez-Sanchez, C. Hammond, N. Dimitratos, M. Sankar, A. F. Carley, C. J. Kiely, D. W. Knight, G. J. Hutchings, Catal. Sci. Technol., 2012, 2, 1914-1924.

[279] P. Miedziak, M. Sankar, N. Dimitratos, J. A. Lopez-Sanchez, A. F. Carley, D. W. Knight, S. H. Taylor, C. J. Kiely, G. J. Hutchings, Catal. Today, 2011, 164, 315-319.

[280] L. Prati, A. Villa, Gold Catalysis: Preparation, Characterization, and Applications, Pan Stanford Publishing, 2016.

[281] A. Villa, D. Wang, D. S. Su, L. Prati, Catal. Sci. Technol., 2015, 5, 55-68.

[282] R. C. Tiruvalam, J. C. Pritchard, N. Dimitratos, J. A. Lopez-Sanchez, J. K. Edwards, A. F. Carley, G. J. Hutchings, C. J. Kiely, Faraday Discuss., 2011, 152, 63-86.

[283] M. C. Daniel, D. Astruc, Chem. Rev., 2004, 104, 293-346.

[284] C. Novo, A. M. Funston, P. Mulvaney, Nat. Nanotechnol., 2008, 3, 598-602. 
[285] R. Narayanan, M. A. El-Sayed, J. Phys. Chem. B, 2005, 109, 12663-12676.

[286] R. Narayanan, M. A. El-Sayed, Nano Lett., 2004, 4, 1343-1348.

[287] J. Yoshihara, C. T. Campbell, J. Catal., 1996, 161, 776-782.

[288] B. M. Choudary, R. S. Mulukutla, K. J. Klabunde, J. Am. Chem. Soc., 2003, 125, 2020-2021.

[289] K. B. Zhou, X. Wang, X. M. Sun, Q. Peng, Y. D. Li, J. Catal., 2005, 229, 206-212.

[290] R. Xu, D. S. Wang, J. T. Zhang, Y. D. Li, Chem. Asian J., 2006, 1, 888-893.

[291] X. L. Li, Y. Yang, G. J. Zhou, S. H. Han, W. F. Wang, L. J. Zhang, W. Chen, C. Zou, S. M. Huang, Nanoscale, 2013, 5, 4976-4985.

[292] M. H. Rashid, T. K. Mandal, Adv. Funct. Mater., 2008, 18, 2261-2271.

[293] G. Li, C. Zeng, R. Jin, J. Phys. Chem. C, 2015, 119, 11143-11147.

[294] S. Kundu, S. Lau, H. Liang, J. Phys. Chem. C, 2009, 113, 5150-5156.

[295] C. Y. Chiu, P. J. Chung, K. U. Lao, C. W. Liao, M. H. Huang, J. Phys. Chem. C, 2012, 116, 23757-23763.

[296] X. T. Bai, Y. A. Gao, H. G. Liu, L. Q. Zheng, J. Phys. Chem. C, 2009, 113, 17730-17736.

[297] R. Kaur, B. Pal, Mater. Res. Bull., 2015, 62, 11-18.

[298] W. Xiong, D. Sikdar, L. W. Yap, P. Guo, M. Premaratne, X. Li, W. Cheng, Nano Res., 2016, 9, 415-423.

[299] Y. Khalavka, J. Becker, C. Sönnichsen, J. Am. Chem. Soc., 2009, 131, 1871-1875.

[300] R. Kaur, B. Pal, J. Mol. Catal. A, 2014, 395, 7-15.

[301] Q. F. Zhang, H. Wang, ACS Catal., 2014, 4, 4027-4033.

[302] H. F. Zarick, W. R. Erwin, J. Aufrecht, A. Coppola, B. R. Rogers, C. L. Pint, R. Bardhan, J. Mater. Chem. A, 2014, 2, 7088-7098.

[303] J. Zeng, Q. Zhang, J. Y. Chen, Y. N. Xia, Nano Lett., 2010, 10, 30-35.

[304] Y. C. Tsao, S. Rej, C. Y. Chiu, M. H. Huang, J. Am. Chem. Soc., 2014, 136, 396-404.

[305] G. T. Fu, L. F. Ding, Y. Chen, J. Lin, Y. Tang, T. Lu, CrystEngComm, 2014, 16, 1606-1610.

[306] Q. L. Cui, A. Yashchenok, L. D. Li, H. Möhwald, M. Bargheer, Colloids Surf., A, 2015, 470, 108-113.

[307] Q. Cui, B. Xia, S. Mitzscherling, A. Masic, L. Li, M. Bargheer, H. Möhwald, Colloids Surf., A, 2015, 465, 20-25.

[308] D. P. Huang, X. J. Bai, L. Q. Zheng, J. Phys. Chem. C, 2011, 115, 14641-14647.

[309] M. Chirea, A. Freitas, B. S. Vasile, C. Ghitulica, C. M. Pereira, F. Silva, Langmuir, 2011, 27, 3906-3913.

[310] R. Bhandari, M. R. Knecht, Catal. Sci. Technol., 2012, 2, 1360-1366.

[311] H. Jia, J. B. An, X. Guo, C. J. Su, L. P. Zhang, H. T. Zhou, C. H. Xie, J. Mol. Liq., 2015, 212, 763-766.

[312] A. Wittstock, V. Zielasek, J. Biener, C. M. Friend, M. Bäumer, Science, 2010, 327, 319-322.

[313] J. W. Park, S. W. Lai, S. O. Cho, Int. J. Hydrogen Energy, 2015, 40, 16316-16322.

[314] S. Rej, K. Chanda, C. Y. Chiu, M. H. Huang, Chem. Eur. J., 2014, 20, 15991-15997.

[315] Z. Zheng, T. Tachikawa, T. Majima, J. Am. Chem. Soc., 2015, 137, 948-957.

[316] S. Hebié, L. Cornu, T. W. Napporn, J. Rousseau, B. K. Kokoh, J. Phys. Chem. C, 2013, 117, 9872-9880.

[317] Q. Zhang, X. Guo, Z. X. Liang, J. H. Zeng, J. Yang, S. J. Liao, Nano Res., 2013, 6, 571-580.

[318] X. L. Wu, L. F. Tan, D. Chen, X. W. Meng, F. Q. Tang, Chem. Commun., 2014, 50, 539-541.

[319] B. H. Wu, D. Y. Liu, S. Mubeen, T. T. Chuong, M. Moskovits, G. D.
Stucky, J. Am. Chem. Soc., 2016, 138, 1114-1117.

[320] J. W. Zhao, P. Y. Xu, Y. Li, J. Wu, J. F. Xue, Q. N. Zhu, X. X. Lu, W. H. Ni, Nanoscale, 2016, 8, 5417-5421.

[321] B. X. Li, T. Gu, T. Ming, J. X. Wang, P. Wang, J. F. Wang, J.C. Yu, ACS Nano, 2014, 8, 8152-8162.

[322] A. Li, P. Zhang, X. X. Chang, W. T. Cai, T. Wang, J. L. Gong, Small, 2015, 11, 1892-1899.

[323] Y. Lu, J. Y. Yuan, F. Polzer, M. Drechsler, J. Preussner, ACS Nano, 2010, 4, 7078-7086.

[324] Y. Yu, K. Kant, J. G. Shapter, J. Addai-Mensah, D. Losic, Microporous Mesoporous Mater., 2012, 153, 131-136.

[325] M.L. Tang, N. Liu, J. A. Dionne, A. P. Alivisatos, J. Am. Chem. Soc., 2011, 133, 13220-13223.

[326] M. Boronat, A. Corma, Dalton Trans., 2010, 39, 8538-8546.

[327] Y. Q. Qu, R. Cheng, Q. Su, X. F. Duan, J. Am. Chem. Soc., 2011, 133, 16730-16733.

[328] B. K. Jena, C. R. Raj, J. Phys. Chem. C, 2007, 111, 15146-15153.

[329] W. J. Wang, J. Zhang, S. C. Yang, B. J. Ding, X. P. Song, ChemSusChem, 2013, 6, 1945-1951.

[330] J. T. Zhang, P. P. Liu, H. Y. Ma, Y. Ding, J. Phys. Chem. C, 2007, 111, 10382-10388.

[331] W. C. Ye, J. F. Yan, Q. Ye, F. Zhou, J. Phys. Chem. C, 2010, 114, 15617-15624.

[332] X. Y. Han, D. W. Wang, J. S. Huang, D. Liu, T. Y. You, J. Colloid Interface Sci., 2011, 354, 577-584.

[333] J. J. Feng, A. Q. Li, Z. Lei, A. J. Wang, ACS Appl. Mater. Interfaces, 2012, 4, 2570-2576.

[334] S. Choi, Y. Moon, H. Yoo, J. Colloid Interface Sci., 2016, 469, 269-276.

[335] A. Q. Li, Y. J. Chen, K. L. Zhuo, C. Y. Wang, C. F. Wang, J. J. Wang, RSC Adv., 2016, 6, 8786-8790.

[336] S. N. Rashkeev, A. R. Lupini, S. H. Overbury, S. J. Pennycook, S. T. Pantelides, Phys. Rev. B, 2007, 76, 035438/1-035438/8.

[337] B. K. Min, C. M. Friend, Chem. Rev., 2007, 107, 2709-2724.

[338] H. Falsig, B. Hvolbæk, I. S. Kristensen, T. Jiang, T. Bligaard, C. H. Christensen, J. K. Nørskov, Angew. Chem. Int. Ed., 2008, 47, 4835-4839.

[339] P. X. Zhao, X. W. Feng, D. S. Huang, G. Y. Yang, D. Astruc, Coord. Chem. Rev., 2015, 287, 114-136.

[340] G.C. Bond, C. Louis, D. Thompson, G. J. Hutchings, in: Catalytic Science Series, Volume 6, Imperial College Press, London, 2006,

[341] D. Astruc, Nanoparticles and catalysis, Wiley Online Library, 2007.

[342] Y. Kuwauchi, H. Yoshida, T. Akita, M. Haruta, S. Takeda, Angew. Chem. Int. Ed., 2012, 51, 7729-7733.

[343] H. Shi, C. Stampfl, Phys. Rev. B, 2008, 77, 094127/1-094127/9.

[344] H. Shi, M. Kohyama, S. Tanaka, S. Takeda, Phys. Rev. B, 2009, 80, 155413/1-155413/10.

[345] M. Haruta, Faraday Discuss., 2011, 152, 11-32.

[346] T. Uchiyama, H. Yoshida, Y. Kuwauchi, S. Ichikawa, S. Shimada, M. Haruta, S. Takeda, Angew. Chem. Int. Ed., 2011, 50, 10157-10160.

[347] I. X. Green, W. Tang, M. Neurock, J. T. Yates, Science, 2011, 333, 736-739.

[348] T. Fujitani, I. Nakamura, Angew. Chem. Int. Ed., 2011, 50, 10157-10160.

[349] Z. Zheng, T. Tachikawa, T. Majima, Chem. Commun., 2015, 51, 14373-14376.

[350] Q. He, P. J. Miedziak, L. Kesavan, N. Dimitratos, M. Sankar, J. A. Lopez-Sanchez, M. M. Forde, J. K. Edwards, D. W. Knight, S. H. Taylor, C. J. Kiely, G. J. Hutchings, Faraday Discuss., 2013, 162, 365-378. 
[351] C. E. Chan-Thaw, L. E. Chinchilla, S. Campisi, G. A. Botton, L. Prati, N. Dimitratos, A. Villa, ChemSusChem, 2015, 8, 4189-4194.

[352] C. L. Bianchi, P. Canton, N. Dimitratos, F. Porta, L. Prati, Catal. Today, 2005, 102-103, 203-212.

[353] W. Q. Ma, Y. Fang, J. Colloid Interface Sci., 2006, 303, 1-8.

[354] W. Xie, B. Walkenfort, S. Schlücker, J. Am. Chem. Soc., 2013, 135, 1657-1660.

[355] P. G. Mertens, P. Vandezande, X. Ye, H. Poelman, I. F. J. Vankelecom, D. E. De Vos, Appl. Catal. A, 2009, 355, 176-183.

[356] P. M. Arnal, M. Comotti, F. Schüth, Angew. Chem. Int. Ed., 2006, 45, 8224-8227.

[357] X. Chen, H. Y. Zhu, J. C. Zhao, Z. F. Zheng, X. P. Gao, Angew. Chem. Int. Ed., 2008, 47, 5353-5356.

[358] W. B. Hou, S. B. Cronin, Adv. Funct. Mater., 2013, 23, 1612-1619.

[359] M. G. Walter, E. L. Warren, J. R. McKone, S. W. Boettcher, Q. Mi, E. A. Santori, N. S. Lewis, Chem. Rev., 2010, 110, 6446-6473.

[360] D. B. Ingram, S. Linic, J. Am. Chem. Soc., 2011, 133, 5202-5205.

[361] C. C. Nguyen, N. N. Vu, T. O. Do, J. Mater. Chem. A, 2015, 3, 18345-18359.

[362] Y. Tian, T. Tatsuma, J. Am. Chem. Soc., 2005, 127, 7632-7637.

[363] A. Takai, P. V. Kamat, Acs Nano, 2011, 5, 7369-7376.

[364] A. Tanaka, S. Sakaguchi, K. Hashimoto, H. Kominami, ACS Catal., 2012, 3, 79-85.

[365] H. Y. Zhu, X. Chen, Z. F. Zheng, X. B. Ke, E. Jaatinen, J. C. Zhao, C. Guo, T. F. Xie, D. J. Wang, Chem. Commun., 2009, 7524-7526.

[366] H. Xu, S. X. Ouyang, L. Q. Liu, P. Reunchan, N. Umezawa, J. H. Ye, J. Mater. Chem. A, 2014, 2, 12642-12661.

[367] T. W. Odom, G. C. Schatz, Chem. Rev., 2011, 111, 3667-3668.

[368] T. Hirakawa, P. V. Kamat, J. Am. Chem. Soc., 2005, 127, 3928-3934.
[369] N. Zhang, S. Q. Liu, X. Z. Fu, Y. J. Xu, J. Phys. Chem. C, 2011, 115, 9136-9145.

[370] C. Wang, D. Astruc, Chem. Soc. Rev., 2014, 43, 7188-7216.

[371] M. Xiao, R. Jiang, F. Wang, C. Fang, J. Wang, J. C. Yu, J. Mater. Chem. A, 2013, 1, 5790-5805.

[372] F. Hao, C. L. Nehl, J. H. Hafner, P. Nordlander, Nano Lett., 2007, 7, 729-732.

[373] M. Rycenga, C.M. Cobley, J. Zeng, W. Li, C.H. Moran, Q. Zhang, D. Qin, Y. Xia, Chem. Rev., 2011, 111, 3669-3712.

[374] C. Noguez, J. Phys. Chem. C, 2007, 111, 3806-3819.

[375] X. C. Ma, Y. Dai, L. Yu, B. B. Huang, Light Sci. Appl., 2016, 5, e16017.

[376] C. Hrelescu, T. K. Sau, A.L. Rogach, F. Jäckel, J. Feldmann, Appl. Phys. Lett., 2009, 94, 153113/1-153113/3.

[377] L. Rodríguez-Lorenzo, R. A. Álvarez-Puebla, F. J. G. de Abajo, L.M. Liz-Marzán, J. Phys. Chem. C, 2010, 114, 7336-7340.

[378] E. N. Esenturk, A. R. Hight Walker, J. Raman Spectrosc., 2009, 40, 86-91.

[379] S. Link, M. B. Mohamed, M. A. El-Sayed, J. Phys. Chem. B, 1999, 103, 3073-3077.

[380] B. H. Yan, Yang, Y. C. Wang, J. Phys. Chem. B, 2003, 107, 9159-9159.

[381] S. Link, M. A. El-Sayed, J. Phys. Chem. B, 2005, 109, 10531-10532.

[382] A. Brioude, X. C. Jiang, M. P. Pileni, J. Phys. Chem. B, 2005, 109, 13138-13142.

[383] B. Nikoobakht, Z. L. Wang, M. A. El-Sayed, J. Phys. Chem. B, 2000, 104, 8635-8640.

[384] R. B. Jiang, B. X. Li, C. H. Fang, J. F. Wang, Adv. Mater., 2014, 26, 5274-5309.

[385] C. Höppener, L. Novotny, Q. Rev. Biophys., 2012, 45, 209-255.

\title{
各向异性金纳米粒子的制备及其在催化中的应用
}

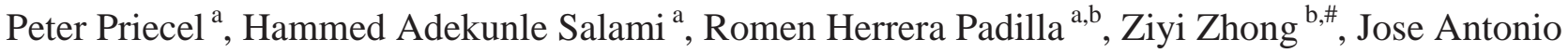 \\ Lopez-Sanchez ${ }^{\mathrm{a}, *}$ \\ a利物浦大学化学系, 可再生能源斯蒂芬森研究所, 利物浦, 英国 \\ b新加坡科技研究局(A*STAR), 化学与工程科学研究所, 裕廊岛 627833, 新加坡
}

摘要: 尽管有关金纳米粒子催化的研究工作很多, 但其中大多数都是采用传统的浸渍法将金盐负载到载体上、共沉淀或沉 积-沉淀法制得负载的纳米粒子, 但这些方法并未吸收最新的纳米技术. 最近, 金催化剂的研究者开发了在胶态悬浮液中制 取金属纳米粒子, 然后进行固载, 从而使得单金属和双金属催化剂的催化活性和形貌控制取得较大进展. 另一方面, 最近 十年出现了金纳米粒子合成的高级控制技术, 得到了许多各向异性的金纳米粒子, 且很容易制得新的形貌, 可以控制纳米 粒子的表面原子配位数和光学特性(可调的等离子体带), 这些都与催化密切相关. 这些形貌包括纳米棒、纳米星、纳米花、 树枝状纳米结构或多面体纳米粒子等. 除了高度关注各向异性金纳米粒子的最新开发的制备方法和性质, 本综述也清楚 地总结了这些纳米粒子独特的催化性能, 以及通过提供更高催化性能的金催化剂、控制暴露的活性位, 以及热、电和光催 化的鲁棒性和可调性, 从而给多相催化领域带来令人惊奇的潜在变革.

关键词: 各向异性金属纳米粒子; 金催化; 光催化; 电催化; 催化氧化; 胶状金纳米粒子; 金纳米棒; 金纳米星; 溶胶固定

收稿日期: 2016-04-30. 接受日期: 2016-05-30. 出版日期: 2016-10-05.

*通讯联系人.电话:+44 (0)151 794 3535; 电子信箱: jals@liverpool.ac.uk

\#通讯联系人. 电话: 65-67963809; 传真: 65-63166182; 电子信箱: zhong_ziyi@ices.a-star.edu.sg

基金来源：新加坡化学与工程研究所(ICES/15-1G4B01).

本文的英文电子版由Elsevier出版社在ScienceDirect上出版(http://www.sciencedirect.com/science/journal/18722067). 